\title{
EL POBLAMIENTO ABORIGEN EN EL MUNICIPIO DE LA LAGUNA (TENERIFE, ISLAS CANARIAS)
}

\author{
THE ABORIGINAL SETTLEMENT IN THE MUNICIPALITY OF LA \\ LAGUNA (TENERIFE, CANARY ISLANDS) ${ }^{1}$
}

\author{
Alfredo Mederos Martín*, Gabriel Escribano Cobo ${ }^{* *}$ y Vicente Valencia Afonso ${ }^{* * *}$
}

Fecha de recepción: 3 de junio de 2019

Fecha de aceptación: 13 de julio de 2019

Cómo citar este artículo/Citation: Alfredo Mederos Martín, Gabriel Escribano Cobo y Vicente Valencia Afonso (2019). El poblamiento aborigen en el municipio de La Laguna (Tenerife, islas Canarias). Anuario de Estudios Atlánticos, nº 66: 066-006.

http://anuariosatlanticos.casadecolon.com/index.php/aea/article/view/10539/9908

ISSN 2386-5571. https://doi.org/10.36980/10539.9908

Resumen: La investigación arqueológica en el municipio de La Laguna, parte del antiguo menceyato de Tegueste, ha sido secundaria en relación con el municipio vecino de Tegueste, donde Diego Cuscoy realizó estudios regulares entre 1961-73. Aunque ha habido diversas excavaciones en cuevas funerarias como Las Goteras (1933), El Becerril (1944), Milán (1946) o La Palmita (1952), con unos 100 enterramientos en conjunto, corresponden a la fase inicial de Diego Cuscoy donde documentaba poco sus excavaciones. Por otra parte, solo se ha realizado una campaña en una cueva de habitación, El Calabazo (1985). La investigación en las últimas tres décadas, desde la primera prospección sistemática de La Laguna en 1989, se ha orientado hacia una catalogación patrimonial. Nuestra prospección, desarrollada principalmente entre 2002 y 2004, trató de contrastar el poblamiento aborigen del municipio, normalmente minusvalorado porque se consideraba un área de pasto por la presencia de una gran laguna, en relación con la distribución de los grabados rupestres. Los yacimientos aborígenes se conservan en los espacios que han sido menos antropizados, como los acantilados de las zonas litorales de valle Guerra y Bajamar, cauces de barrancos como las Cuevas, Milán, Goleta, el Río o Santos y cimas de montañas con gran visibilidad que presentan canales y cazoletas de carácter ritual.

Palabras clave: Tenerife, guanches, menceyato de Tegueste, La Laguna, prospección arqueológica.

\begin{abstract}
The archaeological investigation in the municipality of La Laguna, part of the old Chiefdom of Tegueste, has been secondary in relation to the neighboring municipality of Tegueste, where Diego Cuscoy conducted regular studies between 1961 and 1973. Although there have been several excavations in funerary caves such as Las Goteras (1933), El Becerril (1944), Milán (1946) or La Palmita (1952), with about 100 burials, correspond to the initial phase of Diego Cuscoy where he documented little in his excavations. On the other hand, only one campaign has been carried out in a domestic cave, El Calabazo (1985). Research in the last three decades, since the first systematic exploration of La Laguna in 1989, has been oriented towards a heritage cataloging. Our survey, developed mainly between 2002 and 2004, tried to contrast the aboriginal settlement of the municipality, usually undervalued because it was considered a pasture area due to the presence of a large lagoon, in relationship with the distribution of
\end{abstract}

1 Queremos agradecer a Rodolfo Afonso, durante su periodo como Director General de Patrimonio Histórico del Gobierno de Canarias, la autorización del proyecto en el cual se desarrollaron las prospecciones y a Rafael González Antón por permitirnos consultar el antiguo inventario del Museo Arqueológico de Tenerife.

* Departamento de Prehistoria y Arqueología de la Universidad Autónoma de Madrid. Facultad de Filosofía y Letras. Campus de Cantoblanco. 28049. Madrid. España. Correo electrónico: alfredo.mederos@uam.es

** Profesor de Instituto de Enseñanzas Medias. Programa de Doctorado. Departamento de Prehistoria, Historia Antigua y Antropología. Universidad de La Laguna. Avenida Trinidad 39. 38204. La Laguna. Tenerife. España. Correo electrónico: escribanocobogabriel@gmail.com

*** Arqueólogo, Calle Tizón, 6, La Laguna. Tenerife. España. Correo electrónico: valenciavicente7@gmail.com 
rock engravings. Aboriginal sites are conserved in spaces that have been less anthropized, such as the cliffs of the coastal areas of Valle Guerra and Bajamar, ravines such as Cuevas, Milán, Goleta, Río or Santos and mountain peaks with high visibility that they present channels and bowls of ritual character.

Keywords: Tenerife, Guanches, Kingdom of Tegueste, La Laguna, Archaeological Survey.

\section{INTRODUCCIÓN}

El municipio de La Laguna, a pesar de ser un núcleo urbano importante, presencia de la universidad y proximidad a Santa Cruz de Tenerife, nunca ha tenido una atención significativa porque se ha supuesto como un área escasamente habitada, donde la antigua laguna generaba un espacio de pastoreo comunal de distintos menceyatos.

Dos buenos ejemplos serían la opinión de Diego Cuscoy², «La Laguna y sus contornos carecen de yacimientos arqueológicos (...) por ser exclusivamente tierra de pastizal»; mientras Cebrián Latasa habla de zonas comunales con pastos de verano en Los Rodeos, Los Naranjeros, La Laguna, Geneto y La Cuesta entre los menceyatos de Goymad [Güímar], [A]Naga, Tegueste y Tacoronte ${ }^{3}$.

No obstante, determinados cauces de barranco como Milán, prolongación del barranco de Agua de Dios, que ha sido el lugar más investigado en Tegueste, o el barranco de Santos, debido al expolio de alguna cueva funerarias, ha sido objeto diversas excavaciones puntuales desde poco antes de la Segunda República, caso de barranco Milán (1930), Las Goteras (1933), El Becerril (1944), Milán (1946) o La Palmita (1952), pero nunca dentro de un programa de investigación regular en el municipio por parte de la Universidad de La Laguna o el Museo Arqueológico de Tenerife, con sede en Santa Cruz de Tenerife.

\section{INVESTIGACIONES ARQUEOLÓGICAS EN EL MUNICIPIO DE LA LAGUNA}

La cueva de Las Goteras se ha propuesto como el lugar de procedencia de una momia femenina, presuntamente hallada en 1881, con el abdomen algo encogido y recubierta por dos capas de pieles, depositada en el Instituto de Canarias de La Laguna ${ }^{4}$. Esta información la debió de recibir Jiménez Sánchez en la propia La Laguna, probablemente al asociarse en el instituto la momia con la colección Anatael Cabrera, que procede del barranco de Agua de Dios en Tegueste y de las cuevas de Las Goteras y La Laja de Bajamar (figura 1).

Sin embargo, la cuestión es más compleja. Tenemos una referencia de 1825 que indica que durante

mi primera visita a la Universidad de San Fernando (...) el Convento de San Agustín (...) El Gabinete de Historia Natural forma parte de la Biblioteca (...) Y en medio de ese caos aparecen los tristes despojos de un pobre guanche agujereado por la polilla ${ }^{5}$,

lo que podría sugerir un hallazgo incluso de finales del siglo XVIII.

Esta momia es citada en un inventario de 1847 del Instituto de Canarias, donde se menciona «una momia de guanche maltratada», «un pie y una mano igualmente momificados». La momia vuelve a ser mencionada en un inventario de $1861 \mathrm{y}$ se describe como «incompleta y mal conservada» ${ }^{6}$.

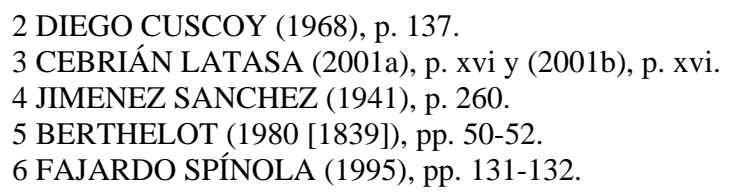




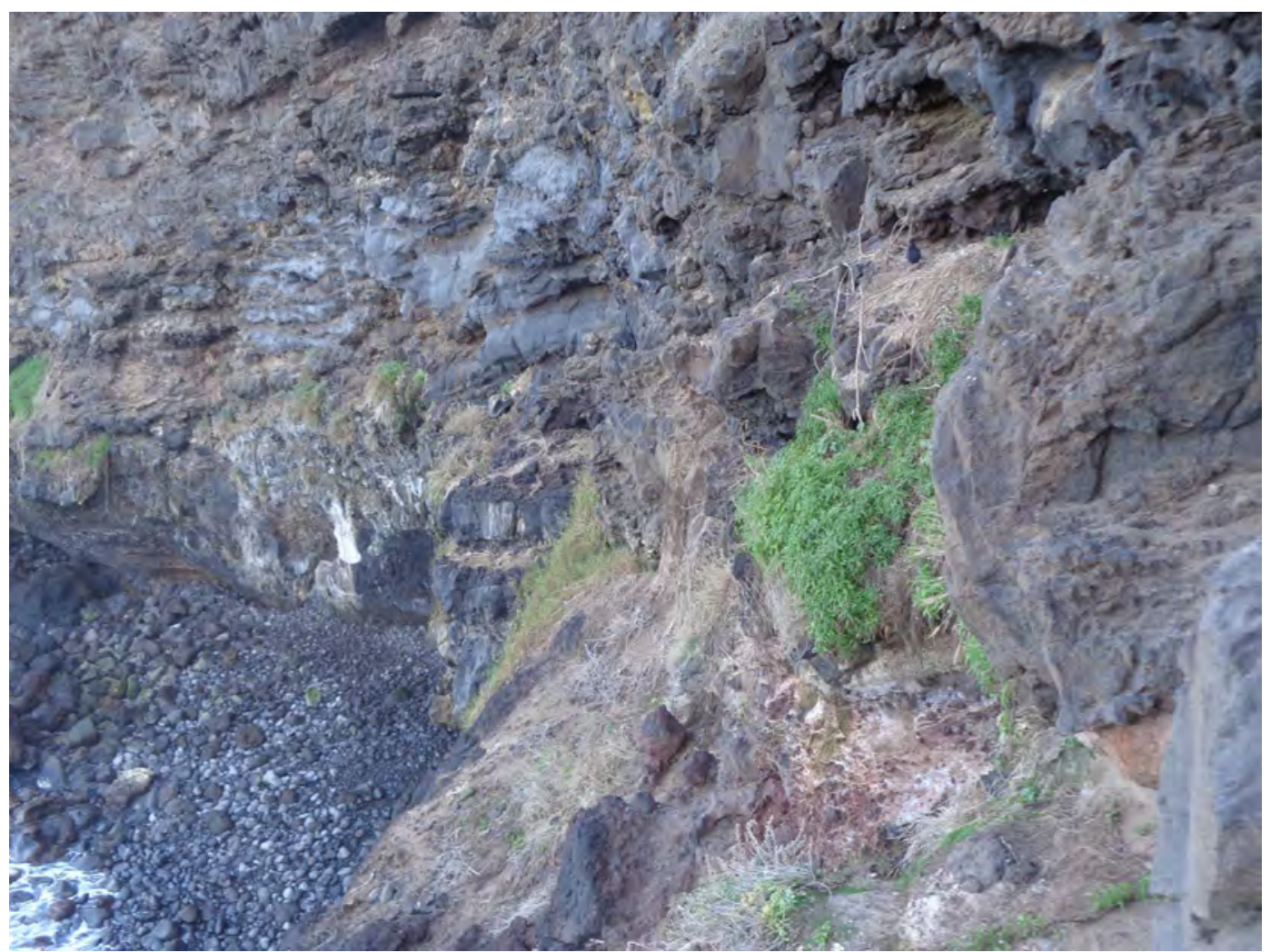

Figura 1. Acceso derrumbado a la cueva de las Goteras, Bajamar.

Por otra parte, con motivo de la visita a Tenerife en 1859 del archiduque imperial Fernando Maximiliano, se interesó en conseguir una momia guanche en buen estado. Esto finalmente lo logró en mayo de 1862 cuando tres rastreadores hallaron 4 momias en una cueva del barranco de Araya (Candelaria, Tenerife). Sin embargo, enterado el alcalde de Candelaria del descubrimiento, informó al gobernador civil de la provincia de Canarias, ordenándose su traslado a Santa Cruz de Tenerife. Después de un complejo proceso burocrático, el director general de Instrucción Pública en marzo de1868 ordenó que «las otras dos momias (...) han sido entregadas, la una al Gabinete de Historia Natural del Instituto de estas islas y la otra a Don Sebastián Casilda Janer» ${ }^{7}$. De estas, probablemente la momia 1, pues carece de la cabeza, fue entregada al Gabinete de Historia Natural del Instituto de Canarias, donde quizás sea la que conserva esta institución, pero de ser así deberían haber dos momias en el Instituto ${ }^{8}$.

Hacia 1930 se produjo el saqueo de una cueva funeraria en el barranco de Milán (Tejina, La Laguna), de la cual «se sacaron momias», luego destruidas, y «rosarios de los guanches» ${ }^{9}$, es decir, cuentas de collar que eran uno de los principales temas de interés de Diego Cuscoy ${ }^{10}$ en su etapa inicial como aficionado y coleccionista.

Probablemente teniendo conocimiento de ello, se explica la primera intervención arqueológica del Instituto de Estudios Canarios en octubre de 1933, a raíz del expolio de la cueva de Las Goteras, situada a unos $20 \mathrm{~m}$ de altura sobre el acantilado de Bajamar. La cueva fue visitada el 19 de septiembre de 1933 por el director, José Peraza de Ayala, y el secretario accidental, Leopoldo de la Rosa Olivera ${ }^{11}$, y localizaron 3 o 4 enterramientos, entre ellos un adulto y un niño en la entrada, pero ya estaba saqueada.

Explorando en las inmediaciones descubrieron otra cueva de $2.50 \mathrm{~m}$ de ancho por $3 \mathrm{~m}$ de profundidad, donde advirtieron cuentas de collar. Tras retirar unas piedras que cubrían la

7 MORA POSTIGO (1995), p. 270.

8 JIMÉNEZ DÍEZ y MEDEROS (2001), pp. 108-109.

9 ÁLVAREZ DELGADO [y DIEGO CUSCOY] (1947d), p. 152.

10 DIEGO CUSCOY (1941); DIEGO CUSCOY (1944).

11 ROSA OLIVERA (1990-92 [1933]), p. 204. 
superficie localizaron 10 enterramientos por la presencia de 10 cráneos, de ellos 9 bien conservados, la mayoría en decúbito supino y alguno en decúbito lateral flexionado ${ }^{12}$.

En el instituto Cabrera Pinto de La Laguna se encuentran los huesos de las cuevas de Las Goteras y La Laja de Bajamar, junto con otros del barranco de Agua de Dios en Tegueste de la colección Anatael Cabrera. Forman una serie que en conjunto suponen 41 pelvis, 42 mandíbulas, 71 húmeros, 67 fémures, 64 tibias -de las cuales 41 son tibias derechas adultas-, 59 cúbitos, 59 radios y 51 peronés, entre otros ${ }^{13}$, que serían restos de 42 individuos. Del estudio de las 41 tibias, de al menos 15 hombres y 11 mujeres, se dedujo una altura media de $1.69 \mathrm{~m}^{14}$.

La primera actuación de Diego Cuscoy en La Laguna fue en la margen derecha del barranco de Santos, en El Becerril, descubierta por dos hermanos que cogían hierba para el ganado en 1944. Esta cueva es importante porque ha sido una de las pocas conservadas intactas en Tenerife antes de su excavación. Con una estratigrafía de $0.75 \mathrm{~m}$, había un nivel superior con desprendimientos del techo, un nivel intermedio con 3 capas y un total de 50 enterramientos aprovechando todo el espacio y finalmente un fino estrato de tierra virgen en la base. La distribución de los materiales, a pesar del alto número de enterramientos, muestra que los punzones y obsidianas solo se encontraban en el nivel inferior de los enterramientos, a $0.45 \mathrm{~m}$, y en la zona del fondo de la cueva. Del mismo modo, las 85 cuentas de collar solo aparecieron en la zona al fondo de la cueva, ocupando una cuarta parte de la superficie, tanto en el nivel inferior como en el superior de los enterramientos ${ }^{15}$ (figuras 2a-2b).

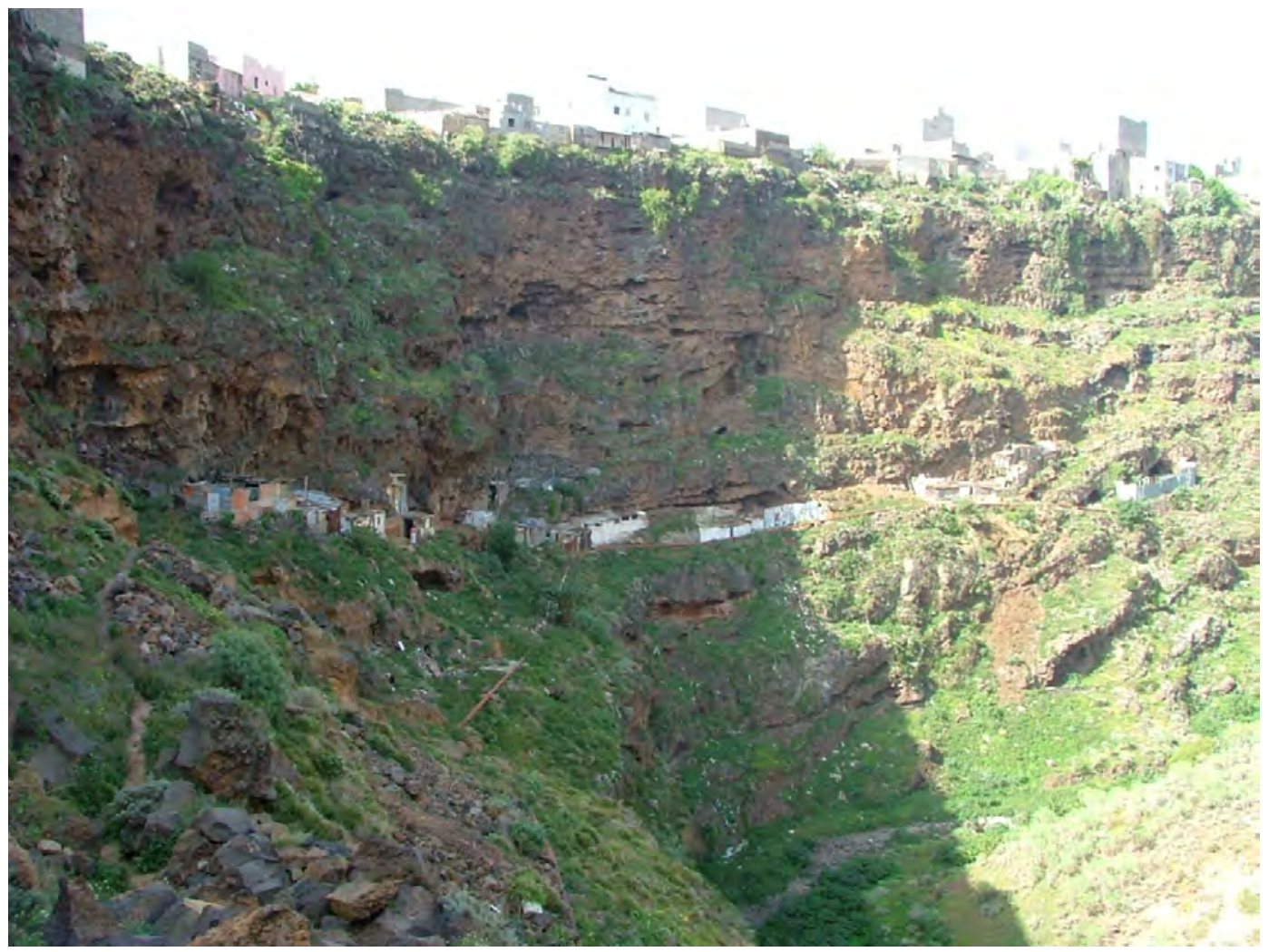

Figura 2a. Emplazamiento de la necrópolis de El Becerril, actualmente con las cuevas reutilizadas.

12 ROSA OLIVERA (1990-92 [1933]), pp. 204-205.

13 ARNAY (2011), pp. 174, 191.

14 GÓNZÁLEZ REIMERS, ARNAY y VELASCO (2006-07), pp. 691-692.

15 ÁLVAREZ DELGADO [y DIEGO CUSCOY] (1947d), pp. 66-67, 64 fig. 20. 


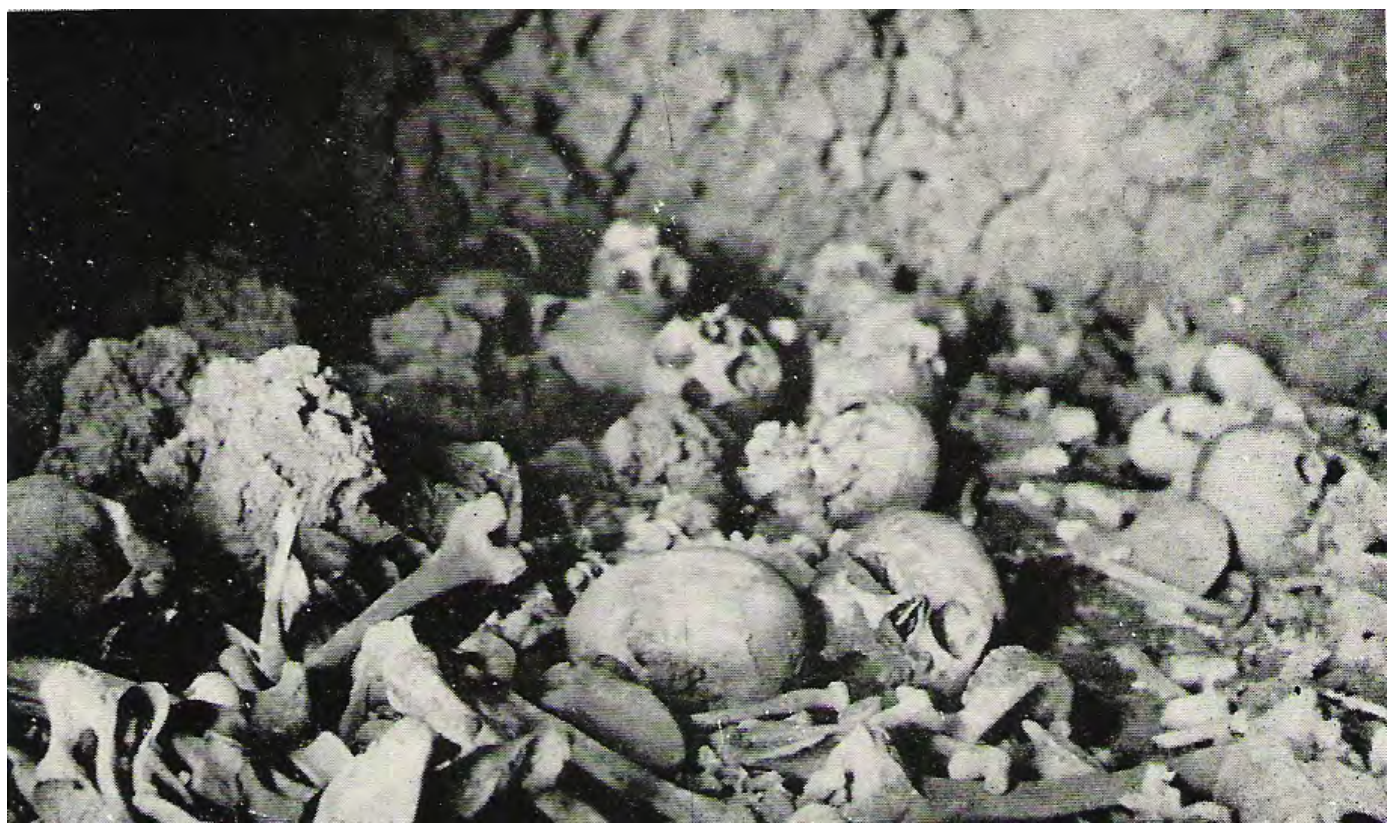

Figura 2b. Enterramientos en superficie de la cueva de El Becerril (Álvarez Delgado, 1947: lam. 8 / fig. 3)

Del estudio paleopatológico de los restos humanos de El Becerril y otros de montaña de Guerra, se han detectado malformaciones congénitas, sobre todo espina bífida oculta, que sugiere una elevada endogamia ${ }^{16 .}$ El estudio de las líneas de Harris en 4 individuos femeninos de El Becerril también sugiere momentos de estrés alimenticio ${ }^{17}$. Del análisis de 14 cúbitos se ha calculado que los hombres tendrían una altura de $1.73 \mathrm{~m}$ y las mujeres $1.60 \mathrm{~m}^{18}$.

Con el conocimiento previo de la cueva expoliada en los años treinta, los estudios de Diego Cuscoy se centraron durante 1946 en el barranco Milán, un conjunto de 6 cuevas de habitación y 2 sepulcrales, casi todas en su margen derecha, que corresponde a la continuación en Tejina, dentro el municipio de La Laguna, del barranco de Agua de Dios ${ }^{19}$, aunque se había sugerido un inicio de los trabajos en 1943 y después en $1944^{20}$. De ellas, Diego Cuscoy excavó en 1946 en una cueva que se levanta unos $9 \mathrm{~m}$ sobre el cauce del barranco a la que se accedía por una entrada de $0.75 \mathrm{~m}$ de ancho. Su interior estaba afectado por la extracción de tierra en polvo cribada para fertilizar los canteros de cultivo, pero un sondeo en el sector norte documentó una estratigrafía de $1.75 \mathrm{~m}$, de los cuales el nivel superior era de derrumbes del techo, bajo el cual había un nivel fértil con cerámica, punzones y un fragmento de molino ${ }^{21}$.

A $55 \mathrm{~m}$ de estas cuevas de habitación, en un andén inferior, a $6 \mathrm{~m}$ sobre el nivel de cauce, Diego Cuscoy señala una cueva sepulcral con restos humanos en toda su superficie de unos 40 $\mathrm{m} 2^{22}$.

Frente a ellas, en la margen izquierda se encontraba la cueva funeraria expoliada hacia 1930. Con unas dimensiones de $1.75 \mathrm{~m}$ de ancho de entrada por $2.50 \mathrm{~m}$ de altura y $6.50 \mathrm{~m}$ de profundidad, presentaba un muro de piedra de cierre y una entrada secundaria de $0.75 \mathrm{~m}$ de ancho. Los enterramientos conservados se concentraban en el lado sur de la cueva y también en un pequeño nicho natural con $1.55 \mathrm{~m}$ de fondo y $1.10 \mathrm{~m}$ de altura, donde había dos enterramientos con eje N-S en el que se concentraban todas las cuentas de collar de la cueva, trozos de piel y un fragmento de cuerda de fibra vegetal. El sondeo mostró una estratigrafía

16 RODRÍGUEZ MARTÍN (1995), pp. 73, 78 fig. 14.

17 KELLEY y BOOM (1995), p. 97 tabla 1.

18 GARCÍA-TALAVERA CASAÑAS (1995), pp. 181 tabla 1; 182 tabla 2.

19 ÁLVAREZ DELGADO [y DIEGO CUSCOY] (1947d), pp. 140-156.

20 SOLER, PÉREZ CAAMAÑO y RODRÍGUEZ (2011), pp. 83 y 85.

21 ÁLVAREZ DELGADO [y DIEGO CUSCOY] (1947d), pp. 146-148.

22 ÁLVAREZ DELGADO [y DIEGO CUSCOY] (1947d), p. 149. 
unos $2.70 \mathrm{~m}$ de profundidad, con un nivel superior estéril de $0.70 \mathrm{~m}$, 24 enterramientos a lo largo de $1.50 \mathrm{~m}$ de profundidad y un estrato base de $0.50 \mathrm{o} 0.60 \mathrm{~m}^{23}$.

Los estudios tuvieron continuidad en 1952 con la excavación de urgencia de la cueva de la Palmita, también en Tejina ${ }^{24}$, localizada «en el centro del patio del que hoy es trapiche de caña de azúcar» ${ }^{25}$, donde se identificaron huesos humanos y un cráneo. Después de la excavación se pudo observar que junto a un bloque basáltico había 8 cadáveres en sentido radial con la cabeza o los pies dirigidos hacia el bloque. Otros 7 enterramientos estaban próximos a este grupo ${ }^{26}$. De uno de los 8 hachones de madera de Pinus canariensis recuperados se realizó un análisis de carbono 14, atribuido a un tablón funerario, M-1057, 1040 $\pm 110 \mathrm{BP}^{27}, 723$ (1000) 1221 DC, que nos indica un enterramiento en torno al siglo X DC (figuras 3a-3b).
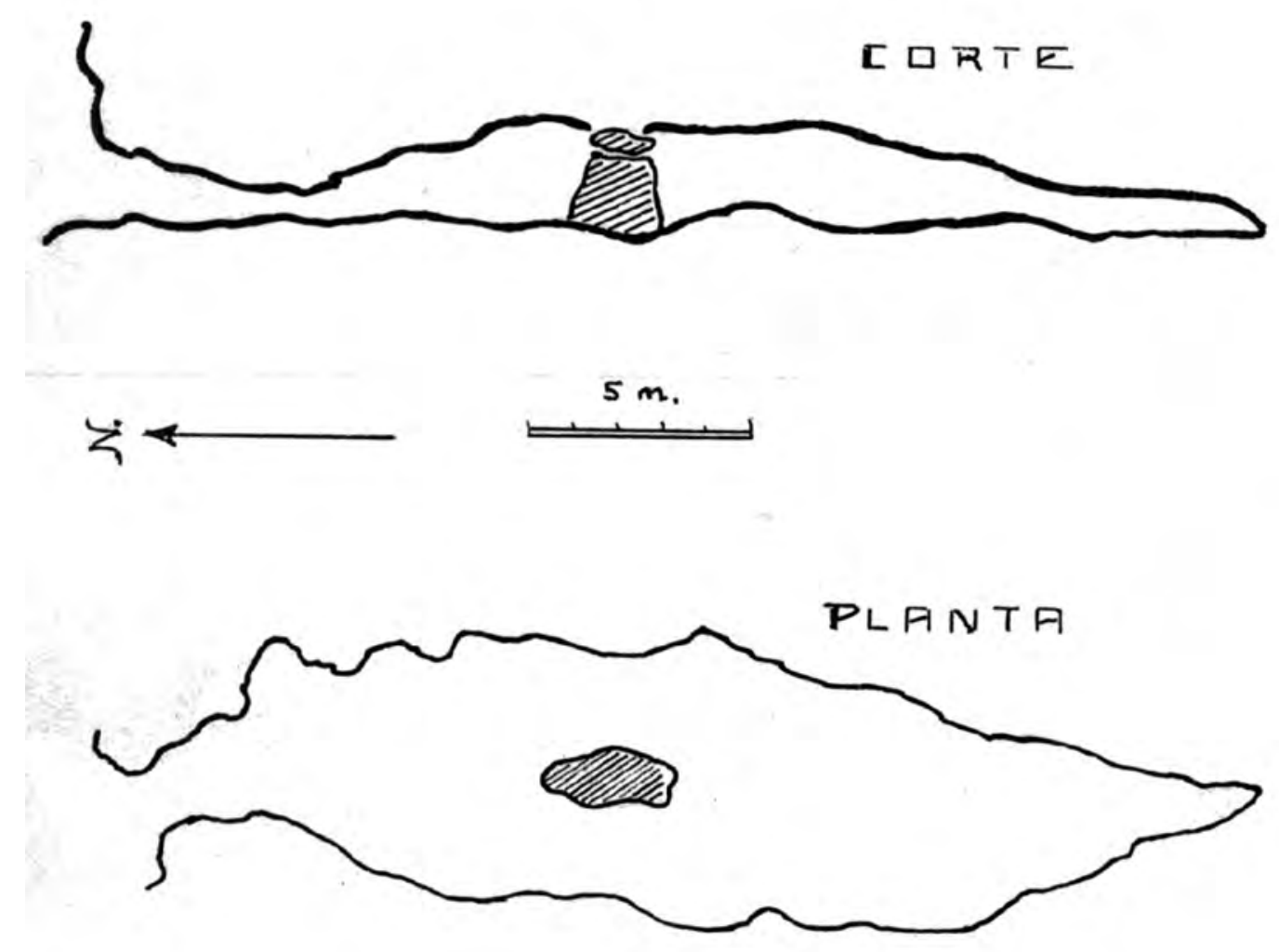

Figura 3a. Planta de la cueva de La Palmita, Tejina (Diego Cuscoy, 2011, p. 560, fig. A4.19).

Finalmente, la única excavación de un espacio de habitación corresponde a El Calabazo después del expolio de la cueva a fines de los años setenta del siglo $\mathrm{XX}^{28}$. La excavación comenzó el 11 de septiembre de 1985 y duró hasta el 5 de octubre. Se identificaron 5 niveles o tallas en un corte de $3 \times 1 \mathrm{~m}$, cuadrículas 5F-6F y 7F, de los que sólo el nivel inferior o 5 era exclusivamente aborigen, aunque también se excavó en otro corte de $4 \times 1 \mathrm{~m}$, cuadrículas 2C, 3C, 4C y 5C, para tratar de definir la cronología de un muro de cierre con dos hiladas de piedra superpuestas y una altura entre $0.80-0.90 \mathrm{~m}$, que resultó de cronología reciente ${ }^{29}$, lo cual se comprobó con la excavación de la cuadrícula 2C (figura 4).

23 ÁLVAREZ DELGADO [y DIEGO CUSCOY] (1947d), pp. 150-153.

24 DIEGO CUSCOY (2011), pp. 555-568.

25 DIEGO CUSCOY (1964), p. 5; DIEGO CUSCOY (2011), pp. 557-558.

26 DIEGO CUSCOY (2011), p. 562.

27 CRANE y GRIFFIN (1968), p. 107; DIEGO CUSCOY (1968), p. 211; ALMAGRO GORBEA (1970), pp. 29-30.

28 GARCÍA BARBUZANO (1983).

29 VALENCIA y ÁLAMO (2011), pp. 93, 91 fig. 1. 


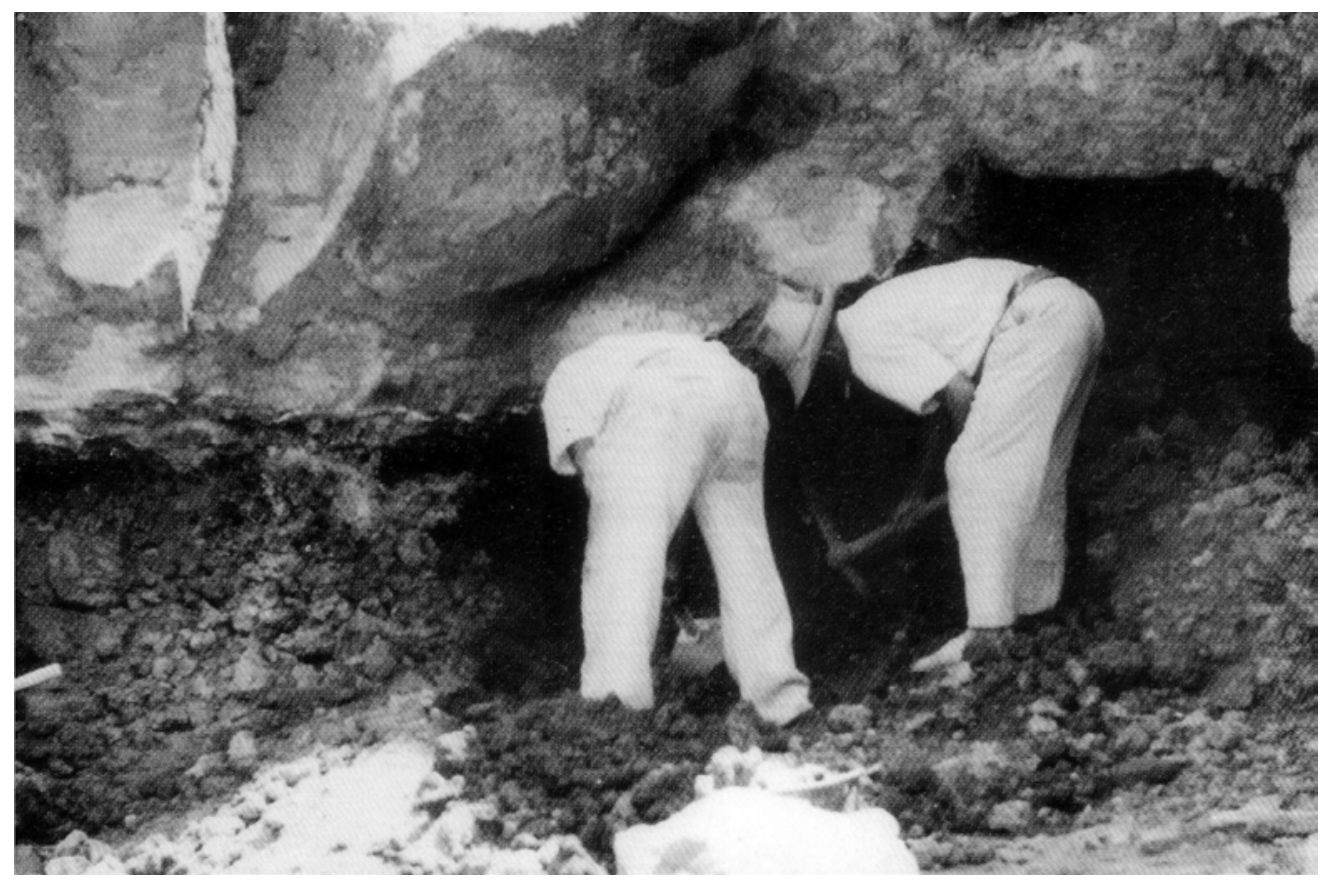

Figura 3b. Excavación de la cueva de La Palmita, Tejina. MAPC.

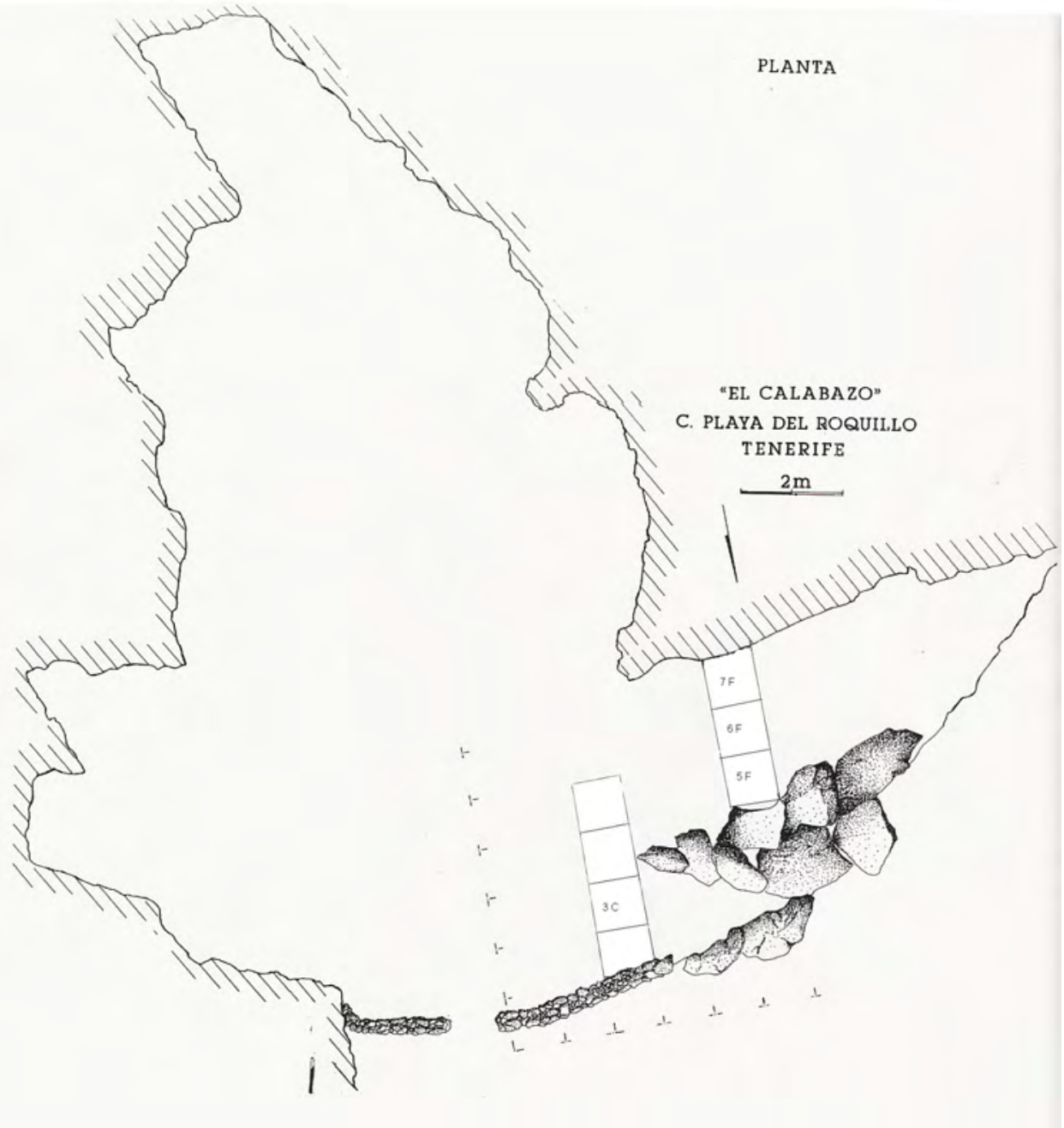

Figura 4. Cueva de habitación de El Calabazo, valle Guerra (Valencia y Álamo, 2011, p. 91 fig. 1). 


\begin{tabular}{|c|c|c|c|c|}
\hline \multicolumn{5}{|c|}{ La Laguna } \\
\hline Yacimiento & $\begin{array}{l}\text { Municipio, } \\
\text { Menceyato }\end{array}$ & $\begin{array}{c}\text { Tipología } \\
\text { Enterramientos } \\
\text { Dimensiones }\end{array}$ & $\begin{array}{c}\text { Campaña } \\
\text { Material } \\
\text { Cronología }\end{array}$ & $\begin{array}{c}\text { Bibliografía } \\
\text { Depósito en MAT }\end{array}$ \\
\hline $\begin{array}{l}\text { Playa de la } \\
\text { Barranquera, } \\
\text { valle Guerra }\end{array}$ & $\begin{array}{l}\text { La Laguna, } \\
\text { Tegueste }\end{array}$ & cueva habitación & $\begin{array}{l}1945 \\
\text { cerámica } \\
\text { obsidiana }\end{array}$ & $\begin{array}{l}\text { Álvarez Delgado, } \\
\text { 1947i: 71-85; } \\
\text { Diego Cuscoy, } \\
\text { 1968: } 236 \text { y 1971: } \\
148\end{array}$ \\
\hline $\begin{array}{l}\text { El Roquillo, } \\
\text { valle Guerra }\end{array}$ & $\begin{array}{l}\text { La Laguna, } \\
\text { Tegueste }\end{array}$ & $\begin{array}{l}\text { cueva sepulcral } \\
\text { expoliada } \\
\text { algunos maxilares } \\
\text { inferiores }\end{array}$ & $\begin{array}{l}1945 \\
28 \text { cuentas de } \\
\text { collar } \\
1 \text { punzón de hueso } \\
\text { cerámica }\end{array}$ & $\begin{array}{l}\text { Álvarez Delgado, } \\
\text { 1947i: 82-84, } 81 \\
\text { fig. 14b; Diego } \\
\text { Cuscoy, 1968: } 236 \\
\text { y 1971: } 148\end{array}$ \\
\hline $\begin{array}{l}\text { El Calabazo, El } \\
\text { Roquillo, } \\
\text { valle Guerra }\end{array}$ & $\begin{array}{l}\text { La Laguna, } \\
\text { Tegueste }\end{array}$ & $\begin{array}{l}\text { cueva habitación } \\
25.6 \text { × } 20 \text { x } 4 \text { m }\end{array}$ & $\begin{array}{l}\text { septiembre } 1985 \\
\text { cerámica decorada } \\
\text { acanalada e incisa } \\
\text { punzones de hueso } \\
\text { obsidiana } \\
\text { pulimentado }\end{array}$ & $\begin{array}{l}\text { García Barbuzano, } \\
\text { 1983: } 25 \text { fig. 5, } 55 \\
\text { fig. 11/1-5, 56-57 } \\
\text { fig. 12-13; } \\
\text { Valencia y Álamo, } \\
\text { 2011: } 89-103,91 \\
\text { fig. 1, } 103 \text { fig. } 2\end{array}$ \\
\hline $\begin{array}{l}\text { El Calabazo II, El } \\
\text { Roquillo, } \\
\text { valle Guerra }\end{array}$ & $\begin{array}{l}\text { La Laguna, } \\
\text { Tegueste }\end{array}$ & $\begin{array}{l}\text { cueva sepulcral } \\
1 \text { adulto } \\
2 \text { mandíbulas } \\
\text { inferiores }\end{array}$ & $\begin{array}{l}\text { punzón de hueso } \\
\text { cuentas de collar } \\
\text { hachones de tea } \\
\text { cuerda de junco } \\
\text { huesos de cabra, } \\
\text { cerdo y perro }\end{array}$ & $\begin{array}{l}\text { García Barbuzano, } \\
\text { 1983: 42-49, } 48 \\
\text { fig. 9/1-7, } 51 \text { fig. } \\
\text { 10, lám. 8-10, 12- } \\
\text { 13; Valencia y } \\
\text { Álamo, 2011: } 103\end{array}$ \\
\hline $\begin{array}{l}\text { El Calabazo III, El } \\
\text { Roquillo, } \\
\text { valle Guerra }\end{array}$ & $\begin{array}{l}\text { La Laguna, } \\
\text { Tegueste }\end{array}$ & $\begin{array}{l}\text { cueva sepulcral } \\
1 \text { adulto y } 1 \text { joven }\end{array}$ & & $\begin{array}{l}\text { Valencia y Álamo, } \\
\text { 2011: } 104\end{array}$ \\
\hline $\begin{array}{l}\text { Callao Márquez, } \\
\text { valle Guerra }\end{array}$ & $\begin{array}{l}\text { La Laguna, } \\
\text { Tegueste }\end{array}$ & $\begin{array}{l}\text { cueva habitación- } \\
\text { sepulcral }\end{array}$ & $\begin{array}{l}\text { cerámica } \\
\text { cuentas de collar } \\
\text { punzones de hueso } \\
\text { obsidiana }\end{array}$ & $\begin{array}{l}1945 \\
\text { Álvarez Delgado, } \\
\text { 1947i: 84-85, } 81 \\
\text { fig. 14c; Diego } \\
\text { Cuscoy, 1968: } 236 \\
\text { y 1971: } 148\end{array}$ \\
\hline $\begin{array}{l}\text { El Boquerón, } \\
\text { valle Guerra }\end{array}$ & $\begin{array}{l}\text { La Laguna, } \\
\text { Tegueste }\end{array}$ & $\begin{array}{l}\text { cueva habitación- } \\
\text { sepulcral }\end{array}$ & $\begin{array}{l}\text { cerámica } \\
\text { cuentas de collar } \\
\text { punzones de hueso } \\
\text { obsidiana } \\
\text { basalto }\end{array}$ & $\begin{array}{l}\text { Diego Cuscoy, } \\
\text { 1968: } 236\end{array}$ \\
\hline $\begin{array}{l}\text { Las Cardoneras, } \\
\text { valle Guerra }\end{array}$ & $\begin{array}{l}\text { La Laguna, } \\
\text { Tegueste }\end{array}$ & $\begin{array}{l}\text { cueva sepulcral } \\
\text { huesos } \\
50 \mathrm{msnm} \\
4 \mathrm{~m}^{2} \\
0.30 \mathrm{~m} \text {. potencia } \\
\end{array}$ & $\begin{array}{l}21 \text { cuentas collar } \\
1 \text { punzón hueso } \\
1 \text { portapunzón } \\
\text { hueso }\end{array}$ & $\begin{array}{l}\text { MAT } 231 \\
1953 \\
\text { Diego Cuscoy, } \\
\text { 1968: } 236\end{array}$ \\
\hline $\begin{array}{l}\text { Costa de valle } \\
\text { Guerra }\end{array}$ & $\begin{array}{l}\text { La Laguna, } \\
\text { Tegueste }\end{array}$ & $\begin{array}{l}\text { cueva habitación } \\
10 \text { msnm }\end{array}$ & & $\begin{array}{l}\text { MAT } 220 \\
1954 \\
\text { Diego Cuscoy, } \\
\text { 1968: } 236\end{array}$ \\
\hline $\begin{array}{l}\text { Costa de Valle } \\
\text { Guerra }\end{array}$ & $\begin{array}{l}\text { La Laguna, } \\
\text { Tegueste }\end{array}$ & $\begin{array}{l}\text { cueva habitación- } \\
\text { sepulcral }\end{array}$ & & $\begin{array}{l}\text { Diego Cuscoy, } \\
\text { 1968: } 236\end{array}$ \\
\hline
\end{tabular}




\begin{tabular}{|c|c|c|c|c|}
\hline $\begin{array}{l}\text { Las Toscas, } \\
\text { valle Guerra }\end{array}$ & $\begin{array}{l}\text { La Laguna, } \\
\text { Tegueste }\end{array}$ & $\begin{array}{l}\text { cueva habitación } \\
200 \text { msnm } \\
5 \times 3.50 \mathrm{~m} \text {. } \\
2 \text { m potencia }\end{array}$ & $\begin{array}{l}\text { cerámica aborigen } \\
\text { cerámica con } \\
\text { engobe rojo }\end{array}$ & $\begin{array}{l}\text { MAT } \\
\text { Aurelio Pérez } \\
\text { Martín-Nicolas } \\
\text { Dorta } 1958 \\
\text { Diego Cuscoy, } \\
\text { 1968: } 236 \text { y 1971: } \\
\text { 148 }\end{array}$ \\
\hline $\begin{array}{l}\text { La Palmita, } \\
\text { Tejina }\end{array}$ & $\begin{array}{l}\text { La Laguna, } \\
\text { Tegueste }\end{array}$ & $\begin{array}{l}\text { cueva sepulcral } \\
15 \text { enterramientos } \\
1.45 \times 25 \text { x } \\
0.75 / 1.50 \mathrm{~m}\end{array}$ & $\begin{array}{l}\text { julio } 1952 \\
17 \text { cuentas de } \\
\text { collar de barro } \\
\text { cocido } \\
2 \text { frag. cerámica de } \\
\text { una vasija } \\
2 \text { punzones de } \\
\text { hueso } \\
2 \text { núcleos de } \\
\text { obsidiana } \\
2 \text { conchas de lapa } \\
8 \text { hachones de tea } \\
1 \text { hachón de } \\
\text { 'maljurada' } \\
723 \text { (1000) } 1221 \\
\text { DC }\end{array}$ & $\begin{array}{l}\text { MAT 240 } \\
\text { Diego Cuscoy, } \\
\text { 1964: 5, 1968: } 236 \\
\text { y 2011: 555-568; } \\
\text { Almagro Gorbea, } \\
\text { 1970: } 29-30\end{array}$ \\
\hline $\begin{array}{l}\text { Los Pilones, } \\
\text { barranco de Milán, } \\
\text { Tejina }\end{array}$ & $\begin{array}{l}\text { La Laguna, } \\
\text { Tegueste }\end{array}$ & cueva sepulcral & & $\begin{array}{l}\text { Diego Cuscoy, } \\
\text { 1968: } 236\end{array}$ \\
\hline $\begin{array}{l}\text { Barranco de Milán } \\
\text { I, Tejina }\end{array}$ & $\begin{array}{l}\text { La Laguna, } \\
\text { Tegueste }\end{array}$ & $\begin{array}{l}\text { cueva sepulcral } \\
21 \text { o } 24 \\
\text { enterramientos } \\
24 \text { cráneos } \\
11 \text { maxilares } \\
\text { inferiores } \\
1.75 \text { x } 2.5 \text { x } 6.5\end{array}$ & $\begin{array}{l}\text { ca. } 1930 \\
164 \text { cuentas de } \\
\text { collar } \\
\text { punzones de hueso } \\
\text { obsidiana } \\
1 \text { conus } \\
1 \text { cuerda de fibra } \\
\text { vegetal } \\
1 \text { piel gamuzada }\end{array}$ & $\begin{array}{l}\text { Álvarez Delgado, } \\
\text { 1947p: } 149-156 \text {, } \\
151 \text { fig. } 26 / 1-2\end{array}$ \\
\hline $\begin{array}{l}\text { Cueva Jurada, } \\
\text { barranco de Milán } \\
\text { II, } \\
\text { Tejina }\end{array}$ & $\begin{array}{l}\text { La Laguna, } \\
\text { Tegueste }\end{array}$ & cueva habitación & $\begin{array}{l}\text { prospección } 1946 \\
\text { cerámica decorada } \\
\text { mango } \\
\text { asa vertedero } \\
\text { mamelón }\end{array}$ & $\begin{array}{l}\text { Álvarez Delgado, } \\
\text { 1947p: 144; Diego } \\
\text { Cuscoy, 1971: 144, } \\
142 \text { fig. 64/4 y } 6\end{array}$ \\
\hline $\begin{array}{l}\text { Barranco de Milán } \\
\text { III, Tejina }\end{array}$ & $\begin{array}{l}\text { La Laguna, } \\
\text { Tegueste }\end{array}$ & cueva habitación & $\begin{array}{l}1946 \\
\text { molino roto al } \\
\text { fabricarse } \\
2 \text { punzones de } \\
\text { hueso }\end{array}$ & $\begin{array}{l}\text { Álvarez Delgado, } \\
\text { 1947p: 146-148, } \\
148 \text { fig. } 25\end{array}$ \\
\hline $\begin{array}{l}\text { Barranco de Milán } \\
\text { IV, Tejina }\end{array}$ & $\begin{array}{l}\text { La Laguna, } \\
\text { Tegueste }\end{array}$ & cueva habitación & $\begin{array}{l}\text { prospección } 1946 \\
\text { cerámica decorada }\end{array}$ & $\begin{array}{l}\text { Diego Cuscoy, } \\
\text { 1971: } 144,142 \text { fig. } \\
64 / 4 \text { y } 6\end{array}$ \\
\hline $\begin{array}{l}\text { Barranco de Milán } \\
\text { V, Tejina }\end{array}$ & $\begin{array}{l}\text { La Laguna, } \\
\text { Tegueste }\end{array}$ & $\begin{array}{l}\text { cueva sepulcral } \\
\text { huesos }\end{array}$ & prospección 1946 & $\begin{array}{l}\text { Álvarez Delgado, } \\
\text { 1947p: } 149\end{array}$ \\
\hline $\begin{array}{l}\text { Las Goteras I, } \\
\text { Bajamar }\end{array}$ & $\begin{array}{l}\text { La Laguna, } \\
\text { Tegueste }\end{array}$ & \begin{tabular}{|l} 
cueva sepulcral \\
expoliada \\
3 o 4 \\
enterramientos
\end{tabular} & $\begin{array}{l}1930 \\
\text { cerámica } \\
\text { obsidiana }\end{array}$ & $\begin{array}{l}\text { MAT 1121 } \\
\text { de la Rosa, } \\
\text { 1933/1990-92: } \\
\text { 203-204; Diego } \\
\text { Cuscoy, 1968: } 236\end{array}$ \\
\hline
\end{tabular}




\begin{tabular}{|c|c|c|c|c|}
\hline $\begin{array}{l}\text { Las Goteras II, } \\
\text { Bajamar }\end{array}$ & $\begin{array}{l}\text { La Laguna, } \\
\text { Tegueste }\end{array}$ & $\begin{array}{l}\text { cueva sepulcral } \\
10 \text { enterramientos } \\
10 \text { cráneos }\end{array}$ & $\begin{array}{l}1930 \\
\text { cuentas collar } \\
3 \text { punzones hueso } \\
1 \text { aguja hueso } \\
\text { pieles } \\
\text { cuerda tejida }\end{array}$ & $\begin{array}{l}\text { de la Rosa, } \\
\text { 1933/1990-92: } \\
\text { 204-205 }\end{array}$ \\
\hline Charco de La Laja & $\begin{array}{l}\text { La Laguna, } \\
\text { Tegueste }\end{array}$ & $\begin{array}{l}\text { cueva funeraria } \\
20 \text { msnm }\end{array}$ & pulidor & $\begin{array}{l}\text { MAT } 703 \\
\text { José Antonio Fiz } \\
\text { Bueno } 1963\end{array}$ \\
\hline Bajamar & $\begin{array}{l}\text { La Laguna, } \\
\text { Tegueste }\end{array}$ & cueva sepulcral & $\begin{array}{l}\text { cuentas de collar } \\
\text { punzón de hueso }\end{array}$ & $\begin{array}{l}\text { MAT } 221 \\
\text { F. de León } 1954 \\
\text { Diego Cuscoy, } \\
\text { 1968: } 236\end{array}$ \\
\hline $\begin{array}{l}\text { Desembocadura y } \\
\text { margen izquierda } \\
\text { del barranco de San } \\
\text { Mateo, Punta } \\
\text { Hidalgo } \\
\end{array}$ & $\begin{array}{l}\text { La Laguna, } \\
\text { Tegueste }\end{array}$ & cueva habitación & 2 muelas molino & $\begin{array}{l}\text { MAT } 772 \\
1969\end{array}$ \\
\hline $\begin{array}{l}\text { Barranco, Punta } \\
\text { Hidalgo }\end{array}$ & $\begin{array}{l}\text { La Laguna, } \\
\text { Tegueste }\end{array}$ & cueva & cerámica & $\begin{array}{l}\text { MAT } 888 \\
1980\end{array}$ \\
\hline $\begin{array}{l}\text { Montaña Tabares, } \\
\text { mirando a barrio de } \\
\text { la Salud }\end{array}$ & $\begin{array}{l}\text { La Laguna, } \\
\text { Tegueste }\end{array}$ & $\begin{array}{l}\text { escondrijo } \\
400 \mathrm{msnm}\end{array}$ & 1 vasija cerámica & $\begin{array}{l}\text { MAT } 889 \\
1971\end{array}$ \\
\hline $\begin{array}{l}\text { Barranco, montaña } \\
\text { de Guerra }\end{array}$ & $\begin{array}{l}\text { La Laguna, } \\
\text { Tegueste }\end{array}$ & \begin{tabular}{|l} 
cueva sepulcral \\
(cráneos) \\
250 msnm \\
0.17 x $0.11 \mathrm{~m}$
\end{tabular} & $\begin{array}{l}\text { cuentas de collar } \\
\text { ópalo } \\
\text { trenza vegetal } \\
\text { pescado } \\
\text { huesos de } \\
\text { ovicápridos, cerdo } \\
\text { y perro }\end{array}$ & $\begin{array}{l}\text { Diego Cuscoy, } \\
\text { 1968: } 236 \\
\text { MAT } 1153 \\
1976\end{array}$ \\
\hline $\begin{array}{l}\text { El Becerril, } \\
\text { barranco de Santos }\end{array}$ & $\begin{array}{l}\text { La Laguna, } \\
\text { Tegueste }\end{array}$ & $\begin{array}{l}\text { cueva sepulcral } \\
50 \text { enterramientos } \\
30 \text { cráneos } \\
15 \text { maxilares } \\
\text { inferiores } \\
250 \text { msnm } \\
0.75 \text { x } 1.50 \text { x } 5.50 \\
\text { m } \\
13.5 \mathrm{~m}^{2} \\
\end{array}$ & $\begin{array}{l}1944 \\
35 \text { cuentas de } \\
\text { collar cilíndricas } \\
15 \text { cuentas de } \\
\text { collar segmentadas } \\
20 \text { cuentas de } \\
\text { collar anulares } \\
3 \text { punzones de } \\
\text { hueso } \\
\end{array}$ & $\begin{array}{l}\text { Álvarez Delgado, } \\
\text { 1947g: 60-69, 83; } \\
\text { Diego Cuscoy, } \\
\text { 1968: } 236 \\
\text { MAT } 802 \\
\text { Octubre } 1972\end{array}$ \\
\hline Тасо & $\begin{array}{l}\text { La Laguna, } \\
\text { Tegueste }\end{array}$ & $\begin{array}{l}\text { cueva habitación- } \\
\text { sepulcral }\end{array}$ & $\begin{array}{l}1 \text { añepa madera } \\
\text { completa } 1.39 \text { m }\end{array}$ & $\begin{array}{l}\text { MAT } 305 \\
\text { Diego Le Brun } \\
\text { Diego Cuscoy, } \\
\text { 1968: } 236 \\
\end{array}$ \\
\hline Тасо & $\begin{array}{l}\text { La Laguna, } \\
\text { Tegueste }\end{array}$ & $\begin{array}{l}\text { cueva habitación- } \\
\text { sepulcral }\end{array}$ & $\begin{array}{l}\text { añepa } \\
\text { punzones de hueso }\end{array}$ & $\begin{array}{l}\text { Diego Cuscoy, } \\
\text { 1968: } 236 \\
\end{array}$ \\
\hline
\end{tabular}

Tabla. 1. Yacimientos publicados o excavados de La Laguna.

La síntesis sobre Los Guanches de Diego Cuscoy ${ }^{30}$ sirvió para presentar brevemente en una tabla 10 nuevos yacimientos del municipio. Parte de estos yacimientos fueron recogidos en la Tesis de Licenciatura de $\mathbf{M}^{\mathrm{a}}$. C. Jiménez ${ }^{31}$ que presentó una carta arqueológica del noreste de Tenerife. En este trabajo se enumeran 9 yacimientos también citados por Diego Cuscoy ${ }^{32}$ y se describen con más detalle otros dos yacimientos excavados por Diego Cuscoy, El Berrecil en $1944^{33}$, y las cuevas del barranco de Milán, en $1946^{34}$. Otra síntesis, en este caso sobre las

30 DIEGO CUSCOY (1968), p. 236.

31 JIMÉNEZ GÓMEZ (1971); JIMÉNEZ GÓMEZ, TEJERA y LORENZO PERERA (1980), pp. 38-40.

32 DIEGO CUSCOY (1968), p. 236.

33 ÁLVAREZ DELGADO [y DIEGO CUSCOY] (1947b), pp. 60-69. 
cuevas funerarias, fueron incluidas en la tesis de licenciatura de $\mathrm{M}^{\mathrm{a}}$. C. del Arco $^{35}$, quien menciona 13 yacimientos del municipio también ya conocidos (tabla 1).

Después del traspaso de competencias arqueológicas a la Comunidad Autónoma de Canarias en 1984, la primera catalogación del poblamiento del municipio se realizó en el Inventario del Patrimonio Arqueológico de las Canarias Occidentales de 1989, financiado por la Viceconsejería de Cultura y Deportes del Gobierno de Canarias. Bajo la dirección de Juan Francisco Navarro, participaron Vicente Valencia como coordinador del norte de Tenerife, Fernando Álamo, Alejandro Cuenca, Cristo Hernández Gómez, Carmen Marante, Carlota Mora, Candelaria Rosario Adrián, Francisco de la Rosa y Pedro Valera, el mismo equipo que realizó simultáneamente el municipio de Tegueste. En la prospección también colaboraron Domingo Acosta, Gregorio Arencibia, Estervina Borges, Alicia Cabrera, Luis Díaz, Isabel Francisco Ortega, María José Lugo, Vicente Morilla, María Teresa Ruiz e Isaac Valencia. Parte de este equipo había participado en la excavación de El Calabazo, dirigida por Valencia y Álamo en 1985, caso de Mora, Rosario y Ruiz. A partir de este trabajo, y de nuestra posterior revisión inédita de 2002-05, una selección de 21 yacimientos de la zona litoral entre la punta de la Barranquera y la punta de la Romba, el límite con el municipio de Tacoronte, fue avanzada por Valencia y Álamo ${ }^{36}$.

La prospección de 1989 fue utilizada en el Plan Territorial Especial del Sistema Viario del Área Metropolitana de Tenerife, encargado a la empresa Arqueocanaria S.L., que incluía el municipio de La Laguna, plan viario que quedó aprobado definitivamente en 2007. Esta misma empresa de Arqueocanaria, dirigida por Valentín Barroso Cruz y Concepción Marrero Quevedo, realizó el año 2000 un Estudio de Impacto Arqueológico del Proyecto de Nueva CarreteraVariante de Tejina-TF.121 de La Laguna a Punta del Hidalgo. PK. 7.500 al 9.000 (La Laguna, Tenerife), que estudiaba la zona del barranco de Milán.

Tres años después se firmó un contrato del Ayuntamiento de La Laguna con la Universidad de La Laguna para estudiar de nuevo el mismo sector del barranco de Milán, denominado Inventario Arqueológico de la margen izquierda del Barranco de Agua de Dios (Tejina, San Cristóbal de La Laguna), realizado por Esther Chávez, Amaya Goñi y Elena Pérez González en 2003, del que se publicó una breve valoración ${ }^{37}$, presentada inicialmente en un congreso ${ }^{38}$, aunque no se describe ningún yacimiento en detalle.

Posteriormente se realizó el Diagnóstico y Limpieza del Patrimonio Cultural de la Isla de Tenerife, financiado por el Instituto Nacional de Empleo (INEM) y el Área de Cultura, Patrimonio Histórico y Museos del Cabildo Insular de Tenerife, que en 2008 incluyó el Inventario del Patrimonio Cultural del Área Metropolitana, ampliando las prospecciones no sólo al patrimonio arqueológico, sino también al etnográfico y arquitectónico. En un equipo coordinado por V. Valencia, participaron Marta Díez, Pilar Galván, Leticia García González y Ana Olga de Paz, bajo la tutela de Unidad de Patrimonio Histórico del Cabildo Insular de Tenerife y la dirección de José Carlos Cabrera.

En los últimos años, a fin de ubicar de un SIG los yacimientos arqueológicos de cada municipio en el PGOU, a pesar de que es una información de la que ya disponían otras administraciones como el Gobierno de Canarias y posteriormente el Cabildo de Tenerife, estos datos no se han compartido y desde muchos ayuntamientos se ha optado por contratar nuevas prospecciones en zonas ya previamente estudiadas, aunque recientemente el Cabildo ha comenzado a ceder esta información patrimonial a los ayuntamientos.

En ocasiones se han multiplicado los yacimientos al individualizarse cada cueva en las prospecciones más recientes, siguiendo un buen criterio fijado desde el Cabildo de Tenerife, frente a una agrupación en conjuntos arqueológicos con una o varias cuevas en las prospecciones de 1989-90, que tenía el problema de no describirse en detalle cada una dentro de una catalogación genérica y que obviaba la visita de algunas.

34 ÁLVAREZ DELGADO [y DIEGO CUSCOY] (1947d), pp. 144-156.

35 DEL ARCO (1976), pp. 40-42.

36 VALENCIA y ÁLAMO (2011), pp. 82-88.

37 PÉREZ GONZÁLEZ, CHÁVEZ y GOÑI (2009-10).

38 PÉREZ GONZÁLEZ, CHÁVEZ y GOÑI (2005). 
Concretamente para La Laguna, en junio de 2018 se anunció el comienzo de una nueva prospección por la empresa Cultania, dirigida por J. Soler y F. Pérez Caamaño, en el barranco Milán $^{39}$, zona previamente objeto de prospecciones en 2000 y 2003 ya mencionadas, donde una vez finalizada se identificaron 25 yacimientos en cueva desglosables en 3 funerarios en el barranco de La Fuente, 2 en Tejina, uno de habitación y otro sepulcral, y 20 en el barranco Milán, de ellos 7 de habitación y 13 sepulcrales $^{40}$. Por otra parte, se ha venido realizado una fotogrametría de una selección de 30 estaciones de grabados y canales y cazoletas del municipio ${ }^{41}$.

En nuestro caso, a partir de 2002, dentro del Proyecto, Arte Rupestre de las Islas Canarias: nueva valoración de los principales conjuntos, aprobado por la Dirección General de Patrimonio Histórico del Gobierno de Canarias, resolución de la Viceconsejería de Cultura y Deportes $n^{\circ}$ 136/02 de 12 de julio de 2002, bajo la codirección del Ldo. Gabriel Escribano Cobo, el Dr. Alfredo Mederos Martín de la Universidad de Harvard y el Ldo. Vicente Valencia Afonso, uno de sus apartados incluía una prospección de los conjuntos rupestres, de habitación y funerarios en los municipios de La Laguna y Tegueste ${ }^{42}$, para buscar una explicación a la concentración de manifestaciones rupestres en La Laguna, en particular al oeste de la Autopista del Norte, mientras la principal concentración de cuevas de habitación y funerarias se encontraba en el vecino municipio de Tegueste y, en concreto, en el barranco de Agua de Dios, con su prolongación en La Laguna en el barranco de Milán.

\section{METODOLOGÍA Y EQUIPO DE LA PROSPECCIÓN}

Las prospecciones del municipio de La Laguna se extendieron de forma discontinua a lo largo de los 3 años de duración del proyecto, 2002-05. En ellas, además de los codirectores, también participaron Gustavo González, Raúl Melo y el Ldo. Tomás Rodríguez.

Para facilitar la consulta a los investigadores se ha tratado de asociar en lo posible los yacimientos de la prospección con la inicialmente realizada en 1989. Cuando el yacimiento no figura consideramos que no se trata de un yacimiento aborigen por falta de suficientes evidencias de material arqueológico en superficie o bien su acceso actualmente no es posible por el derrumbe de los andenes o por el cierre por los propietarios del acceso a ese sector del barranco, básicamente en zonas concretas del barranco Milán.

La prospección sistemática superficial de un área delimitada utilizó como unidad referencial básica el transect longitudinal, siempre previa valoración de la orografía del terreno. El transect es subdividido internamente en un número variable de líneas imaginarias que deben ser recorridas por los prospectores en función del grado de intensidad de cobertura prefijado, que oscila entre los 50 y $100 \mathrm{~m}$. y que se comprimió de 1 a $5 \mathrm{~m}$ en los espacios delimitados como yacimientos, con lo que se incrementa así la intensidad y la probabilidad de localizar e identificar un mayor número de artefactos. Estos fueron catalogados y conservados in situ en el terreno mediante el uso de fichas de cada yacimiento y documentación fotográfica, para facilitar el contraste de los datos en el futuro, siguiendo la normativa actual que impide el levantamiento del material del yacimiento.

Al perseguirse siempre como objetivo una prospección sistemática, frente al muestreo, fue requisito imprescindible para la consecución de resultados óptimos la realización continuada de dichas prospecciones, de forma que dentro de una malla imaginaria se vayan interrelacionándose los distintos transect con nichos ecológicos naturales.

A la hora de fijar los criterios válidos a nivel metodológico y conceptual para definir un "yacimiento" o site, frente al hallazgo aislado y lugares de actividad limitada o de baja intensidad, non-site, se valoraron convenientemente la densidad de artefactos o ecofactos identificados o recuperados en una superficie prefijada para permitir un posterior uso de criterios estadísticos y conseguir una adecuada representación y tamaño de muestra.

39 La Opinión de Tenerife, 22-6-2018.

40 El Día, 11-11-2018.

41 El Día, 5-12-2017.

42 MEDEROS, ESCRIBANO y VALENCIA (2015). 
No obstante, siempre se sopesó cuidadosamente este criterio ante la posible presencia de factores taxonómicos que provocan alteraciones postdeposicionales, caso de fenómenos de tipo erosivo -arroyada, bioturbaciones, etc.-, o de factores antrópicos, tanto involuntarios, fruto de labores agrícolas como arado, desbrozado, reutilización de estructuras o cuevas, etc., como voluntarios, por la actuación de aficionados o expoliadores incontrolados.

En general, ha habido cinco factores que han incidido en la distribución de artefactos o ítem identificados: el grado de vegetación que reduce su visibilidad en superficie y puede obligar en ocasiones a reprospectar un yacimiento cuando el número de evidencias es insuficiente, pues no es lo mismo vegetación arbórea, monte bajo, uso agrícola ocasional o parcela en cultivo. La mayor o menor incidencia de la erosión pone al descubierto los posibles artefactos o ecofactos y modifica su posición primaria por lo que los desplaza a una secundaria, fenómeno en el que tiene mucha importancia notable el grado de pendiente del terreno. La dificultad en la accesibilidad por la topografía reduce también el espacio circundante a una cueva. La composición edafológica influye sobre la conservación del registro arqueológico, caso de ecofactos como la fauna. Finalmente, en el grado de perceptibilidad de los artefactos inciden las condiciones de luz presentes, el tamaño de los artefactos y el grado de pedregosidad del suelo, lo que es más difícil en elementos de talla lítica como obsidiana y mejor cuando hay un contraste cromático más intenso, como la malacología o algunos tipos de cerámica a torno.

\section{YACIMIENTOS DOCUMENTADOS}

\section{Punta de la Romba I, valle Guerra}

A $30 \mathrm{~m}$ de distancia del mar, se localiza un conchero con restos malacológicos muy dispersos y sin relleno. Está asociado a un pequeño abrigo de piedra seca que ha sido reutilizado en fechas históricas. La superficie aproximada del conchero es de $17.10 \mathrm{~m}$ por $14.40 \mathrm{~m}$. Solo se han identificado pequeños fragmentos de cerámica y algunas lascas de obsidiana. CALL n ${ }^{\circ} 44$.

\section{Punta de la Romba II-IV, valle Guerra}

Tres cuevas sepulcrales, con orientación al norte, a $55 \mathrm{msnm}$, en el tracto superior. Las tres cuevas que han sido expoliadas presentan restos óseos humanos. En la primera las dimensiones son $3 \mathrm{~m}$ de ancho en la entrada, $1.40 \mathrm{~m}$ de altura y $2.80 \mathrm{~m}$ de largo hasta el fondo. En la boca de entrada existen restos de una pared de piedra seca de $1 \mathrm{~m}$ de longitud por $1 \mathrm{~m}$ de altura conservada y se identificó una cuenta de collar del ajuar funerario en superficie.

A la misma cota, por la derecha, se localiza otra cueva funeraria con escasos restos óseos muy fragmentados. Orientada al norte, mide $5 \mathrm{~m}$ de ancho en la entrada, $1.10 \mathrm{~m}$ de altura y 3.5 $\mathrm{m}$ de largo hasta el fondo.

La tercera cueva, con orientación al norte, mide $2.50 \mathrm{~m}$ de ancho en la entrada, $0.88 \mathrm{~m}$ de altura y 3.20 m de largo hasta el fondo. CALL n ${ }^{\circ} 45$ (figura 5).

\section{Finca del Apio, punta de la Baja Izquierda, valle Guerra}

Cueva de habitación, a 56 msnm, localizada en el tercio superior del acantilado, por encima de una pista privada que comunica la finca del Apio con la playa, muy cerca de la punta de la Baja Izquierda. Mide $10 \mathrm{~m}$ de ancho en la entrada, $1.5 \mathrm{~m}$ de altura y $7 \mathrm{~m}$ de largo hasta el fondo. Conserva algo de relleno, con restos malacológicos y fragmentos de cerámica aborigen dispersos al exterior y desplazados por la escorrentía debido al desnivel del propio acantilado. Ha sido reutilizada en actividades ganaderas. La fuente del Apio es una de las principales de la zona litoral. CALL $n^{\circ} 40$. 


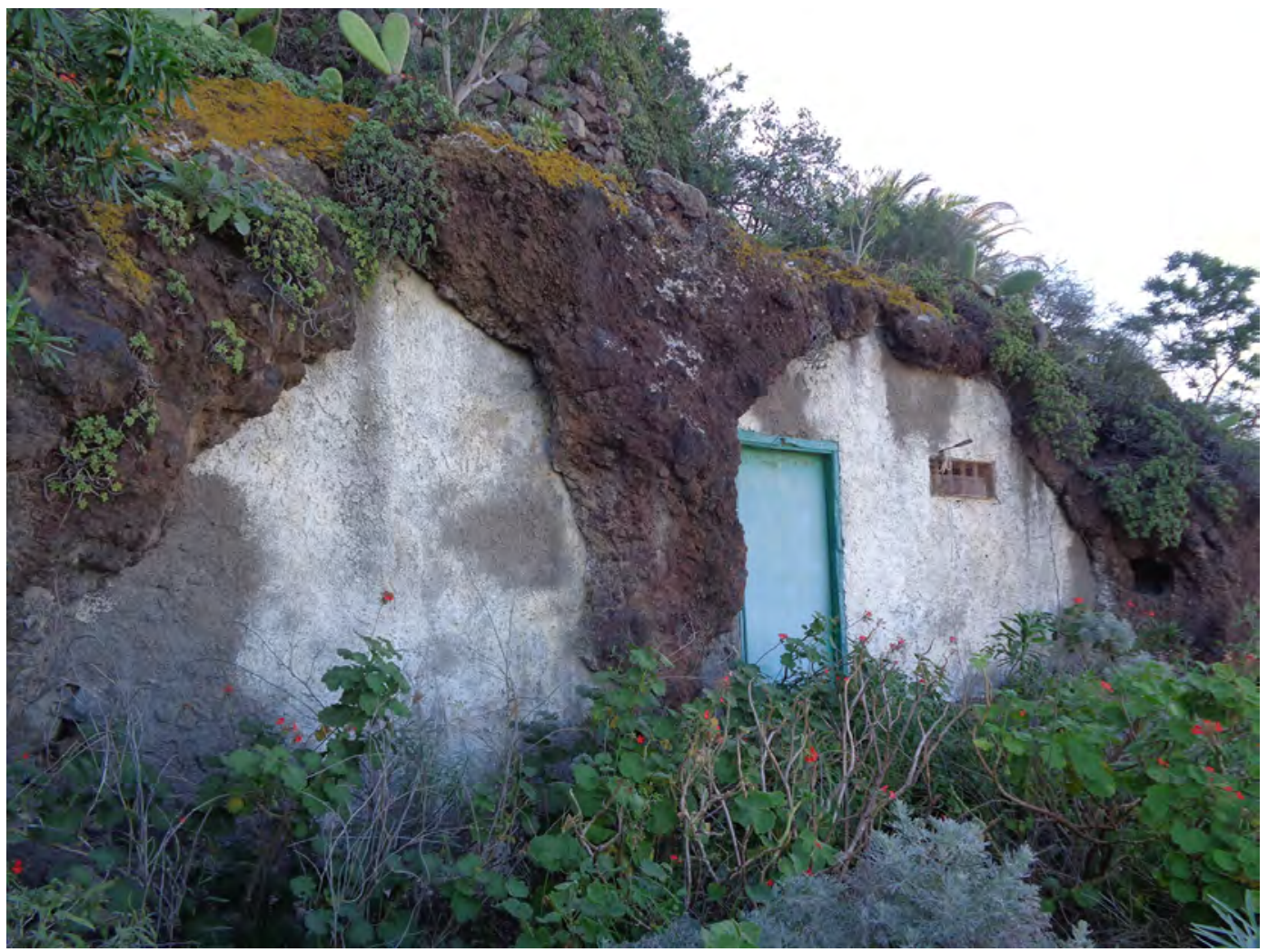

Figura 5. Cueva de punta de la Romba, valle Guerra.

\section{Punta de la Baja Izquierda I, valle Guerra}

Cueva natural de habitación, a 45 msnm, en el tracto medio, con una orientación N-NW. Mide $2 \mathrm{~m}$ de ancho en la entrada, $1.20 \mathrm{~m}$ de altura y $3.50 \mathrm{~m}$ de largo hasta el fondo. Conserva relleno y escasos fragmentos cerámicos y malacológicos en superficie. Los materiales se dispersan pendiente abajo por la propia inclinación del terreno, empujados por las escorrentías. CALL n ${ }^{\circ} 42$.

\section{Punta de la Baja Izquierda II, valle Guerra}

Cueva sepulcral a 40 msnm, en el cantil costero, con orientación N-NW, en zona de solana. Mide $1.50 \mathrm{~m}$ de ancho en la entrada, $0.95 \mathrm{~m}$ de altura y $5.15 \mathrm{~m}$ de largo hasta el fondo. Se trata de un pequeño tubo volcánico que en su interior conserva restos de una pared de cerramiento. Expoliada, ya no conserva restos humanos, pero por información oral parece que era una cueva funeraria. CALL n ${ }^{\circ} 41$.

\section{Punta de la Baja Izquierda III, barranco Chamorro, valle de Guerra}

Cueva de habitación, a 60 msnm, localizada en la ladera izquierda, en solana, del barranco Chamorro, en su tracto superior. Orientada de E-W, mide $6.20 \mathrm{~m}$ de ancho en la entrada, $1.80 \mathrm{~m}$ de altura y $4.90 \mathrm{~m}$ de largo hasta el fondo. CALL n ${ }^{\circ} 38$.

\section{Barranco Chamorro I, valle Guerra}


Cueva de habitación que se encuentra a 70 msnm, ubicada en el tracto superior de la ladera izquierda, junto al salto del barranco, en zona de umbría. Mide $16 \mathrm{~m}$ de ancho en la entrada, 15 $\mathrm{m}$ de largo hasta el fondo y $4.50 \mathrm{~m}$ de altura. La orientación es N-S con la boca abierta hacia $20^{\circ}$ $\mathrm{N}$. Hay restos derruidos de un muro en la entrada con $1.20 \mathrm{~m}$ de ancho. Debió de ocuparse estacionalmente porque presenta filtraciones al interior, que serían más acentuadas en invierno. En superficie se observa fauna de ovicápridos, espinas de pescado y Patella sp. CALL no 37.

\section{Barranco Chamorro II, valle Guerra}

Gran cueva de habitación a $68 \mathrm{msnm}$, ubicada en el tracto superior de la ladera derecha. Mide $15.50 \mathrm{~m}$ de ancho en la entrada, $8 \mathrm{~m}$ de largo hasta el fondo y $2.95 \mathrm{~m}$ de altura. La orientación principal es S.SE-N.NW, hacia $305^{\circ} \mathrm{NW}$. En superficie se observó cerámica aborigen decorada acanalada, basalto trabajado, fauna de ovicápridos y Patella sp., aunque ha sido reutilizada guardándose bloques de cemento en su interior.

\section{El Calabazo I, barranco de las Cuevas, valle Guerra}

Conjunto de varias cuevas emplazadas en la desembocadura del barranco de las Cuevas, donde se localiza el yacimiento de El Calabazo y situadas al SW de la punta del Jurado. Se han formado a partir de la desagregación de las escorias basales que se alternan entre sucesivas capas de coladas, por la humedad ambiental y la maresía. La cueva principal, situada a 64 msnm, está inmediatamente por debajo de un camino que pertenece a una finca de plataneras. Se accede desde $255^{\circ} \mathrm{W}$ descendiendo o bien desde $10^{\circ} \mathrm{N}$ por el andén superior donde están otras cuevas. En su interior se definen tres sectores en la cueva, al W-SW, E y al S.SE. Presenta unas dimensiones de $17 \mathrm{~m}$ de largo, $8 \mathrm{~m}$ de ancho, que llegan a ser $13 \mathrm{~m}$ en el extremo oeste, y $2 \mathrm{~m}$ de altura, con una orientación hacia $335^{\circ} \mathrm{N}$. El acceso presenta un muro de cierre de $6 \mathrm{~m}$ de longitud por $1.30 \mathrm{~m}$ de ancho y $0.85 \mathrm{~m}$ de altura, con 4 hiladas de piedra conservadas.

La cueva ha sido objeto de diversos expolios en los años setenta del siglo XX y sus materiales fueron valorados inicialmente por García Barbuzano ${ }^{43}$ quien cribó y estudió los restos del expolio. Por la limpieza del perfil de uno de los hoyos excavados se pudo apreciar una estratigrafía de $0.47 \mathrm{~m}$.

Dos años después de esta publicación se autorizó en 1985 una excavación codirigida por Valencia y Álamo ${ }^{44}$. Se trabajaron $7 \mathrm{~m}^{2}$ en dos sectores, las cuadrículas 5F, 6F, 7F por un lado, y las cuadrículas 2C, 3C, 4C y 5C por otro. De ellos destaca el primer grupo de 3 cuadrículas con una estratigrafía más definida: un nivel 1, entre 3 y $12 \mathrm{~cm}$, un nivel 2, entre 3 y $13 \mathrm{~cm}$, ambos presentan también cerámicas históricas; un nivel 3 de transición, entre 2 y $5 \mathrm{~cm}$, que responde a la fracción fina del nivel superior, un nivel 4, que oscila entre 15 y $30 \mathrm{~cm}$, donde aún existe cerámica aborigen y a torno histórica, quizás por una intrusión en la cuadrícula 5F, y un nivel 5, o de base, el primero aborigen intacto, donde se aprecia en el perfil $\mathrm{N}$ de la cuadrícula $5 \mathrm{~F}$ un hogar, próximo a la entrada y protegido por grandes bloques de basalto desprendidos de techo de la entrada de la cueva. CALL n 31 (figura 6).

\section{El Calabazo II, barranco de las Cuevas, valle Guerra}

Saliendo por el andén superior en dirección norte, a $9 \mathrm{~m}$ se encuentra una segunda cueva ubicada a $63 \mathrm{msnm}$, que carece de condiciones adecuadas de habitación porque se inunda desde el norte, aunque hay un espacio que se ha reutilizado para dormir en el extremo NE y hay basuras en su lado $\mathrm{S}$. La cueva presenta unas dimensiones de $8 \mathrm{~m}$ de longitud por $8 \mathrm{~m}$ de fondo

43 GARCÍA BARBUZANO (1983), p. 39 cuadro 2.

44 VALENCIA y ÁLAMO (2011), pp. 101, 104-107. 
y 2.40 m de altura, cuya entrada está orientada hacia $295^{\circ}$ W.NW, y aún conserva un pequeño muro de cierre exterior en el lado oeste.

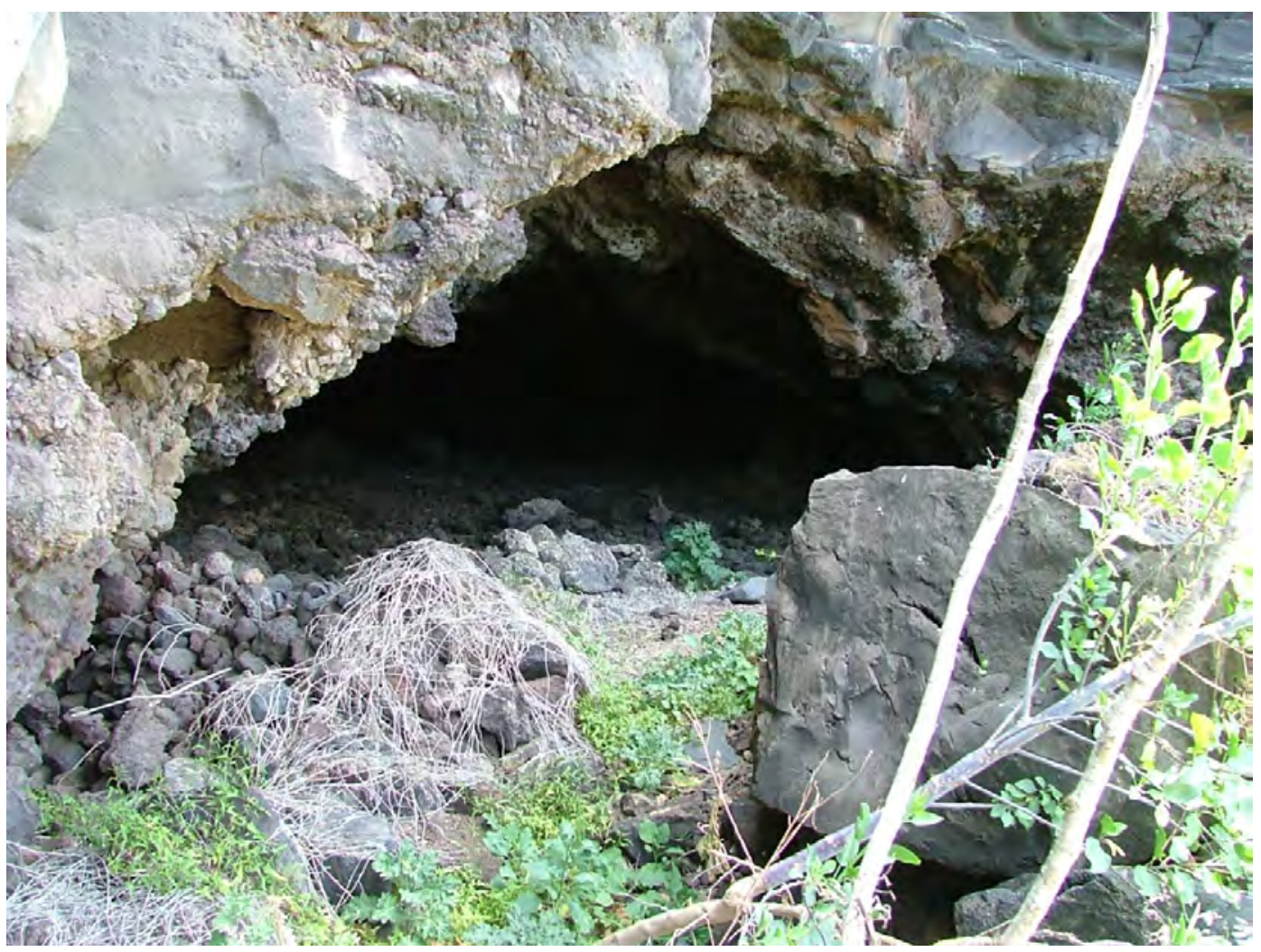

Figura 6. Cueva de habitación de El Calabazo, valle Guerra.

El Calabazo III, barranco de las Cuevas, valle Guerra

Avanzando por el mismo andén superior otros $15 \mathrm{~m}$ existe una tercera cueva, funeraria, a 62 msnm, expoliada cuando fue estudiada por García Barbuzano ${ }^{45}$, con unas dimensiones de 1.10 $\mathrm{m}$ de longitud por $2 \mathrm{~m}$ de fondo y $0.90 \mathrm{~m}$ de altura y orientada su entrada hacia $265^{\circ} \mathrm{W}$.NW. La existencia de dos mandíbulas inferiores y los dientes documentados, 30 muelas, 10 incisivos y 8 caninos $^{46}$ sugieren la presencia de un adulto y un joven ${ }^{47}$. Desde esta zona hay otro acceso a la parte superior del barranco (figura 7).

\section{Barranco de las Cuevas, valle Guerra}

Cueva de habitación, a 155 msnm, en la margen izquierda de una pequeña barranquera, al inicio de la pista que baja al barranco de Chamorro. Mide $16 \mathrm{~m}$ de ancho en la entrada, $2 \mathrm{~m}$ de altura y 6 m de largo hasta el fondo. CALL $\mathrm{n}^{\circ} 72$.

45 GARCÍA BARBUZANO (1983), pp. 42-48, cuadro 3.

46 GARCÍA BARBUZANO (1983), p. 46 fig. 8.

47 VALENCIA y ÁLAMO (2011), pp. 103-104. 


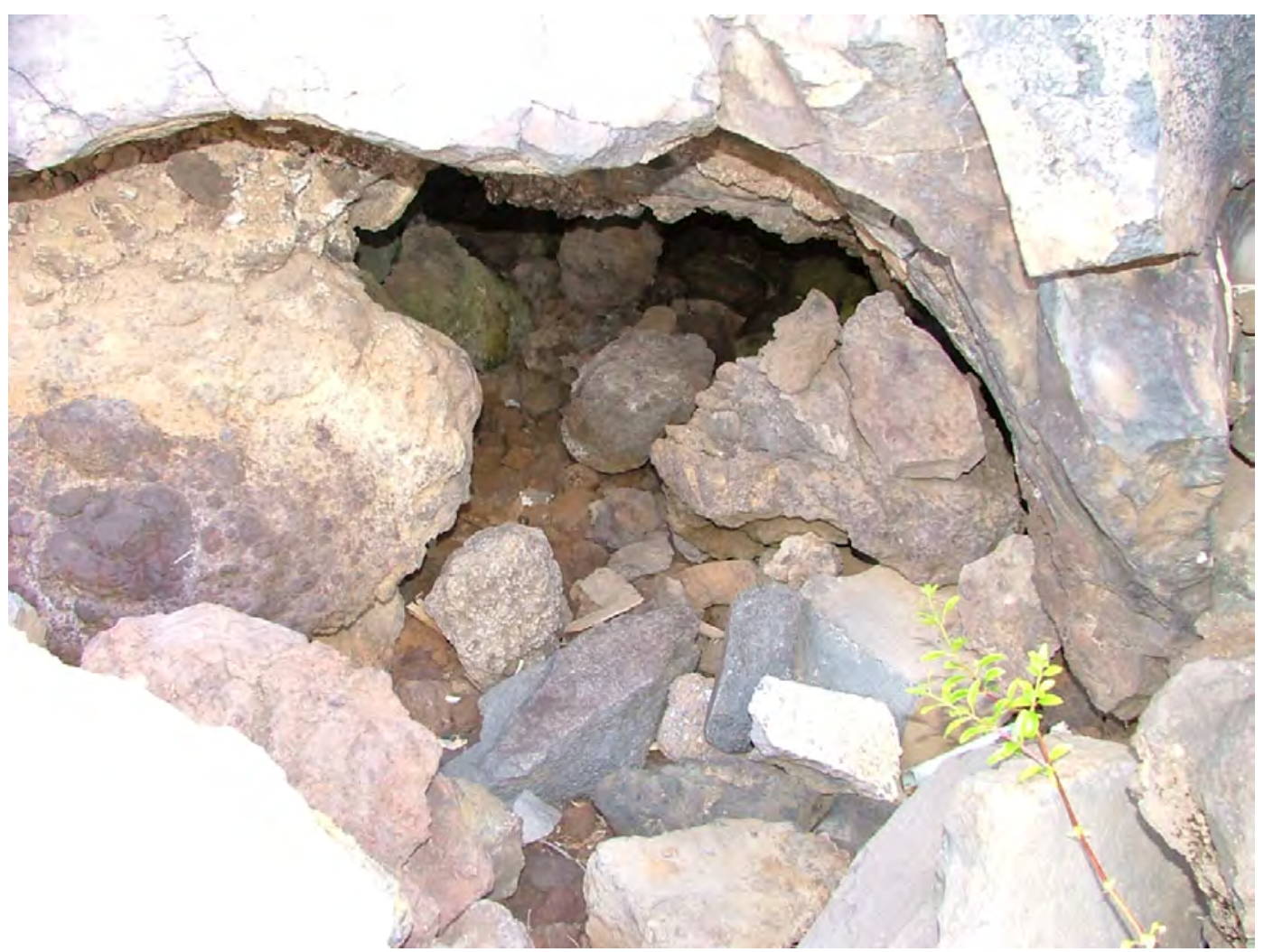

Figura 7. Cueva funeraria de El Calabazo, valle Guerra.

\section{Punta de la Barranquera I, valle Guerra}

Conjunto de 4 cuevas, a $15 \mathrm{msnm}$, que se sitúan a escasos metros por debajo de la carretera de la punta de la Barranquera. La primera, orientada al noroeste, mide $3.25 \mathrm{~m}$ de ancho en la entrada, 2.25 m de altura y 3.50 m de largo hasta el fondo. Reutilizada, se construyó una pared de piedra seca que deja un vano de entrada y en el interior se acondicionó la pared con enfoscado, poyete y piso de callado de playa. Está afectada por bloques de basalto, que rodaron abajo cuando se realizó la carretera. Parece tratarse de la cueva mencionada por Álvarez Delgado (y Diego Cuscoy) ${ }^{48}$, donde aún entonces residía una familia de pescadores, que parece fue originariamente una cueva funeraria. CALL n 13 (figura 8).

\section{Punta de la Barranquera II-III, valle Guerra}

La segunda cavidad, orientada al suroeste, se sitúa a la derecha, a una distancia aproximada de $20 \mathrm{~m}$, y mide $3.50 \mathrm{~m}$ de ancho de boca, $1.20 \mathrm{~m}$ de altura y $4 \mathrm{~m}$ de largo hasta el fondo. Contiene relleno sedimentario y está reutilizada.

La tercera cueva se sitúa encima de la anterior, también orientada al Suroeste, y mide $8 \mathrm{~m}$ de ancho de boca, $1.80 \mathrm{~m}$ de altura máxima en la visera, descendiendo hacia el interior, y $3 \mathrm{~m}$ de largo hasta el fondo. Presenta restos de una posible pared de protección. Está conectada a la segunda cueva por una perforación natural de la roca con derrumbes del techo en algunos sectores. En superficie se observan fragmentos de cerámica decorada, restos de fauna, obsidiana, Stramonita haemastoma y Patella sp.

48 ÁLVAREZ DELGADO [y DIEGO CUSCOY] (1947c), p. 85. 


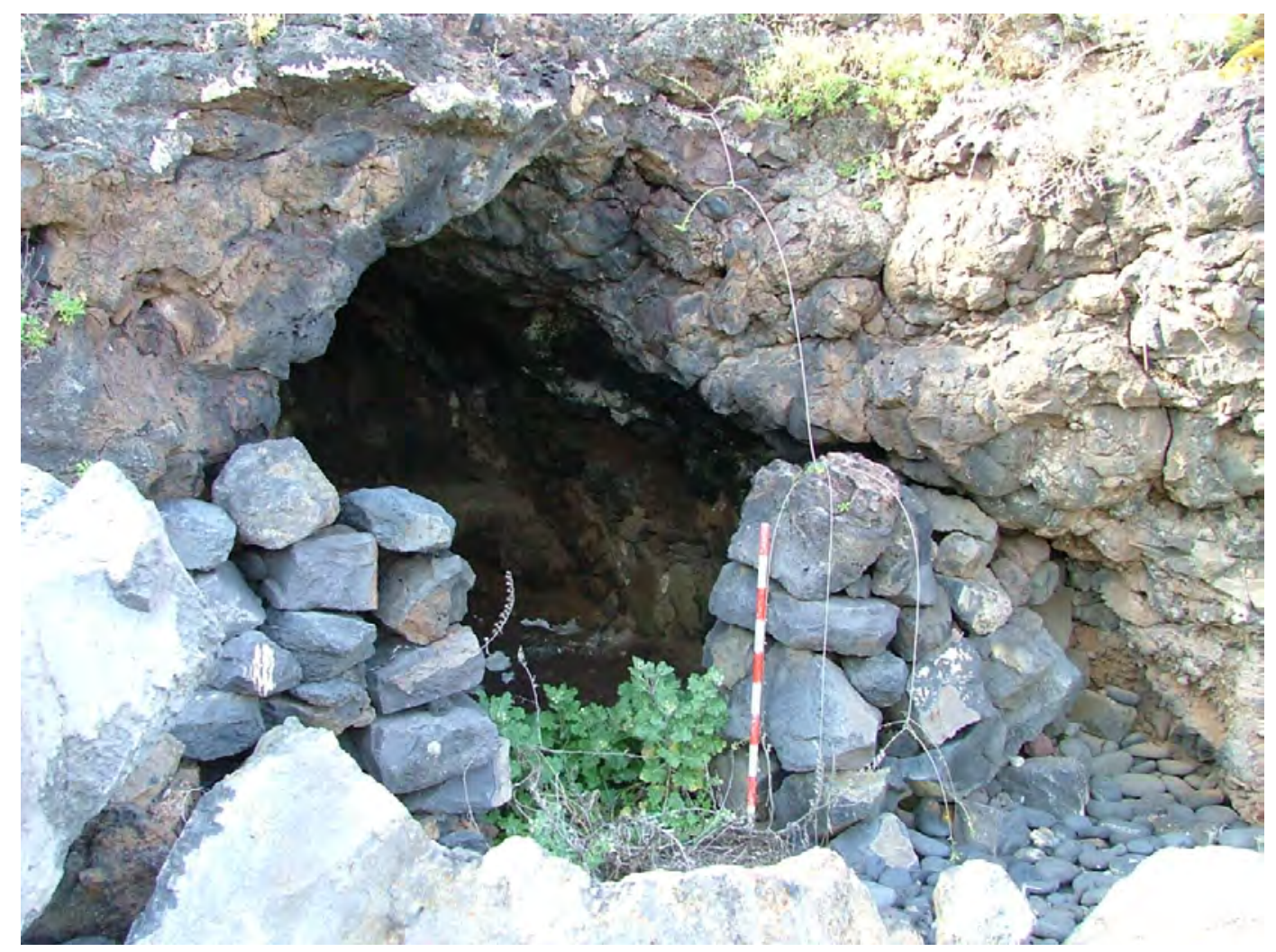

Figura 8. Cueva de punta de la Barranquera, valle Guerra.

\section{Punta de la Barranquera IV, valle Guerra}

La cuarta cueva, orientada al noreste y a una cota de $15 \mathrm{msnm}$, mide $3 \mathrm{~m}$. de ancho de boca, $1.50 \mathrm{~m}$ de altura, que aumenta en su interior, y $7 \mathrm{~m}$ de largo hasta el fondo. Conserva una pared de piedra en la entrada de $1 \mathrm{~m}$ de altura, $0.80 \mathrm{~m}$ de grosor y 5 hiladas superpuestas, con restos de argamasa.

\section{La Caleta I-II, punta de la Barranquera, valle Guerra}

Dos cuevas naturales, una de habitación y otra sepulcral, situadas a $10 \mathrm{msnm}$ y apenas $10 \mathrm{~m}$ de la orilla. La primera mide $3 \mathrm{~m}$ de ancho en la entrada, $2 \mathrm{~m}$ de altura y $5 \mathrm{~m}$ de largo hasta el fondo. Una pared de bloques cierra la entrada y actualmente está reutilizada como almacén. Un abrigo natural se localiza junto a esta y en su interior mana el agua. Mide $4 \mathrm{~m}$ de ancho en la entrada, $2 \mathrm{~m}$ de altura y $4.20 \mathrm{~m}$ de largo de fondo.

La cueva sepulcral, de $3.5 \mathrm{~m}$ de ancho de entrada y $3 \mathrm{~m}$ de fondo, fue explorada por Diego Cuscoy, y, al haber sido expoliada, no presentaba huesos humanos, salvo algunos huesos carpianos y 41 cuentas de collar ${ }^{49}$. CALL $\mathrm{n}^{\mathrm{0}} 11$.

\section{Barranco del Horno I, valle de Guerra}

Cueva de habitación, a 33 msnm, localizada en la margen derecha del barranco del Horno. Orientada a $265^{\circ} \mathrm{W}$, las dimensiones son de $6.5 \mathrm{~m}$ de ancho en la entrada, $1 \mathrm{~m}$ de altura y $7 \mathrm{~m}$ de largo hasta el fondo, presentando una gatera interior con dirección SW-NE. Tiene derrumbes en el lado norte y en el lado sur ofrece las mejores condiciones de habitabilidad. No hay

49 ÁLVAREZ DELGADO [y DIEGO CUSCOY] (1947c), pp. 84-85. 
acondicionamientos internos. En superficie se reconoce cerámica aborigen, obsidiana, Patella sp. y Stramonita haemastona. El acceso al yacimiento es dificultoso por la densa vegetación de tarajales, tabaibas, cornicales y tuneras que ocupa el cauce y las laderas del barranco. CALL n ${ }^{\circ} 17$.

\section{Barranco del Horno II, valle de Guerra}

Cueva emplazada a $37 \mathrm{msnm}$, en la margen izquierda, en el penúltimo salto del barranco del Horno, antes de su desembocadura. Las dimensiones son $1.50 \mathrm{~m}$ de ancho en la entrada, $1.30 \mathrm{~m}$ de altura y $5.30 \mathrm{~m}$ de largo hasta el fondo. Sobre la cueva crece una higuera de gran porte. Su acceso es dificultoso por la densa vegetación. CALL n ${ }^{\circ} 18$.

\section{Barranco del Horno III, valle de Guerra}

Cueva sepulcral ubicada a $40 \mathrm{msnm}$, en el tracto superior de la margen izquierda del barranco del Horno, desde el que se visualiza la Barranquera. El enterramiento se efectuó en un pequeño tubo volcánico, con eje N-S, que se abre en el interior de la cavidad, que mide $2 \mathrm{~m}$ de ancho en la entrada, $2.25 \mathrm{~m}$ de altura y $3.5 \mathrm{~m}$ de largo hasta el fondo. El suelo de la cueva tiene una fuerte inclinación. Expoliada, al exterior del tubo se reconocieron en superficie restos humanos de una falange, un fragmento de costilla y una vértebra. CALL nº 19.

\section{Playa El Roquillo I-IV, valle Guerra}

Tres cuevas de habitación y una sepulcral, situadas en las proximidades de la Barranquera, a $40 \mathrm{msnm}$. La primera cueva de habitación está situada en el extremo Suroeste del conjunto, en el andén superior y mide $11 \mathrm{~m}$. de ancho en la entrada, $4.5 \mathrm{~m}$ de altura y $6 \mathrm{~m}$ de largo hasta el fondo. La orientación es de $45^{\circ} \mathrm{NE}$. Reutilizada, presenta derrumbes de bloques de basalto. Una pared de $4.5 \mathrm{~m}$, con 3 hiladas y $0.55 \mathrm{~m}$ de altura, permite nivelar el suelo horizontal en el extremo este de la cueva. Tiene una superficie de $20 \mathrm{~m}^{2}$.

En el andén inferior existen dos cuevas naturales de habitación, una de las cuales, con orientación $355^{\circ} \mathrm{N}$, mide $5 \mathrm{~m}$ de ancho en la entrada, $1.85 \mathrm{~m}$ de altura y $8 \mathrm{~m}$ de largo hasta el fondo. Conserva una pared de protección en el extremo este, con una hilada conservada, que mide $2.50 \mathrm{~m}$ de longitud.

La segunda cueva de este andén tiene una orientación de $185^{\circ} \mathrm{W}$, y visualiza El Roquillo. Cuenta con mejores condiciones de habitabilidad en el sector NE. Presenta filtraciones en el sector S y SE por su proximidad al salto del barranco. Mide $6 \mathrm{~m}$ de ancho en la entrada, $1.80 \mathrm{~m}$ de altura y $3.50 \mathrm{~m}$ de largo hasta el fondo. En el exterior se acumulan grandes bloques basálticos desprendidos del acantilado.

La cueva funeraria presenta dos entradas bajas y estrechas, que aprovechan un tubo volcánico. La longitud de la superior es $8 \mathrm{~m}$ y la de la inferior de $10 \mathrm{~m}$. La boca que debió de tener un muro de piedras, al estar abierta actualmente, ha debido de penetrar por ella abundante agua de lluvia, ya que se encuentra al pie mismo de una torrentera. Estas aguas han arrastrado al interior del enterramiento a veces grandes cantidades de tierra y arena y parte de los huesos hacia el exterior. Fue expoliada, localizándose varios cráneos humanos en la boca $\mathrm{B}^{50}$. Presumiblemente CALL n ${ }^{\circ} 27$.

50 ÁLVAREZ DELGADO [y DIEGO CUSCOY] (1947c), pp. 82-83. 


\section{Playa El Roquillo V, valle Guerra}

Material de superficie, a una cota $15 \mathrm{msnm}$, entre la punta del Jurado y la desembocadura del barranco del Horno, en el acantilado costero, caso de fragmentos de cerámica aborigen y obsidiana, que se dispersan por las escorrentías y un buzamiento del acantilado de 30 a $40^{\circ}$. Hay densa vegetación de cardonal-tabaibal y los tarajales dificultan la observación, pero no pudimos identificar unas supuestas estructuras de fondos de cabañas que Valencia y Álamo ${ }^{51}$ también apuntan. CALL n 26.

\section{Punta del Jurado I, valle Guerra}

Cueva natural de habitación, a $37 \mathrm{msnm}$, dividida en tres sectores. El sector SE, con orientación $350^{\circ} \mathrm{N}$, mide $6 \mathrm{~m}$ de ancho en la entrada por $4.5 \mathrm{~m}$ de largo hasta el fondo. Existen evidencias de reutilización reciente con un hogar en el extremo SE y una pared de cerramiento con una altura de $1.10 \mathrm{~m}$ y 3 hiladas conservadas.

El segundo sector, orientado a $65^{\circ} \mathrm{E}$, está a un nivel más alto, desde el que se visualiza la playa de El Roquillo. Una pared de piedra cierra los laterales y el frente dejando un hueco de entrada de $0.95 \mathrm{~m}$ de ancho en la entrada y $0.70 \mathrm{~m}$ de altura. El muro mantiene una altura máxima de 5 hiladas y $1.12 \mathrm{~m}$ de altura. Se forma un espacio rectangular de $6 \mathrm{~m}$ de ancho, 1.50 $\mathrm{m}$ de altura y por $7.5 \mathrm{~m}$ de largo hasta el fondo. En superficie hay fragmentos cerámicos aborígenes, algunos decorados, obsidiana, restos malacológicos y cerámica histórica a mano que se desplazan al exterior y caen por la ladera. El tercer sector es el extremo norte, carece de pared de cierre, mide $2.5 \mathrm{~m}$ de ancho en la entrada, $1.40 \mathrm{~m}$ de altura y $3.5 \mathrm{~m}$ de largo hasta el fondo. Este espacio está reutilizado como redil de ganado caprino. CALL no 28 (figura 9).

\section{Punta del Jurado II, valle de Guerra}

Cueva de habitación, a $43 \mathrm{msnm}$, orientada a $20^{\circ} \mathrm{N}$, con dimensiones de $3.50 \mathrm{~m}$ de ancho en la entrada, $1.85 \mathrm{~m}$ de altura y $2.75 \mathrm{~m}$ de largo hasta el fondo. Presenta una pared de protección de $5 \mathrm{~m}$ de longitud en la entrada y doble paramento con un grosor de $1.10 \mathrm{~m}$ y 4 hiladas de piedra superpuestas, que alcanzan una altura de $1.50 \mathrm{~m}$. Conserva relleno sedimentario y materiales arqueológicos abundantes en superficie. Al exterior, en una plataforma horizontal, también presenta en superficie restos arqueológicos. CALL n ${ }^{\circ} 29$.

\section{Punta del Jurado III, valle de Guerra}

Gran tubo volcánico, con eje N-S, a $43 \mathrm{msnm}$, situado al extremo SE del conjunto y orientación $10^{\circ} \mathrm{N}$. Presenta $4.80 \mathrm{~m}$ de ancho en la entrada, $2.95 \mathrm{~m}$ de altura y $9 \mathrm{~m}$ de largo hasta el fondo. El tubo se prolonga $1.50 \mathrm{~m}$ en una gatera más estrecha. Hay una pared de protección de $1.25 \mathrm{~m}$ de alto, de doble paramento con 6 hiladas conservadas y puerta de entrada de $0.80 \mathrm{~m}$ de ancho. En su interior cuenta con unas dimensiones de $0.75 \mathrm{~m}$ de altura y $9 \mathrm{~m}$ de fondo. A partir de aquí el tubo continúa hacia el interior con una sección menor. Las paredes laterales presentan alzados que permiten homogeneizar las paredes de la cueva, con una altura máxima de $1.20 \mathrm{~m}$ y 5 hiladas de piedras superpuestas. Reutilizada hasta los años sesenta del siglo XX, los materiales arqueológicos se dispersan al exterior de la cavidad. CALL $n^{\circ} 30$.

51 VALENCIA y ÁLAMO (2011), p. 85. 


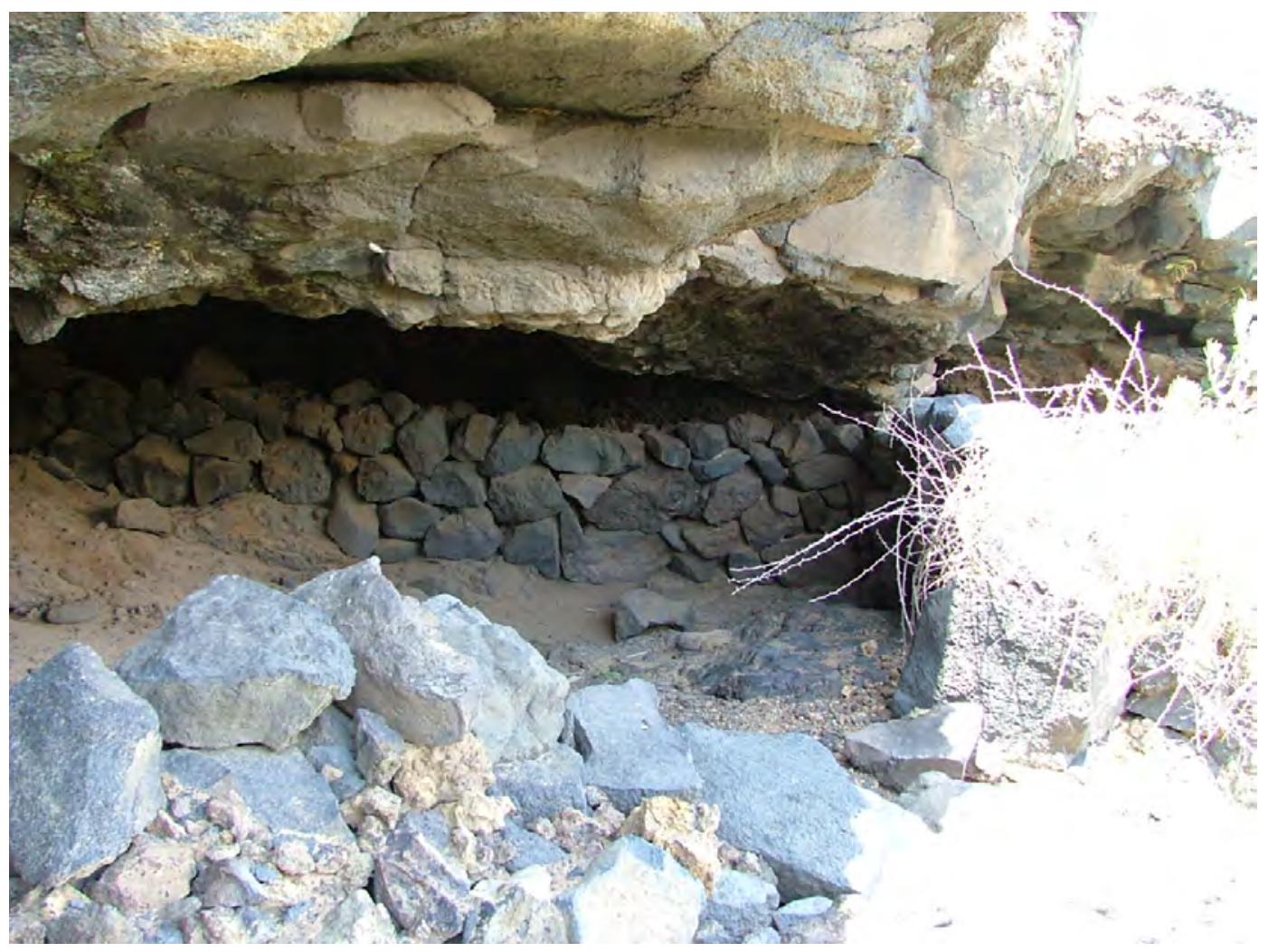

Figura 9. Cueva de punta del Jurado, valle Guerra.

\section{Punta del Guincho I, valle Guerra}

Cueva natural de habitación, situada a $12 \mathrm{msnm}$, con orientación al noroeste. Mide $10 \mathrm{~m}$ de ancho en la entrada, $1.90 \mathrm{~m}$ de altura y $3 \mathrm{~m}$ de largo hasta el fondo. Está reutilizada y acondicionada con paredes de mampostería de bloques de toba blanca, el suelo es de cemento y está actualmente abandonada.

Junto a esta existe un abrigo de $25 \mathrm{~m}$ ancho en la entrada por $4 \mathrm{~m}$ de largo hasta el fondo, y en la plataforma exterior hay fragmentos de cerámica aborigen, obsidiana y restos malacológicos dispersos. Está parcialmente cerrado con una pared de piedra y utilizado como pozo de aguas residuales de la vivienda superior. CALL n ${ }^{\circ} 9$.

\section{Punta del Guincho II, caleta de Méndez, valle Guerra}

Cueva situada a $20 \mathrm{msnm}$, cerca de la punta de El Guincho, en el tracto superior del acantilado sobre la caleta de Méndez. Las dimensiones son $8 \mathrm{~m}$ de ancho en la entrada, $1.50 \mathrm{~m}$ de altura y $1.5 \mathrm{~m}$ de largo hasta el fondo. Presenta derrumbes de las paredes y, aunque quizás fuera una cueva funeraria, no conserva restos óseos humanos. CALL n ${ }^{\circ} 8$.

\section{Punta del Fraile, Tejina}

Cueva sepulcral situada a $30 \mathrm{msnm}$, en el tracto superior del acantilado, en La Solana, con orientación W-NW. Presenta unas dimensiones de $9 \mathrm{~m}$ de ancho en la entrada, $1.10 \mathrm{~m}$ de altura y $6 \mathrm{~m}$ de largo hasta el fondo. CALL $\mathrm{n}^{\circ} 6$. 


\section{Montaña o lomo del Cardón, valle Guerra}

Estación con una cazoleta a $397 \mathrm{msnm}$, sobre pumita o toba rojiza. Mide $0.44 \mathrm{~m}$ por $0.46 \mathrm{~m}$ de diámetro, presentando un canal de $0.50 \mathrm{~m}$ de largo, con una profundidad de $17 \mathrm{~cm}$. El canal tiene orientación $310^{\circ} \mathrm{NW}$ (figura 10).

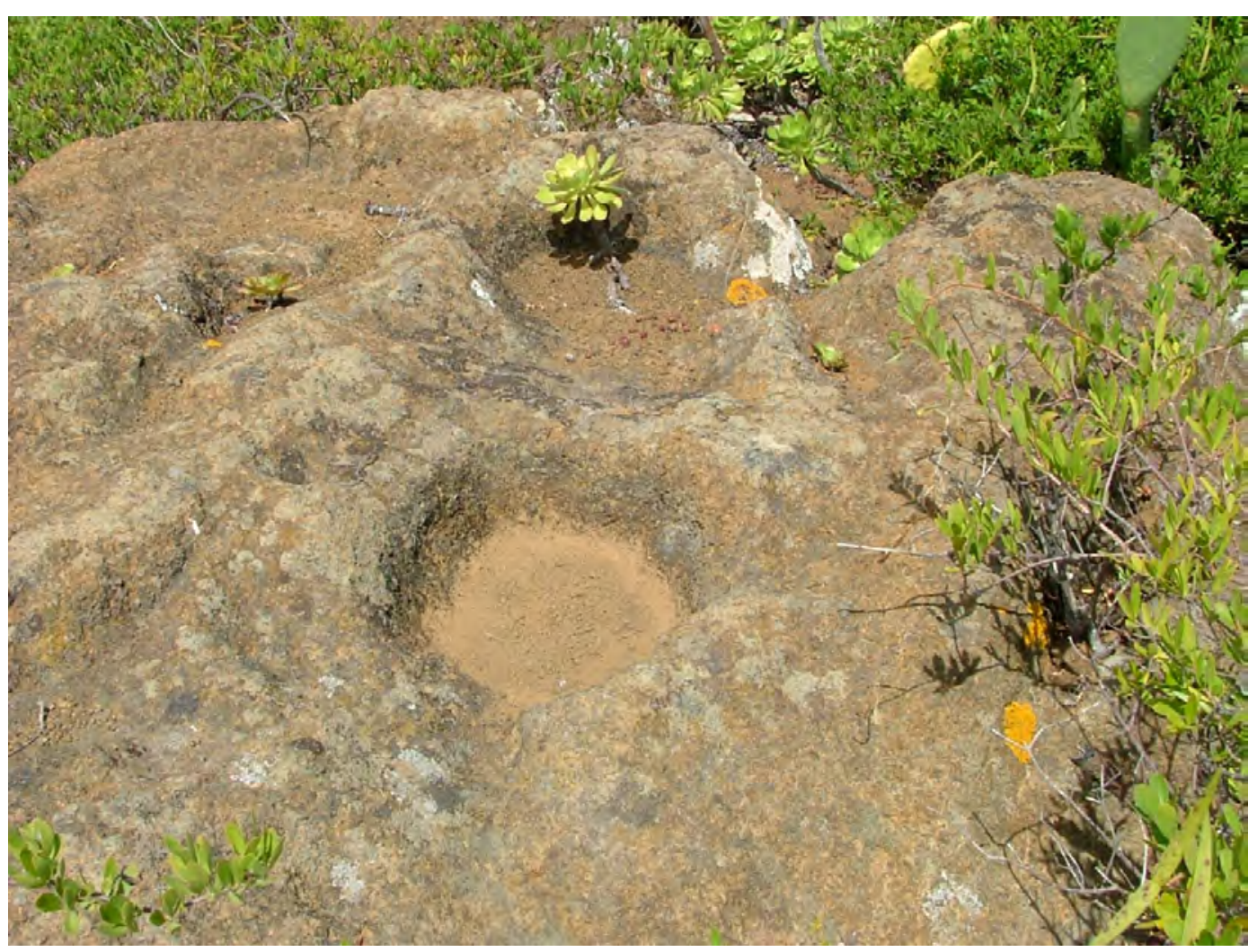

Figura 10. Cazoleta de lomo del Cardón, valle Guerra.

\section{El Majuelo, lomo del Cardón, valle Guerra}

A inicios de los años 70 del siglo XX, con motivo de la construcción del colegio Lope de Guerra, a 194 msnm, parece que apareció una cueva sepulcral, bien en falda del lomo del Cardón o quizás de rebuscas efectuadas en las cuevas situadas en la parte de arriba del lomo, donde se encuentran varias, entre ellas la cueva de las Palomas y la cueva Rajada.

\section{El Bucio, picacho los Lázaros}

Estación de cazoletas y canales, a $461 \mathrm{msnm}$, que tiene un gran dominio visual del valle de Tegueste, El Socorro y la costa de valle Guerra y Tejina. Se disponen sobre una plataforma de pumita de $25 \mathrm{~m}$ de largo por $6 \mathrm{~m}$ de ancho. Hay cuatro grandes cazoletas interconectadas: la primera mide $1.20 \mathrm{~m}$ por $0.75 \mathrm{~m}$, la segunda $2.70 \mathrm{~m}$. por $0.60 \mathrm{~m}$; la tercera $1.35 \mathrm{~m}$ por $1.20 \mathrm{~m} \mathrm{y}$ la cuarta $0.75 \mathrm{~m}$ por $0.45 \mathrm{~m}$. Conservan el agua de lluvia.

\section{Pico Bermejo I, Tejina}

Estación de cazoletas circulares y rectangulares, algunas provistas de canal vertedero, sobre afloramiento pumítico o tosca rojiza. Están localizadas en la ladera S-SE, a $241 \mathrm{msnm}$. El eje 
principal de la loma, N-S, concretamente $345^{\circ} \mathrm{N}$. Tiene muy buena visibilidad de la costa de valle de Guerra al oeste, el paso del Boquerón al sur, Tejina al norte, Bajamar al noreste y Tegueste al este, con la Mesa de Tejina a $95^{\circ}$ E. Presenta una gran cazoleta central de forma rectangular de $1.35 \mathrm{~m}$ por $0.90 \mathrm{~m}$ y profundidad máxima de $0.35 \mathrm{~m}$. Tiene un canal de salida en dirección NE de $0.18 \mathrm{~m}$ de ancho por $0.49 \mathrm{~m}$ de largo. Otras cazoletas circulares situadas más arriba vierten a esta. Muy próximo se encuentra otro grupo formado por al menos 7 cazoletas circulares que se intercomunican con vertederos de salida orientados al SW. Un tercer grupo está formado por dos cazoletas circulares que vierten a otra gran cazoleta receptora, que también recoge del grupo de cazoletas anterior, al situarse a una cota más baja. Tiene un canal que mide $2.80 \mathrm{~m}$ de largo y un ancho de $0.16 \mathrm{~m}$. La cazoleta receptora mide $0.92 \mathrm{~m}$ por $1.05 \mathrm{~m}$. Presentan afecciones por tallados o rebajes de la tosca, algunas en forma de asientos, pues pudo haber una estructura hoy desaparecida entre la gran cazoleta rectangular y la cruz. En la parte más alta del afloramiento se encuentra una cruz de madera sujeta con cemento (figura 11).

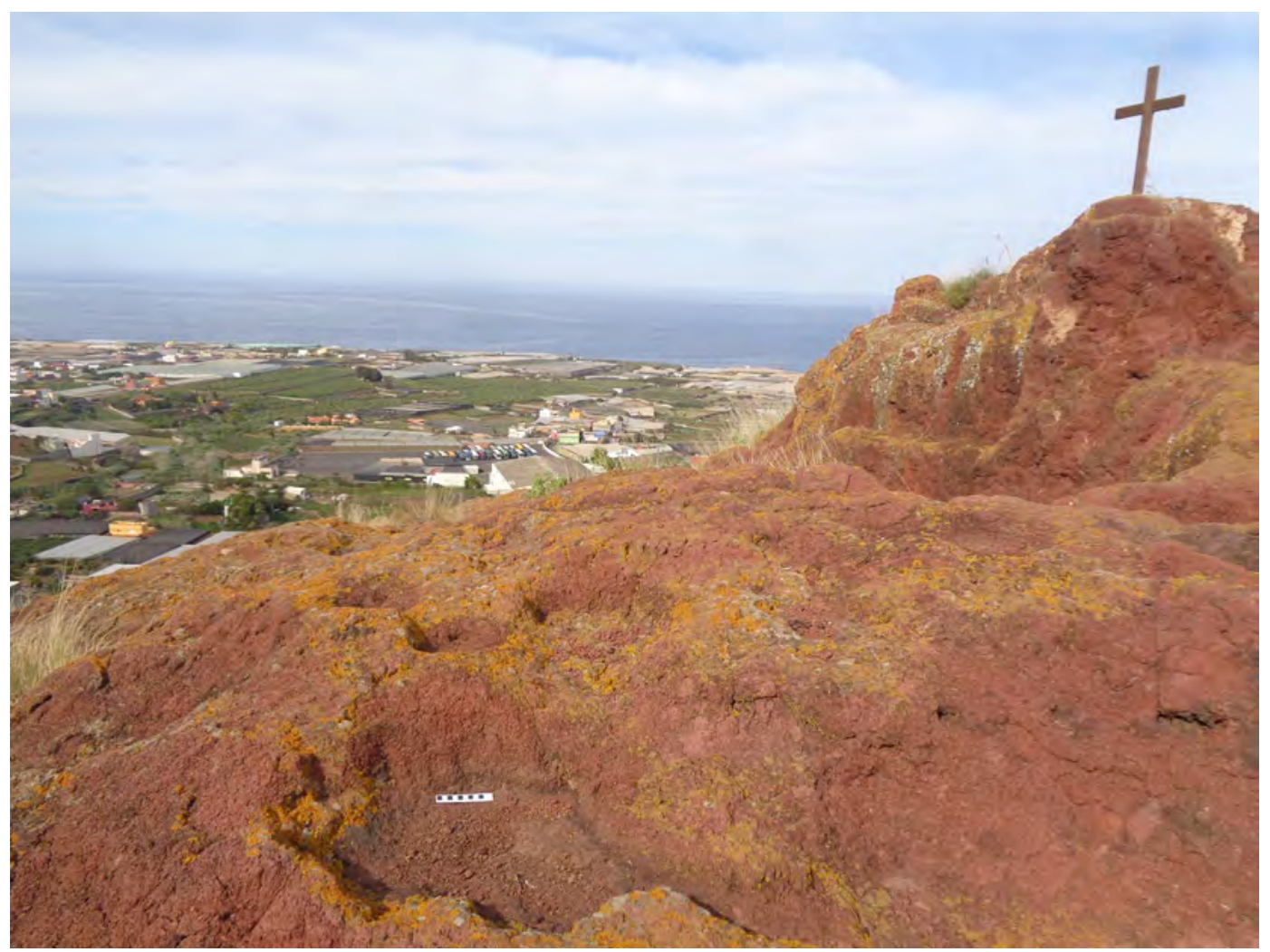

Figura 11. Cazoletas de pico Bermejo, Tejina.

\section{Pico Bermejo II, Tejina}

Cueva de habitación en un tubo volcánico, a $214 \mathrm{msnm}$, localizada en un barranco que desciende por la ladera media de Pico Bermejo, con buena visibilidad de valle Guerra. La boca de entrada mide $6.50 \mathrm{~m}$ de ancho por $3 \mathrm{~m}$ de altura. Ya en su interior, las dimensiones son $7 \mathrm{~m}$ de ancho, $2.80 \mathrm{~m}$ de altura y $22.50 \mathrm{~m}$ de largo hasta el fondo. El eje del tubo tiene una dirección E-W, con orientación $255^{\circ} \mathrm{W}$. En el $70 \%$ de la superficie interior aflora la roca madre, con escasos materiales arqueológicos, a excepción de un sector de la cueva que presenta relleno sedimentario y fragmentos de cerámica aborigen, algunos con claros indicios de haber estado sometidos al fuego. También se identificaron pequeñas lascas de basalto y obsidiana, fauna de ovicápridos y fragmentos de cerámica histórica. Al otro lado de la carretera se encuentran las instalaciones de la Compañía Agrícola de Tenerife, CATESA. CALL nº 46. 


\section{Cueva de la Palmita, Tejina}

Cueva sepulcral, a $250 \mathrm{msnm}$, dentro del casco urbano de Tejina, en el patio de la fábrica de licores Guajiro (COCAL) ${ }^{52}$. Se ha sugerido que quizás fuera parte de una necrópolis dependiente del poblado de cuevas de habitación en el barranco de Milán ${ }^{53}$. La cueva presenta unas dimensiones de $25 \mathrm{~m}$ de longitud, con una entrada de $1.45 \mathrm{~m}$ de anchura y $0.75 \mathrm{~m}$ de altura, aunque aumenta al penetrar en su interior hasta $1.50 \mathrm{~m}$ de alto, y en algún punto alcanza hasta $5.50 \mathrm{~m}$. Se localizaron hasta 15 enterramientos, de los cuales 13 eran de adultos y 2 de adolescentes $^{54}$. Fue datado un fragmento de madera M-1057 1040 $\pm 110 \mathrm{BP}^{55}, 723$ (1000) 1221 AC. CALL n ${ }^{\circ} 70$.

\section{Barranco las Cuevas I, Jover, Tejina}

Abrigo abierto en la margen izquierda u oriental de la desembocadura del barranco de las Cuevas, situado a $51 \mathrm{msnm}$, orientado a $350^{\circ} \mathrm{N}$, con buena visibilidad de la costa, los Dos Hermanos a $70^{\circ} \mathrm{E}$ y el charco de Jover a $210^{\circ} \mathrm{NW}$, de $5.50 \mathrm{~m}$ de longitud por $1.70 \mathrm{~m}$ de ancho y $2.85 \mathrm{~m}$ de altura, que presenta en superficie cerámica histórica con engobe rojo, patella, principalmente $P$. piperata y Stramonita haemastoma, que suelen indicar una utilización histórica.

\section{Barranco las Cuevas II-III, Jover, Tejina}

Ascendiendo por la margen izquierda, en el andén medio, hay una cueva situada a $57 \mathrm{msnm}$, con unas dimensiones de $8 \mathrm{~m}$ de longitud por $3.50 \mathrm{~m}$ de fondo y $1.82 \mathrm{~m}$ de altura, orientada su entrada a $265^{\circ} \mathrm{W}$, con el acceso parcialmente oculto por la vegetación, que ha sido reutilizada con presencia de basuras, parte de la superficie cubierta de cañizo trenzado y se ha vertido un mortero de cemento en el lado norte. En superficie se observó escasa cerámica aborigen, cerámica histórica con engobe rojo y fauna de ovicápridos. Quizás CALL nº 69 (figura 12).

Avanzando en dirección sur por el andén medio, a $56 \mathrm{msnm}$, en un abrigo de $2.50 \mathrm{~m}$ de longitud por $3 \mathrm{~m}$ de fondo y $2.10 \mathrm{~m}$ de altura, hay un posible enterramiento a nivel del suelo con tres piedras en su boca desplazadas, con unas dimensiones de $0.90 \mathrm{~m}$ de ancho en la entrada, $1.30 \mathrm{~m}$ de fondo y $0.45 \mathrm{~m}$ de altura.

\section{Barranco las Cuevas IV, Jover, Tejina}

Continuado por el andén medio de la margen izquierda del barranco las Cuevas, se entra en un gran abrigo con eje principal NW-SE y dimensiones de $30 \mathrm{~m}$ de longitud por $5 \mathrm{~m}$ de ancho y $8 \mathrm{~m}$ de altura, próximo a un eres del barranco. La mejor zona es un sector más abrigado, aprovechando el derrumbe de una gran piedra, de $7 \mathrm{~m}$ de longitud por $4 \mathrm{~m}$ de fondo y $3 \mathrm{~m}$ de altura, con un eje N.NW-S.SE, y entrada orientada a $240^{\circ}$ SE, que ha sido reutilizado para estabular ganado. En superficie se observaron varias Patella $s p$.

52 DIEGO CUSCOY (1964), p. 5.

53 DIEGO CUSCOY (1968), p. 211.

54 DIEGO CUSCOY (2011), pp. 559-562.

55 ALMAGRO GORBEA (1970), pp. 29-30. 


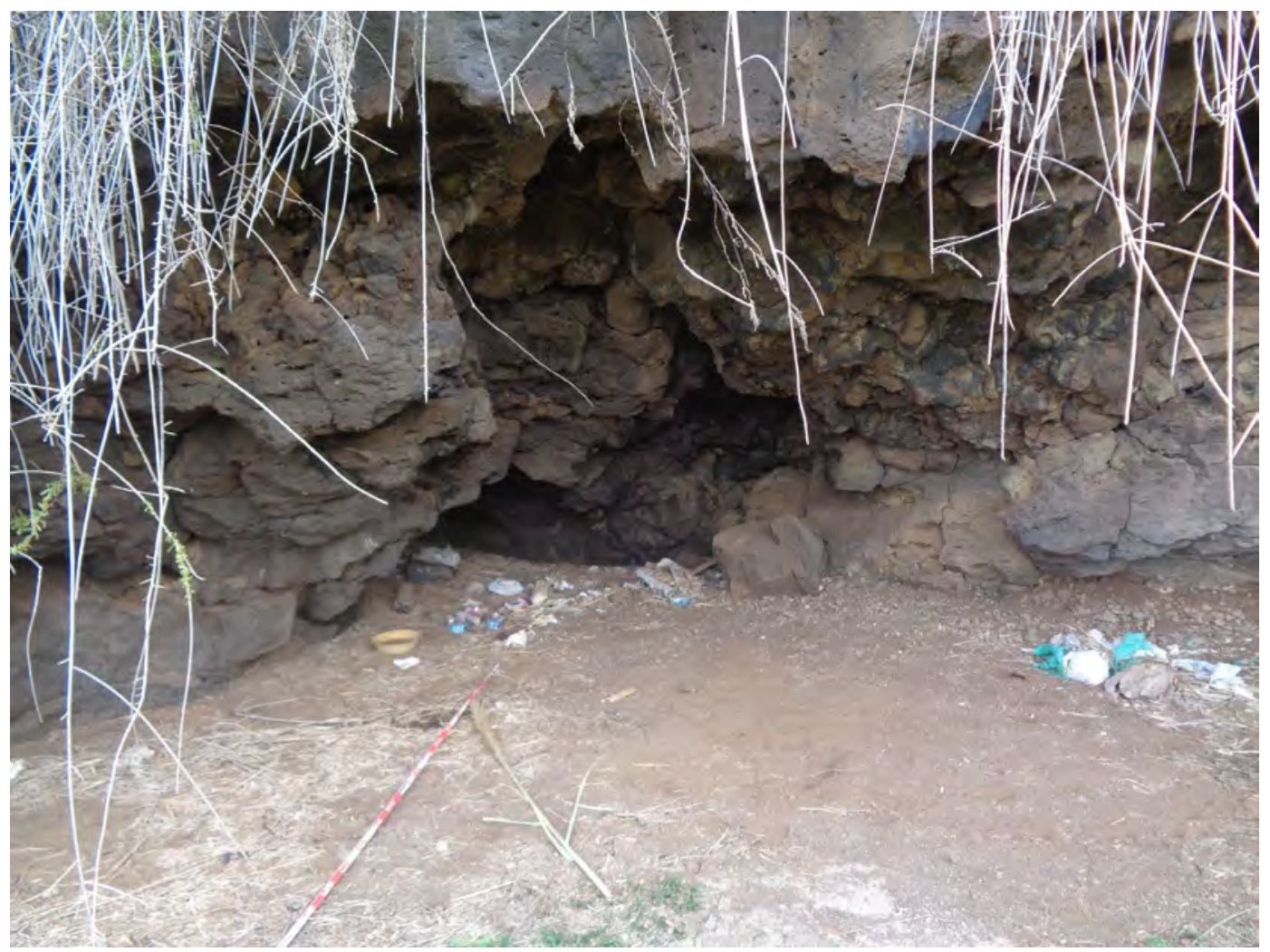

Figura 12. Cueva II de la desembocadura del barranco de las Cuevas, Jover, Tejina.

\section{Barranco las Cuevas V, Jover, Tejina}

Frente a la desembocadura del barranco las Cuevas, en su andén superior de la margen izquierda, a $68 \mathrm{msnm}$, hay una excelente visibilidad hacia la costa y el cauce bajo del barranco, y abunda la cerámica histórica con y sin engobe rojo, pero también hay algún fragmento aborigen a mano y Patella sp. Mirando al mar hay un espacio rehundido entre piedras de $4 \mathrm{~m}$ de longitud por $2 \mathrm{~m}$ de ancho y $0.70 \mathrm{~m}$ de altura, que pudo servir como punto de abrigo en esta zona de atalaya.

\section{Barranco las Cuevas VI-VIII, Jover, Tejina}

En el andén superior, ahora de la margen derecha del barranco de las Cuevas, próximo al cauce y a un eres existente en su desembocadura, hay una cueva a $32 \mathrm{msnm}$, con buenas condiciones de habitabilidad de $4 \mathrm{~m}$ de longitud por $6 \mathrm{~m}$ de fondo y $1.52 \mathrm{~m}$ de altura en la entrada, con la boca orientada hacia $45^{\circ} \mathrm{NE}$, que está reutilizada actualmente con cajas y tuberías de plástico para uso agrícola.

A pocos metros avanzando hacia la desembocadura en la margen derecha, completamente cubierta por la vegetación, a $30 \mathrm{msnm}$, hay un abrigo de $2.20 \mathrm{~m}$ de longitud por $1.20 \mathrm{~m}$ de anchura y 1.40 de altura, que presenta una grieta de $1.30 \mathrm{~m}$ de longitud por $2.25 \mathrm{~m}$ de fondo y $0.62 \mathrm{~m}$ de altura con posible uso funerario y orientada a $170^{\circ} \mathrm{S}$.

Finalmente, siguiendo por la margen derecha, sobre el eres, a $36 \mathrm{msnm}$, hay una cueva en pumita volcánica de $3.20 \mathrm{~m}$ de longitud por $8 \mathrm{~m}$ de fondo y $1.72 \mathrm{~m}$ de altura que se bifurca en dos cavidades independientes que parecen haber sido realizadas artificialmente, una orientada a $245^{\circ} \mathrm{SW}$, de $1.30 \mathrm{~m}$ de longitud por $1.10 \mathrm{~m}$ de ancho en la entrada y otra orientada a $205^{\circ} \mathrm{S}$, de $1.20 \mathrm{~m}$ de longitud por $1.20 \mathrm{~m}$ de ancho. En superficie sólo se identificó Patella piperata y Stramonita haemastoma. 


\section{Cueva de Cha Paula, barranco de las Cuevas, Tejina}

El acceso al cauce medio del barranco de las Cuevas de Tejina se realiza a partir del camino de la Cruz, entrándose por el pasaje Ave María. Se desciende, después de pasar un salto del barranco a $153 \mathrm{msnm}$. Esta parte del cauce medio del barranco de Tejina, desde la iglesia tiene varias covachas fruto de la erosión diferencial del agua pero están a la altura del cauce del barranco y no son susceptibles de habitación regular ni tampoco de uso funerario. Algo por encima del cauce se levanta una posible cueva de habitación a $147 \mathrm{msnm}$, en el tracto bajo de la margen derecha. Con una orientación NE, mide $14 \mathrm{~m}$ de ancho en la entrada, $2 \mathrm{~m}$ de altura y 8 $\mathrm{m}$ de largo hasta el fondo. En sus inmediaciones hay una tajea de agua que atraviesa el barranco con un eje N-S y dirección $195^{\circ}$ N. CALL nº 67.

\section{Cauce bajo del barranco de Milán, Tejina}

Agrupación de 6 cuevas de habitación, a $65 \mathrm{msnm}$, en el tracto superior de la margen izquierda, antes de la desembocadura del barranco de Milán. Se localizan debajo de las casas que se asientan junto al borde del barranco y presentan graves afecciones antrópicas al ser reutilizadas como perreras, estabulado de ganado caprino y cría de aves de corral. Este grupo de cuevas situadas próximas al mirador de los Abuelos, actualmente por el vertido de aguas negras y el crecimiento de la vegetación, hace unos 15 años estaban más a la vista, pero actualmente casi no son visibles por el crecimiento de la vegetación que desciende por las paredes del barranco. El mejor acceso se realiza hacia el tracto medio del barranco por un camino hacia un invernadero, por debajo del mirador. CALL $\mathrm{n}^{\circ} 63$.

\section{Cauce medio-bajo del barranco de Milán I-II, Tejina}

Abrigo posiblemente funerario en el andén superior de la margen derecha del barranco de Milán a $87 \mathrm{msnm}$. Presenta unas dimensiones de $2.10 \mathrm{~m}$ de longitud por $3.5 \mathrm{~m}$ de ancho y 1.18 $\mathrm{m}$ de altura y está orientado a $225^{\circ} \mathrm{SW}$. En superficie se observa cerámica con decoración acanalada aborigen, incluyendo algún borde con impresiones en el labio, obsidiana tallada, basalto trabajado y fauna de ovicápridos.

Descendiendo hacia el tracto medio, hay una segunda posible cueva funeraria en un segundo abrigo a $82 \mathrm{msnm}$, con unas dimensiones de $1.85 \mathrm{~m}$ de longitud por $2.70 \mathrm{~m}$ de ancho y $1.02 \mathrm{~m}$ de altura, que presenta una grieta de $0.54 \mathrm{~m}$ de ancho y $0.74 \mathrm{~m}$ de altura orientada a $220^{\circ} \mathrm{SW}$. En superficie hay cerámica aborigen como un borde impreso, obsidiana, basalto trabajado y Patella sp.

\section{Cueva Jurada, cauce medio-bajo del barranco de Milán III, Tejina}

Gran cueva a 90 msnm en el tracto alto de la margen derecha del barranco de Milán, bajo la antigua finca de José Barreto «el Manisero», quien la puso en cultivo trayendo tierra desde Bajamar, para lo cual se rellenó una cueva situada bajo la finca, que presentaba una abertura natural horadada o jurada en la parte superior ${ }^{56}$, la cual se rellenó con multitud de piedras. La cueva queda dividida en dos zonas por la acumulación de piedras, un sector oeste de $6 \mathrm{~m}$ de longitud por $12 \mathrm{~m}$ de fondo y $1.90 \mathrm{~m}$ de altura orientado al exterior a $190^{\circ} \mathrm{S}$ y un sector este de $6 \mathrm{~m}$ de longitud, $3.75 \mathrm{~m}$ de fondo y $2.50 \mathrm{~m}$ de altura orientado hacia $225^{\circ} \mathrm{SW}$. Hay una reocupación reciente en el sector NW de la cueva. En superficie se observó cerámica aborigen, basalto trabajado, Patella sp. y fauna de ovicápridos. CALL no 53 (figura 13a-13b).

56 ÁLVAREZ DELGADO [y DIEGO CUSCOY] (1947d), pp. 144, 146. 

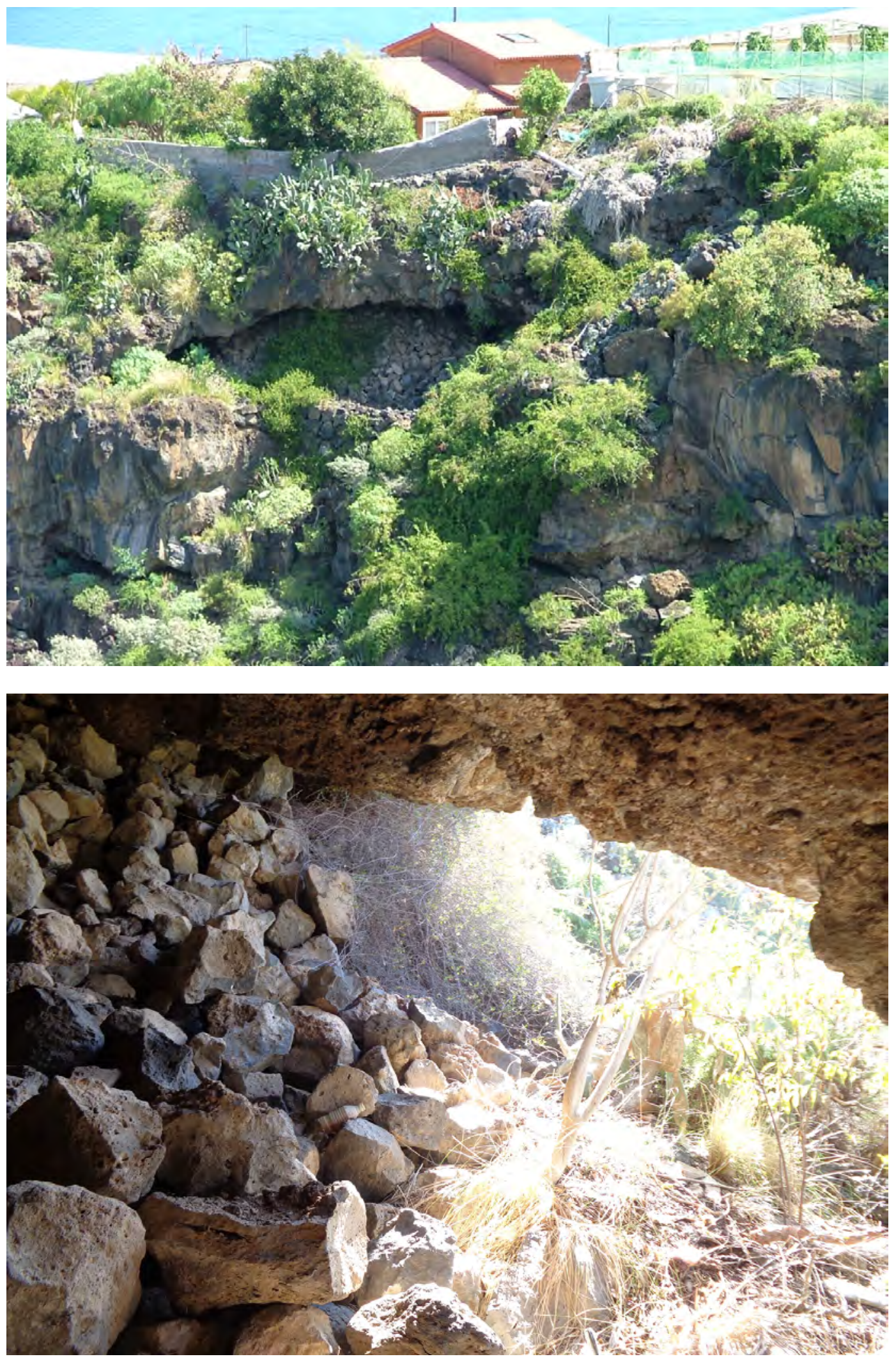

Figura 13a-b. Exterior e interior de la cueva del Jurado, barranco Milán. 


\section{Cauce medio-bajo del barranco de Milán IV, Tejina}

Bajo la cueva Jurada, en el andén medio del barranco de Milán, a $88 \mathrm{msnm}$, hay una gran cueva en escoria volcánica con unas dimensiones de $5.50 \mathrm{~m}$ de longitud, $13 \mathrm{~m}$ de fondo y $5 \mathrm{~m}$ de altura, orientada su entrada a $210^{\circ} \mathrm{S}$.SW. Es posible que su zona más profunda haya sido excavada o expoliada. En superficie se observa cerámica aborigen, basalto trabajado, fauna de ovicápridos y Patella sp.

\section{Cauce medio-bajo del barranco de Milán V-VI, Tejina}

Justo por debajo de la cueva IV, a 86 msnm, se encuentra la cueva más importante de este sector, que debe de ser la que fue objeto de excavación por Diego Cuscoy ${ }^{57}$ por los indicios de un corte en el sector S.SE, la clara presencia de relleno arqueológico y la abundancia de material en superficie, aunque menciona otras 3 cuevas en el entorno. Sus dimensiones son de $12 \mathrm{~m}$ de longitud por $4.25 \mathrm{~m}$ de fondo y $1.70 \mathrm{~m}$ de altura, cuya entrada está orientada a $240^{\circ} \mathrm{W}$. En superficie y entre los fragmentos de materiales desechados agrupados en montones, se identificó cerámica aborigen decorada, obsidiana, basalto trabajado, cantos de barranco, fauna de ovicápridos, malacología de Osilinus atratus y Patella sp. (figura 14).

A unos $5 \mathrm{~m}$ en dirección oeste, a $83 \mathrm{msnm}$, se localizó otra cueva más pequeña, con peores condiciones de habitabilidad, de $3.30 \mathrm{~m}$ de longitud por $3.50 \mathrm{~m}$ de fondo y $1.30 \mathrm{~m}$ de altura, que presenta restos de un posible muro derruido en su entrada y una posible cata al interior. En superficie se documentó cerámica aborigen, fauna de ovicápridos, malacología de Osilinus atratus y Patella sp.

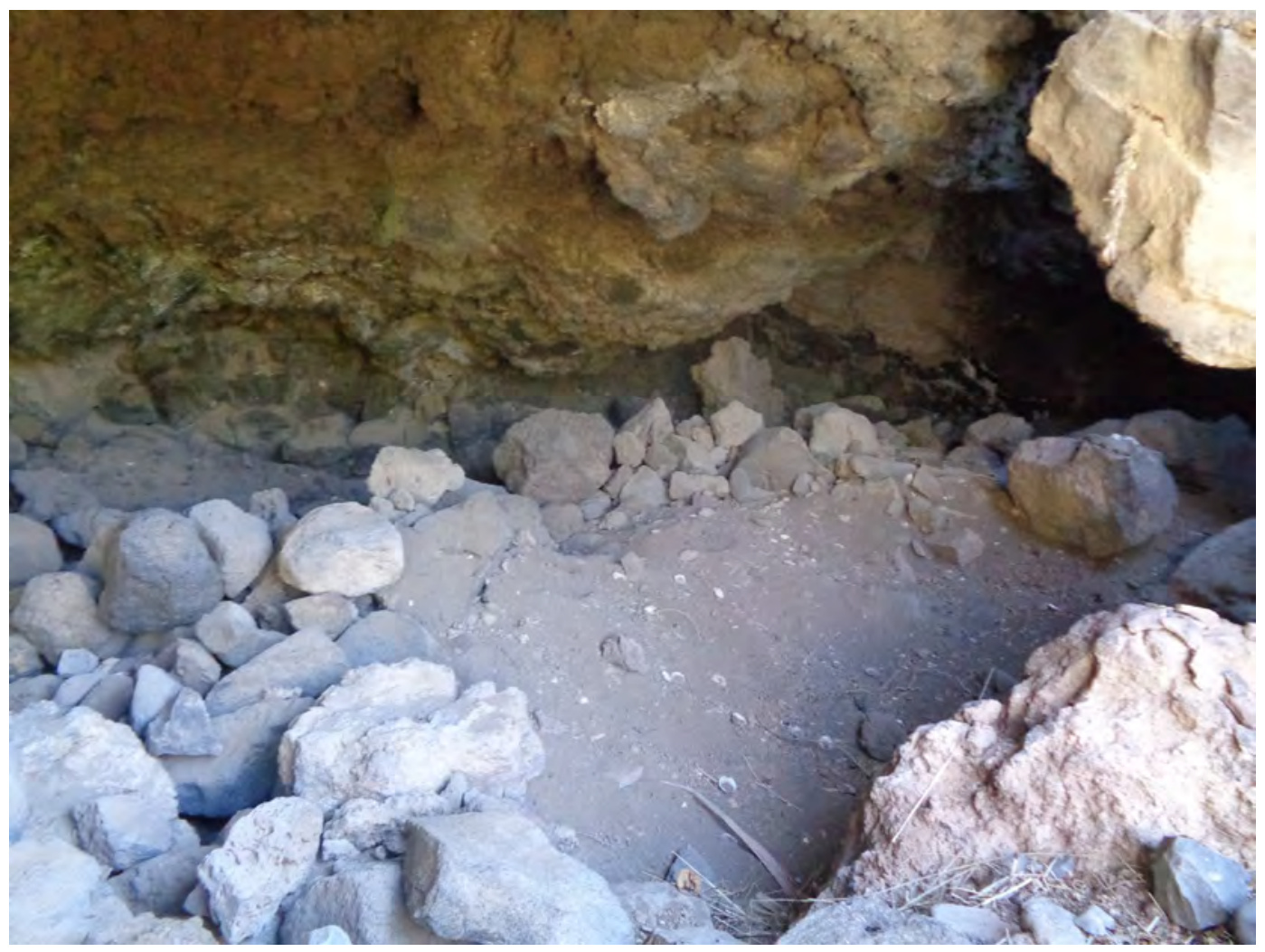

Figura 14.Cueva V de habitación del barranco Milán.

57 ÁLVAREZ DELGADO [y DIEGO CUSCOY] (1947d), p. 146. 


\section{El Riego I-III, barranco de Milán, Tejina}

Junto a un importante salto en el barranco, hay un conjunto de varias cuevas sepulcrales en el tracto medio, que se elevan en escarpes verticales de más de $30 \mathrm{~m}$ de altura. En el tracto superior de la margen derecha a dos terrazas artificiales de cultivo, de las cuales la superior tiene una cueva actualmente reutilizada para almacenar cosas, cuyo acceso sólo es posible descendiendo desde una vivienda que accede a las dos terrazas.

Pasado el salto del barranco, en la misma margen derecha, hay un conjunto de cuevas conectadas entre ellas, la primera, a $106 \mathrm{msnm}$, en el tracto superior rellena por desplomes del techo, cuyo acceso desde arriba es muy difícil por el vertido de basuras y escombros. CALL $\mathrm{n}^{0} 57$.

Desde esta cueva se accede a una cueva sepulcral en el tracto medio, a $98 \mathrm{msnm}$, que podría tratarse de la excavada por Diego Cuscoy y que tiene unas dimensiones de 6.50 por $3.70 \mathrm{~m}$ y una altura de $2.50 \mathrm{~m}$. La cueva conservaba un sector intacto de 1.60 por $1.55 \mathrm{~m}$ y $1.10 \mathrm{~m}$ de altura. En la cueva se conservaban 4 enterramientos, dos de ellos frente al espacio en decúbito lateral flexionado ${ }^{58}$.

El salto del barranco es franqueado por un estrecho andén por la margen izquierda donde se ha construido un bancal agrícola bajo una vivienda, desde el cual se accede hacia otra cueva de la margen izquierda, a 117 msnm, que también está dentro de una propiedad privada vallada, junto a la cual se ha construido un cobertizo con bloques, pero que realmente se encuentra debajo de un invernadero de plantas.

\section{El Pozo I, barranco de Milán, Tejina}

Cueva de habitación situada a 126 msnm, en el tracto medio-superior de la margen izquierda, que presenta parte de la visera derrumbada. Mide $6 \mathrm{~m}$ de ancho en la entrada, $8.25 \mathrm{~m}$ de fondo y $3 \mathrm{~m}$ de altura y, con orientación hacia $100^{\circ} \mathrm{E}$, con mejores condiciones de hábitat en el lado sur. $\mathrm{El}$ acceso solo se puede hacer desde el cauce bajo del barranco. En la otra margen se encuentra un pozo de agua que da nombre al sector del barranco. CALL n 59 (figura 15).

\section{El Pozo II, barranco de Milán, Tejina}

Cueva de habitación, a 129 msnm, en el tracto medio de la ladera derecha, con orientación hacia $145^{\circ}$ SE. Mide $18 \mathrm{~m}$ de ancho en la entrada, $13 \mathrm{~m}$ de fondo y $3 \mathrm{~m}$ de altura, con buenas condiciones de habitabilidad, pero que está muy reutilizada. Se accede descendiendo por una escalera desde el NE parcialmente oculta por un gran árbol. El interior esta casi completamente ocupado por una estructura de piedra de planta rectangular, parcialmente derrumbada. CALL $n^{\circ} 60$.

\section{El Pozo III, barranco de Milán, Tejina}

Cueva de habitación, a $119 \mathrm{msnm}$, con la boca orientada hacia $145^{\circ} \mathrm{SE}$, en el tracto bajo de la margen izquierda del barranco de Milán, fácilmente accesible desde el cauce. Sin embargo, al estar reutilizada y con la zona inmediata vallada, exige acceder desde la parte superior y descender por una escalera que llega hasta la cueva. En la boca se levanta una pared de piedra semiderruida y de construcción reciente y presenta grandes dimensiones, con $19 \mathrm{~m}$ de ancho en la entrada, $14 \mathrm{~m}$ de largo hasta el fondo y $1.75 \mathrm{~m}$ de altura. CALL n ${ }^{\circ} 61$.

58 ÁLVAREZ DELGADO [y DIEGO CUSCOY] (1947d), pp. 150-152. 


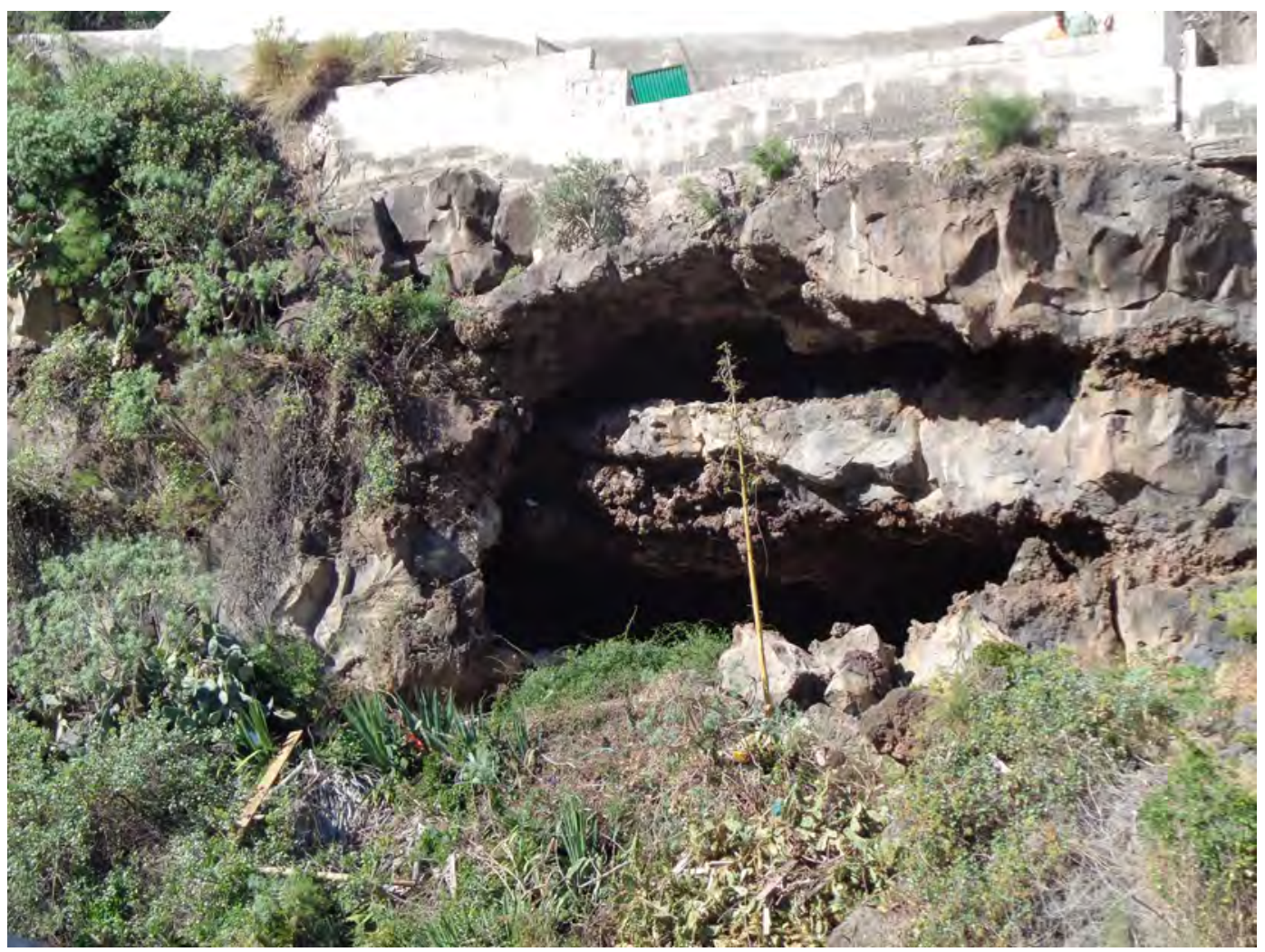

Figura 15. El Pozo I, cueva de habitación del barranco Milán.

\section{Los Pilones I-V, barranco de Milán, Tejina}

Conjunto de 5 cuevas en el tracto medio del barranco, a $178 \mathrm{msnm}$, en la ladera izquierda, junto a la presa del Manisero. Este conjunto de cuevas están dispuestas en los andenes medio y superior. Antiguamente se accedía por un canal de agua que pasa a escasos metros de las cuevas del nivel inferior, el cual permite el acceso también a una de las cuevas del nivel superior. En el actualidad, debido al crecimiento de la vegetación que cubre al canal y el muro sobre el que se apoya, el mejor camino es siguiendo otro canal inferior que también aprovechan diversas tuberías de agua que procede de la presa por el que accede al andén inferior, completamente cubierto de vegetación. La cueva sepulcral de Las Pilones ${ }^{59}$ está en el andén superior, orientada a $40^{\circ} \mathrm{NE}$ y actualmente sólo es accesible descolgándose desde la parte superior. En el andén medio hay 3 cuevas agrupadas, una de mayores dimensiones y en su parte superior otras dos, orientadas a $350^{\circ} \mathrm{N}$. En la mayor se puede observar cerámica aborigen, obsidiana y una pieza dental humana, que quizás haya caído de una de las dos cuevas superiores de menores dimensiones, alguna de las cuales pudo tener una función funeraria. CALL $n^{\circ} 62$. Avanzando hacia la derecha en el andén medio hay otra cueva pequeña en una posición algo más elevada, 180 msnm, tampoco accesible, también con posible función funeraria, orientada hacia $30^{\circ} \mathrm{N}$.

\section{Cueva de las Goteras, Bajamar}

Cueva sepulcral, a $22 \mathrm{msnm}$, con orientación $330^{\circ} \mathrm{N}$, que se localiza en el tracto medio del acantilado en la ensenada de La Gotera, entre la punta de Las Goteras, donde se sitúa el Club Náutico de Bajamar, y la punta del Charco de la Laja. El tracto inferior no es accesible ya que está acantilado al romper las olas junto a una playa de grandes bloques de piedra. El acceso a la cueva por el andén, practicable hasta hace una década, actualmente se ha derrumbado. En su

59 DIEGO CUSCOY (1968), p. 236. 
interior gotea el agua desde el techo. Fue descubierta en 1933 y, aunque estaba saqueada, se localizaron 3 o 4 enterramientos ${ }^{60}$.

\section{Cueva de Cho Matilde, barranco de La Goleta I, Goleta Baja, Bajamar}

Cueva de habitación, a 113 msnm, localizada en el tracto inferior de la margen izquierda del barranco de La Goleta. Es una cueva de grandes dimensiones, con un eje principal SE-NW, que tiene $14.5 \mathrm{~m}$ de ancho en la entrada, $4.5 \mathrm{~m}$ de altura en la zona central y un fondo máximo de 5 $\mathrm{m}$ de en el extremo NW, orientada a $75^{\circ} \mathrm{E}$. En el sector más resguardado de la cueva, el SE, donde la altura disminuye, se construyó en época histórica un habitáculo en piedra seca adosado a las paredes y techo de la cueva que tiene $6.5 \mathrm{~m}$ de longitud, $2.55 \mathrm{~m}$ de ancho y $0.70 \mathrm{~m}$ de grosor del muro exterior. Presenta una puerta con unas dimensiones de $1.56 \mathrm{~m}$ de altura y 1.18 $\mathrm{m}$ de ancho. Sigue siendo reutilizada para comidas de cazadores por lo que se encuentra en su interior sillas, y una gran mesa al exterior. Al exterior se localizó cerámica decorada aborigen, cerámica con engobe rojo, patellas y huesos de ovicápridos recientes. CALL no 49.

Ascendiendo en dirección SE un poco en la misma margen hay una posible cueva funeraria, a $116 \mathrm{msnm}$, orientada a $320^{\circ} \mathrm{NW}$ (figura 16).

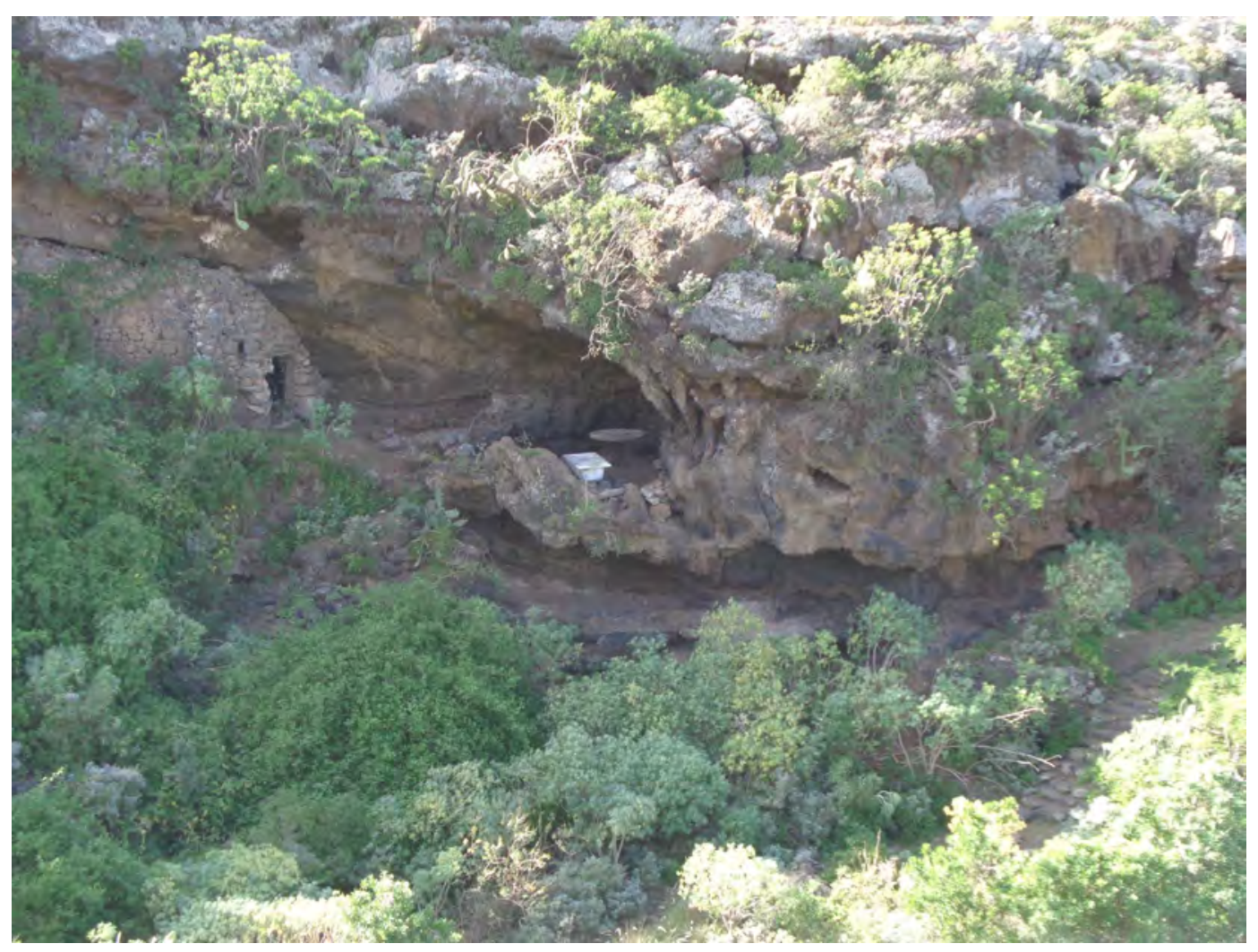

Figura 16. Cueva de Cho Matilde, barranco de La Goleta, Bajamar.

\section{Barranco de la Goleta II, Goleta Baja, Bajamar}

A 15 m en dirección NW de la cueva de Cho Matilde, hay una segunda cueva de habitación, a 111 msnm, también en el tracto inferior de la margen izquierda del barranco de La Goleta. La cueva presenta dos sectores, una zona más alta, más adecuada para habitación, o sector 1 en el lado $\mathrm{N}$, de $7 \mathrm{~m}$ de ancho en la entrada, $4.5 \mathrm{~m}$ de altura y $4 \mathrm{~m}$ de fondo, orientada a $90^{\circ} \mathrm{E}$. Se separa del lado sur con un muro de piedra interior de $1.80 \mathrm{~m}$ de longitud, $0.38 \mathrm{~m}$ de ancho y

60 ROSA OLIVERA (1990-92 [1933]), p. 204. 
$0.55 \mathrm{~m}$ de altura, que conserva 3 hiladas superpuestas con una dirección E-W. El segundo sector, bastante más bajo, tiene $4.5 \mathrm{~m}$ de largo por $5.75 \mathrm{~m}$ de fondo y 1.40 de altura, por lo que la entrada de la cueva tiene en conjunto unos $11.5 \mathrm{~m}$ de ancho.

\section{Barranco de la Goleta III, Goleta Baja, Bajamar}

En la margen opuesta o derecha, a $119 \mathrm{msnm}$, descendiendo hasta $104 \mathrm{msnm}$, en una zona accesible siguiendo el sendero de La Goleta hasta la Cruz del Carmen, hay una cueva difícilmente accesible porque se han vertido basuras y derrubios desde las viviendas inmediatas. Presenta condiciones de habitación y ha sido reutilizada construyéndose un gran muro de piedra al exterior, orientada a $215^{\circ} \mathrm{SW}$.

\section{Barranco de la Goleta, Goleta Baja, La Laguna}

Cueva sepulcral localizada a $155 \mathrm{msnm}$, en el propio salto del barranco de La Goleta. Su descubrimiento se debe a un vecino que informó en 1980 al Departamento de Arqueología de la Universidad de La Laguna. En la visita de inspección se pudo recuperar un cráneo humano de adulto. CALL n ${ }^{\circ} 47$.

\section{Cueva del Rey, La Hoya, punta del Hidalgo}

Cueva del Rey o de Zebenzui, situada a $82 \mathrm{msnm}$, al pie de la montaña de Guacada y el cauce del barranco de Flandes, a la derecha de La Hoya, presenta dos entradas, actualmente tapiadas. La más oriental tiene unas dimensiones en la entrada de $2.05 \mathrm{~m}$ de ancho por $2.85 \mathrm{~m}$ de altura, mientras que la más occidental tiene $4.60 \mathrm{~m}$ de ancho por $2.80 \mathrm{~m}$ de altura. Fue propiedad de Eugenio de Sainte Marie y Saint Martin, catedrático de francés del Instituto de Segunda Enseñanza de Canarias. A mediados del siglo XX la habían tapiado y utilizado como lugar para guardar cabras y forraje ${ }^{61}$. Según Viana, «Llamose Zebensuí (...) fue llamado Hidalgo pobre, que archimenseu, decían en su lengua, a cuya imitación quedó a este término la punta del Hidalgo» ${ }^{62}$.

\section{Tagoro de la Hoya, punta del Hidalgo}

El único tagoro que Bethencourt Alfonso ${ }^{63}$ menciona en punta del Hidalgo, que denomina achimenceyato de Aguahuco, estaba situado en el caserío de La Hoya, concretamente frente a la cueva del Rey, en la antigua finca de Cristina Afonso, indicando Eugenio de Sainte Marie a finales del siglo XIX que «llaman 'tagoro' a aquel lugar» ${ }^{64}$. Este topónimo actualmente se mantiene en la curva de la carretera encima de la ermita del Carmen ${ }^{65}$. El espacio al exterior de la cueva es una antigua finca que actualmente está dividida en pequeñas parcelas en la ladera baja y el sector más llano, ca. 119 msnm, ha sido urbanizado.

61 ALONSO RODRÍGUEZ (2000 [1944]), pp. 47, 56

62 VIANA (1986 [1604]), pp. 266-267; X.

63 BÉTHENCOURT ALFONSO (1994 [1911]), p. 111.

64 ALONSO RODRÍGUEZ (2000 [1944]), pp. 47, 56.

65 MELO DAIT (2007), p. 6. 


\section{La Pedrera, Los Dos Hermanos, punta del Hidalgo}

Estación de grabados rupestres situada entre 175 y 203 msnm en la ladera norte de los roques de Los Dos Hermanos. Se trata de una plancha de toba de forma triangular de unos $100 \mathrm{~m}$ de largo con pendiente de este a oeste, que presenta grabados en dos sectores. La zona occidental con 22 grabados acanalados, donde destaca un pisciforme, tiene $6 \mathrm{~m}$ de largo por $4.15 \mathrm{~m}$ de ancho, mientras que el sector oriental, de $10 \mathrm{~m}$ de largo y $1 \mathrm{~m}$ ancho cuenta con 4 grabados y un canal descendente en dirección E-W que atraviesa una cazoleta ${ }^{66}$ (figura 17).

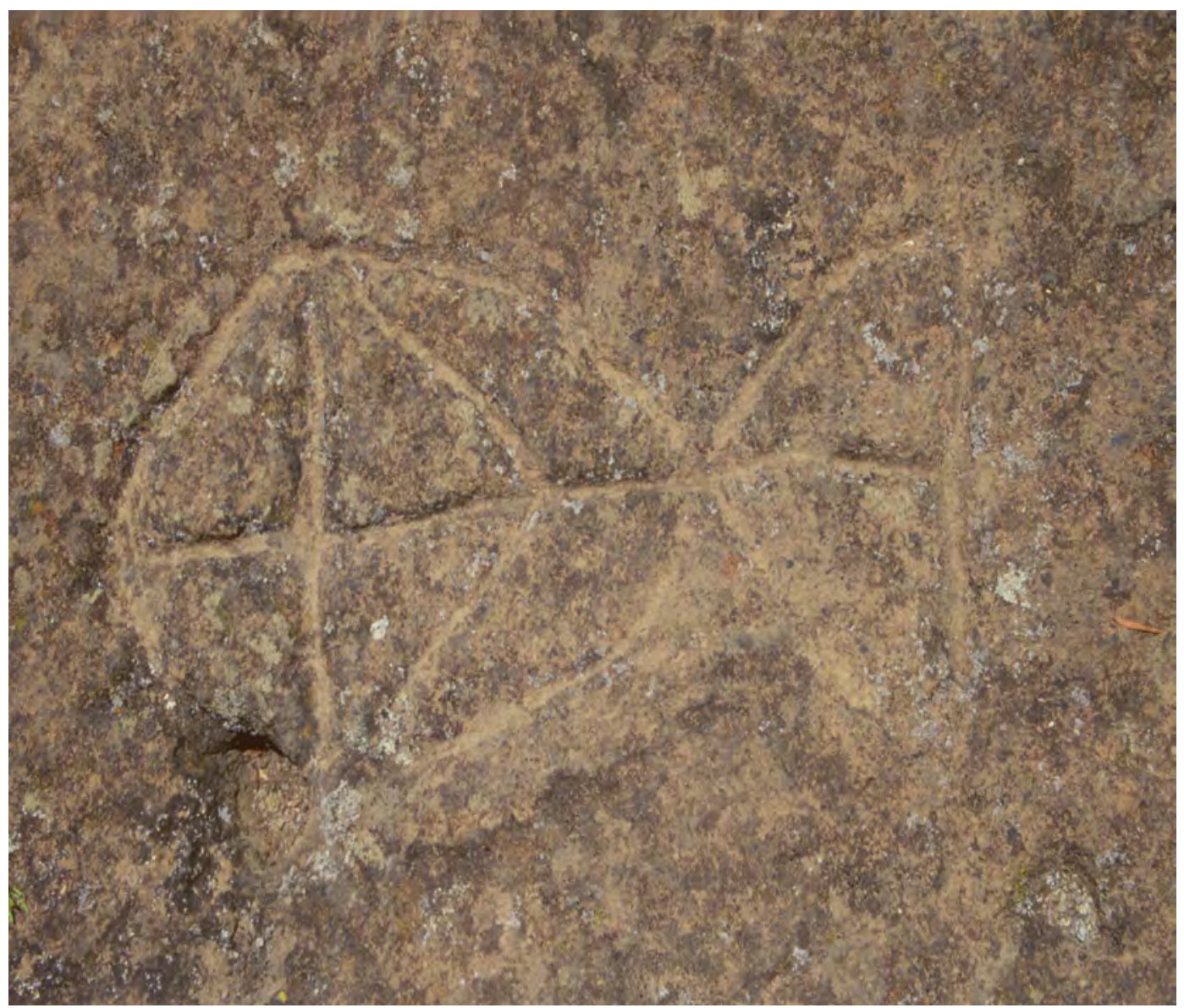

Figura 17. Grabado de pisciforme, Los Dos Hermanos, punta del Hidalgo.

\section{Los Dos Hermanos, punta del Hidalgo}

Estación de cazoletas y canales, a 150 msnm, junto a un sendero de pescadores, justo debajo de los roques de Los Dos Hermanos. Una vez que rebasamos las terrazas de cultivo abandonadas en las faldas del barranco, sobre un bloque pumítico o toba roja de $3 \mathrm{~m}$ por $2 \mathrm{~m}$, se contabilizan al menos 11 pequeñas cazoletas con canales. Foto en Vivancos et alii ${ }^{67}$ (figura 18).

66 PERERA LÓPEZ (1992), pp. 37, 47, 56 lám. 2, 72 lám. 18; VIVANCOS y otros (2016), pp. 291-297 f. 413-420.

67 VIVANCOS y otros (2016), p. 298 f. 422. 


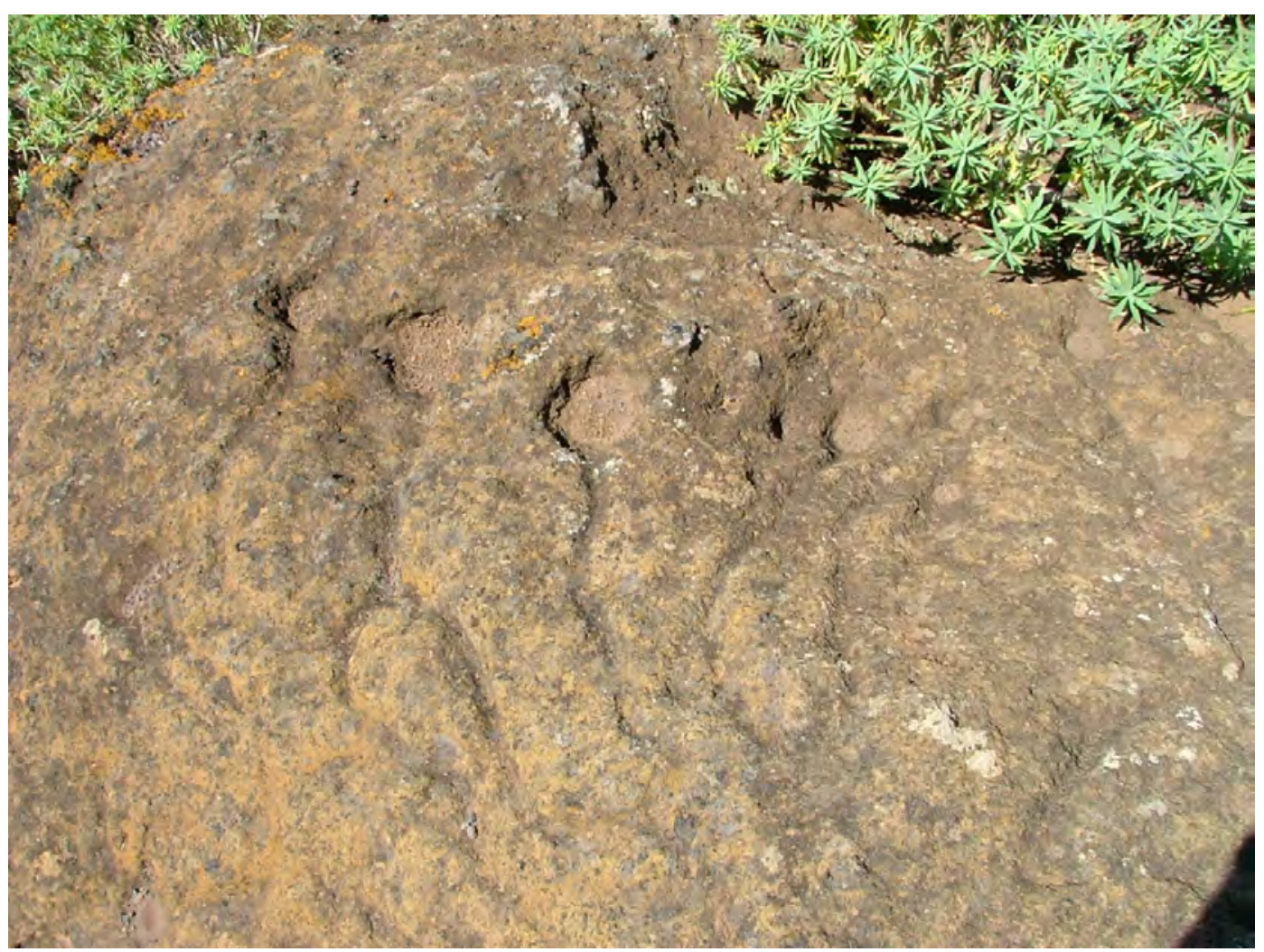

Figura 18. Estación de cazoletas y canales, Los Dos Hermanos, punta del Hidalgo.

\section{Barranco del Río, punta del Hidalgo}

Cueva de enterramiento en toba situada a $200 \mathrm{msnm}$, orientada al sureste y en la margen derecha del barranco del Río o del Tomadero. Mide $2.80 \mathrm{~m}$ de ancho en la entrada por $5.50 \mathrm{~m}$ de largo hasta el fondo. Se accede por un sendero, que se inicia en la desembocadura del barranco y comunica con el caserío de Chinamada. En un recodo de la ladera, cerca de un abrigo natural reutilizado por pastores, se encuentra la cueva a $5 \mathrm{~m}$ debajo de un dique basáltico. Presenta un orificio en el techo. La pared que cerraba la entrada se encuentra derruida, hallándose las piedras tanto en el interior como al exterior. Expoliada, algunos restos óseos humanos se conservan en el interior y también exteriormente asociados a Patella sp. y otros están desplazados por escorrentía en la ladera. A la misma altura de la cueva, subiendo el sendero, encontramos un abrigo natural que fue utilizado en el pasado y que conserva parte de una pared de piedra seca de protección en la entrada. CALL $\mathrm{n}^{\circ} 1$.

\section{Roque de los Cardos, punta del Hidalgo}

Cueva sepulcral, a $230 \mathrm{msnm}$, en el roque de los Cardos, frente a la cueva sepulcral del barranco del Río, pero a una cota más alta. El acceso es bastante dificultoso y es necesario trepar por un fuerte escarpe hasta llegar a un orificio estrecho que comunica con la cueva. Fue localizada en 1988 por José Esteban Suárez, vecino de la punta del Hidalgo, quien informó a V. Valencia. CALL n ${ }^{\circ} 2$. 
Tagoro de los Almácigos, punta del Hidalgo

Se sitúa junto al camino que va desde punta del Hidalgo hacia Chinamada, a $284 \mathrm{msnm}$, con un eje principal E-W. Desde este punto se visualiza Los Dos Hermanos a $320^{\circ}$ al NW y la punta Fajana a $80^{\circ}$ E. A finales del siglo XIX recibía los nombres de El Tagorillo, Tagoro de Juagae 0 la Baja del Tagoro ${ }^{68}$, y en la actualidad se denomina Era de los Almácigos, si bien los vecinos le indicaron a Melo ${ }^{69}$ que «eso no era una era».

\section{Gollada de las Nubes I, Chinamada}

Cazoleta situada a 525 msnm, próxima al camino de Chinamada, con unas dimensiones de $0.28 \mathrm{~m}$ de longitud por $0.18 \mathrm{~m}$ de ancho y $6 \mathrm{~cm}$ de profundidad, orientada a $320^{\circ} \mathrm{NW}$.

\section{Gollada de las Nubes II, Chinamada}

Cazoleta situada a $487 \mathrm{msnm}$, en un afloramiento basáltico que presenta tosca en su ladera sur, con unas dimensiones de $0.20 \mathrm{~m}$ de longitud por $0.21 \mathrm{~m}$ de ancho y $6 \mathrm{~cm}$ de profundidad, orientada a $357^{\circ} \mathrm{N}$.

\section{Hoya del Viento, Monte de San Diego}

Posible cazoleta situada en el Monte de San Diego, a $699 \mathrm{msnm}$. Presenta unas dimensiones máximas de $6.5 \mathrm{~cm}$ de longitud, por $9 \mathrm{~cm}$ de ancho y $6 \mathrm{~cm}$ de profundidad, con eje principal SW-NE, visualizando la montaña Birmagen a $220^{\circ} \mathrm{SW}$.

\section{Solís}

Estación de canales y cazoletas, a 691 msnm, sobre pumita, situada en la parte superior de unas cuevas artificiales, actualmente reutilizadas con dos puertas metálicas y dos ventanas, que han sido seriamente afectadas por un vertido de pintura blanca (figura 19).

\section{Camino Real de la Verdellada}

Afloramiento rocoso por encima de una pared de piedra seca, a 525 m.s.n.m., que delimita el camino real de la Verdellada y a $7 \mathrm{~m}$ del cauce del barranco en su margen izquierda. A $1.55 \mathrm{~m}$ sobre el suelo, se sitúa un panel de grabados de 0.52 x $0.32 \mathrm{~m}$, realizado con técnica incisa, con un motivo cruciforme en la zona central en cuyo lado izquierdo hay posibles letras a lo largo de $20 \mathrm{~cm}$, identificadas como alfabéticos líbicos por del Arco y otros ${ }^{70}$, que también creen así interpretarlas Vivancos y otros $^{71}$ junto con 3 antropomorfos femeninos (figura 20).

68 BÉTHENCOURT ALFONSO (1994 [1911]), p. 119 n. 18.

69 MELO DAIT (2007), p. 6.

70 ARCO $y$ otros (1999).

71 VIVANCOS y otros (2016), pp. 313, 324 f. 465. 


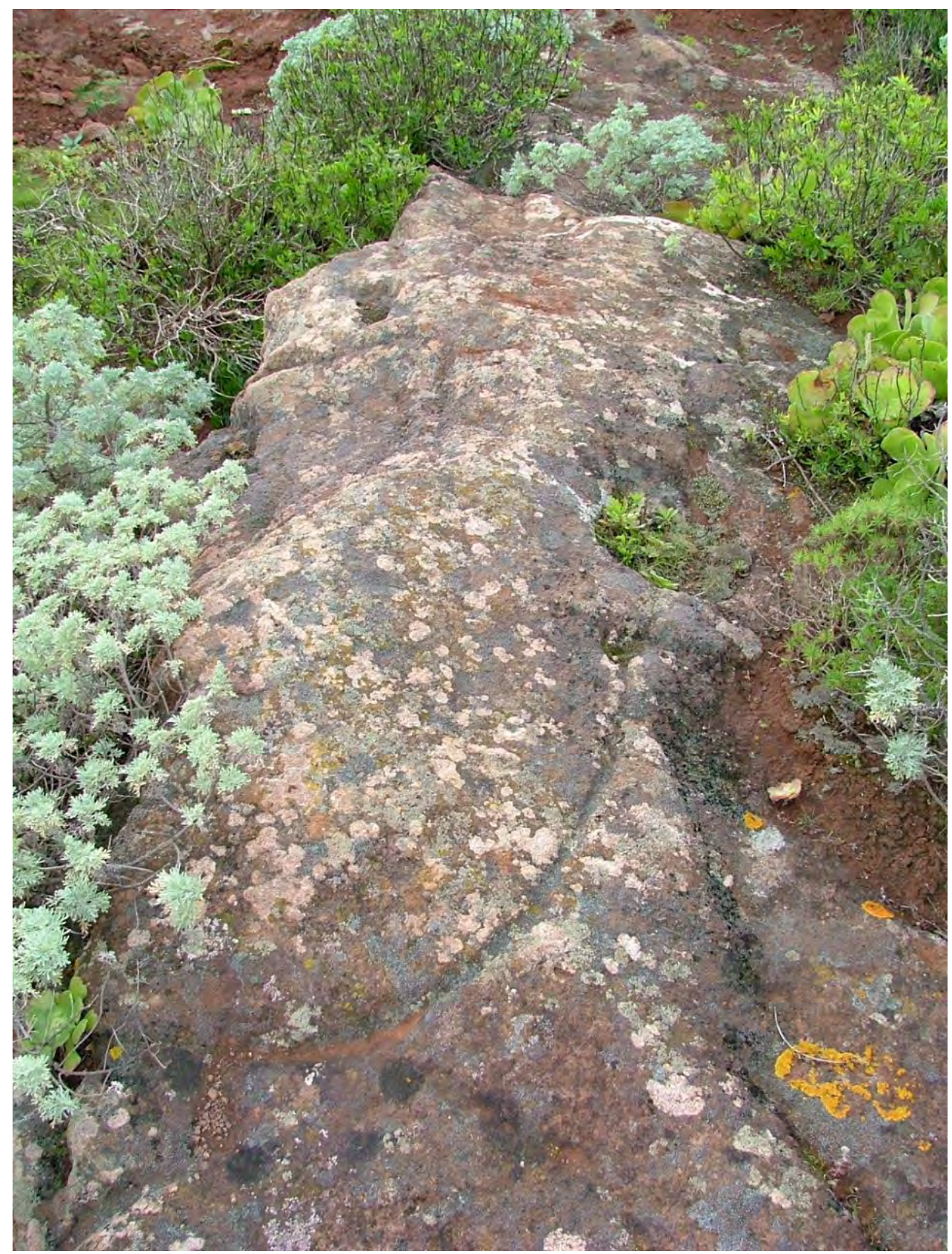

Figura 19. Estación de cazoletas y canales, Solis.

\section{Gracia, barranco Guajara}

En la margen izquierda del barranco Guajara, a su paso por Gracia, en el tracto superior, a 3 $m$ del cauce en dirección sur, en un sector afectado por el trazado del puente del tranvía entre La Laguna y Santa Cruz. Dicha margen continúa, pasado el puente, por los límites de la finca Borges Estévanez del Cabildo de Tenerife. Aunque parte de esta formación basáltica en el tracto superior del barranco está afectada por vertidos de cemento y las cimentaciones del puente, hay diversos paneles que alcanzan hasta $2.50 \mathrm{~m}$ de altura con grabados rupestres incisos, con motivos reticulados y lineales, unos orientados hacia $220^{\circ} \mathrm{SW}$ y otros hacia $170^{\circ} \mathrm{S}$ (figura 21). 


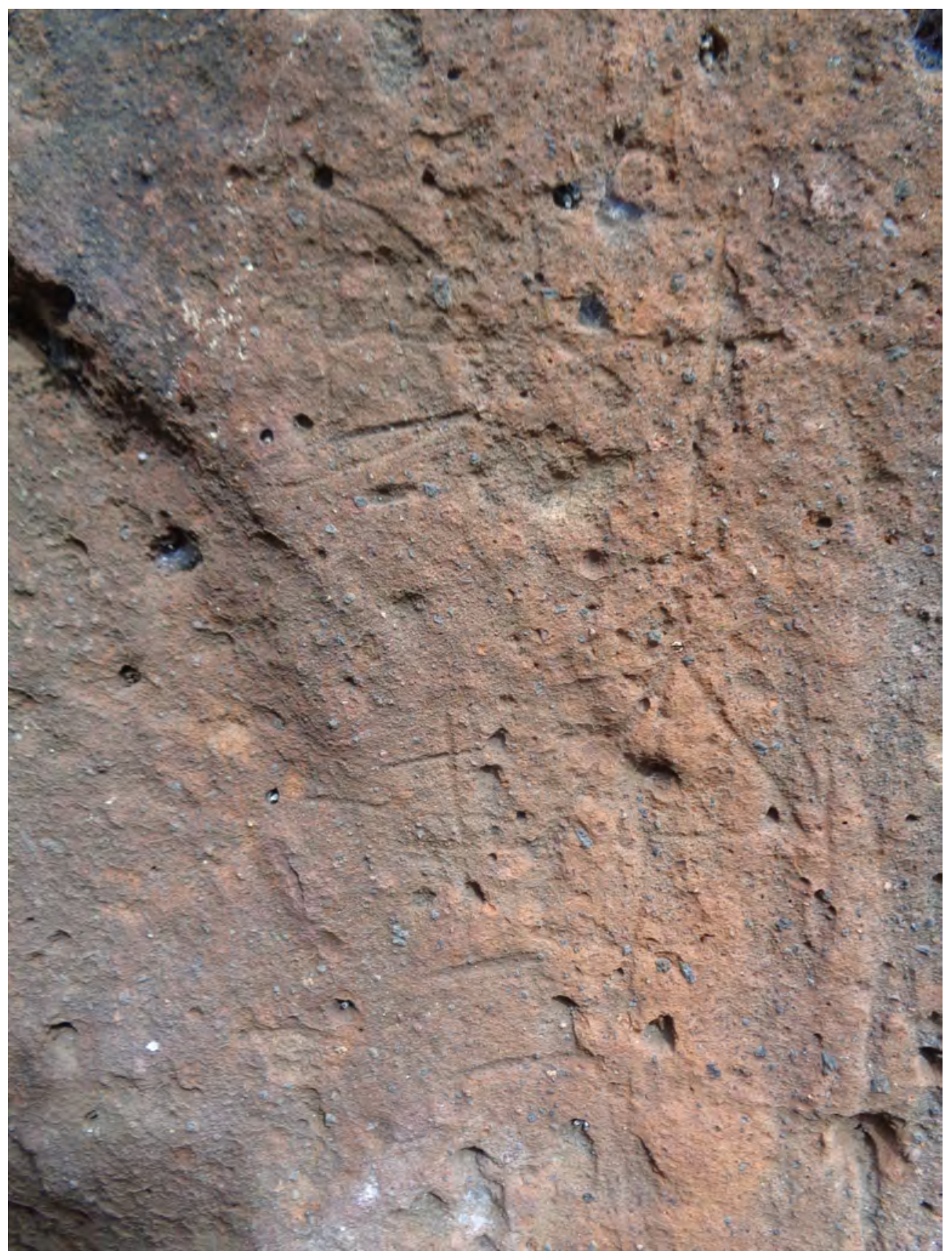

Figura 20. Grabado antropomorfo y alfabético inciso del camino real de La Verdellada.

\section{Risco Negro, Finca España}

Posible estación de cazoletas y canales, a 576 msnm, compuesta por dos cazoletas. La mayor, de $0.43 \mathrm{~m}$ de largo por $0.42 \mathrm{~m}$ de ancho, y la más pequeña, de 0.34 por $0.22 \mathrm{~m}$, que presenta un canal de $0.60 \mathrm{~m}$, orientado a $60^{\circ} \mathrm{E}$.

\section{Valle Colino}

Posible cabaña derruida a $525 \mathrm{msnm}$, con unas dimensiones de $1.80 \mathrm{~m}$ de longitud, por 1.70 $\mathrm{m}$ de ancho y $0.50 \mathrm{~m}$ de altura conservada de las paredes, con un eje mayor orientado a $75^{\circ} \mathrm{S}$. 


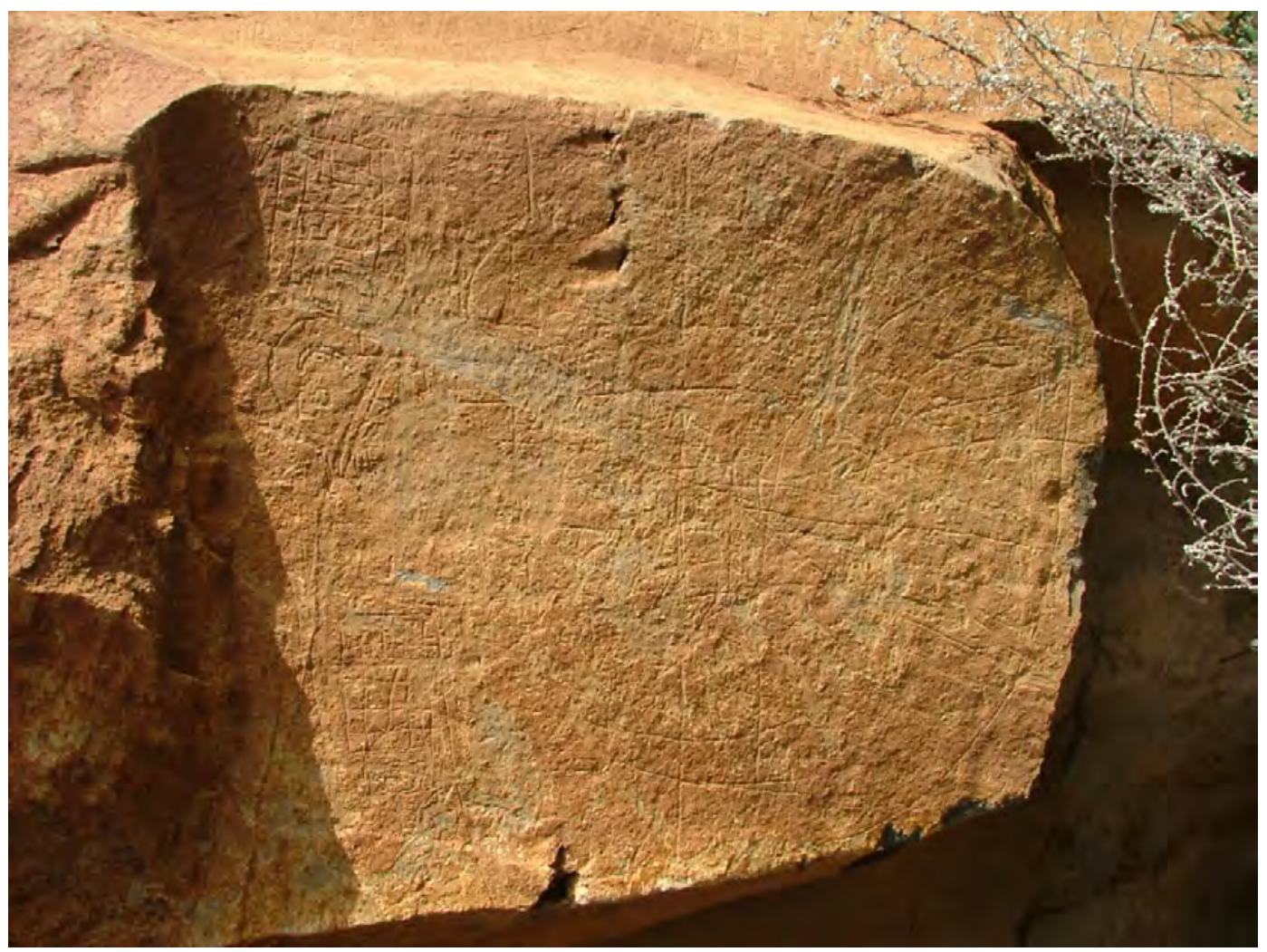

Figura 21. Grabado geométrico inciso de Gracia, barranco Guajara.

\section{Pico Cho Canino, barrio de La Higuerita}

Concentración de material arqueológico en superficie, a $480 \mathrm{msnm}$, con fragmentos de cerámica aborigen, obsidiana y basalto tallado. Mide $15 \mathrm{~m}$ por $9 \mathrm{~m}$. CALL n 80 .

\section{Pico el Canario-Huertas Blancas}

Posible cazoleta en un afloramiento de toscas negras junto al camino real empedrado, a 772 msnm, desde donde se visualiza la vega de La Laguna. Tiene unas dimensiones de $0.17 \mathrm{~m}$ de longitud, por $0.15 \mathrm{~m}$ de ancho y $14 \mathrm{~cm}$ de profundidad, con un eje principal $220^{\circ} \mathrm{SW}$.

\section{Pico de la Fuente del Lomo I, Finca España}

Estación de cazoletas y canales, a $506 \mathrm{msnm}$, en el tracto superior de la ladera derecha. La orientación de los canalillos es $45^{\circ} \mathrm{NE}$. La cazoleta mayor mide $0.55 \mathrm{~m}$ por $0.29 \mathrm{~m}$, el canal mayor es de $0.32 \mathrm{~m}$ y el canal menor $0.24 \mathrm{~m}$. El eje mayor es de W-NW a E-SE, con orientación a $120^{\circ}$ E. CALL n ${ }^{\circ} 78$.

\section{Pico de la Fuente del Lomo II, Finca España}

Posible fondo de cabaña, a 485 msnm, localizado en el interfluvio. Su eje mayor mide 4.10 $\mathrm{m}$ y el eje menor $1.90 \mathrm{~m}$, mientras el grosor de la pared es de $0.50 \mathrm{~m}$ y alcanza una altura máxima conservada de $0.55 \mathrm{~m}$. CALL nº 79 . 


\section{Gonzaliánez, valle de Las Chozas}

Estación de grabados rupestres, a 695 msnm, en un dique basáltico con técnica de ejecución incisa y motivos reticulados. El término de valle de Las Chozas, según información recogida por vecinos de la zona, proviene de unas cabañas que fueron utilizadas por ganaderos de vacas. Las cuevas artificiales de los Correas que se localizan en las inmediaciones sirvieron de vivienda a una familia con ese apellido. CALL n ${ }^{\circ} 73$ (figura 22).

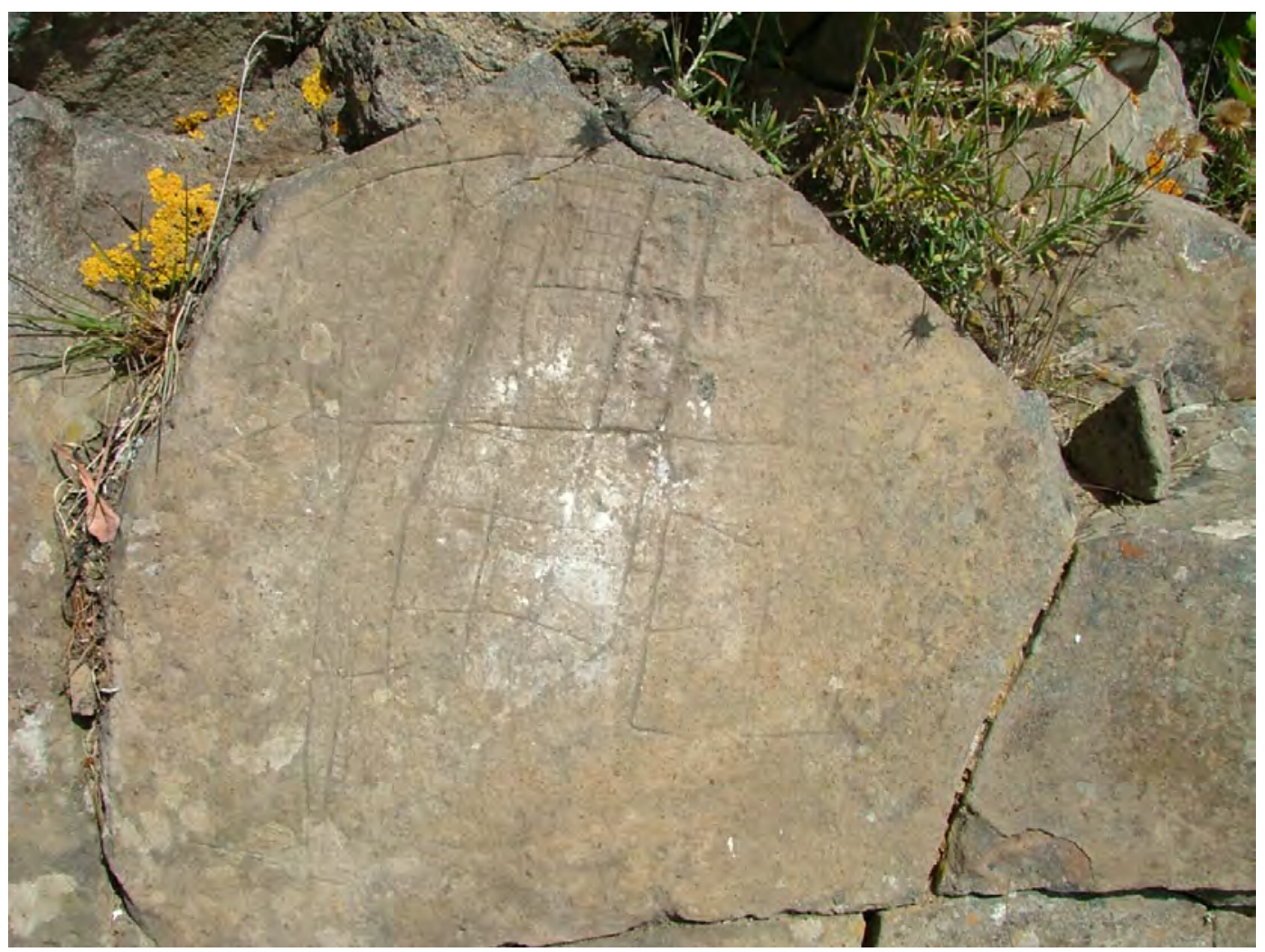

Figura 22. Grabado geométrico inciso de Gonzalianes, valle de las Chozas.

\section{Montaña de Guerra I, valle Jiménez}

Conjunto de una cueva de habitación y dos funerarias. La cueva de habitación se encuentra a $353 \mathrm{msnm}$, con unas dimensiones de $3.90 \mathrm{~m}$ de ancho en la entrada por $1.30 \mathrm{~m}$ de altura y 2.70 $\mathrm{m}$ de largo hasta el fondo, aunque se prolonga más de $10 \mathrm{~m}$ en una galería hacia al NE. Su entrada está orientada a $315^{\circ} \mathrm{NW}$. Tiene un muro de cierre de $0.80 \mathrm{~m}$ de grosor y $1.05 \mathrm{~m}$ de altura, con 5 hiladas de piedra de escoria volcánica.

\section{Montaña de Guerra II-III, valle Jiménez}

La cueva funeraria mide $1.85 \mathrm{~m}$ de ancho en la entrada por $0.85 \mathrm{~m}$ de altura y $3 \mathrm{~m}$ de fondo, orientada a $265^{\circ} \mathrm{W}$. Cuenta con un muro exterior de cierre de $1.25 \mathrm{~m}$ de grosor y $0.85 \mathrm{~m}$ de altura.

La segunda cueva funeraria, a $349 \mathrm{msnm}$, tiene unas dimensiones de $4.10 \mathrm{~m}$ de ancho en la entrada por $1.20 \mathrm{~m}$ de altura y $2.30 \mathrm{~m}$ de fondo, orientada a $315^{\circ} \mathrm{NW}$. Hay un posible muro derruido en el lado NW, con $0.45 \mathrm{~m}$ de grosor que ayuda a ampliar la superficie útil de la cueva. 
Presenta restos de un enterramiento y de él se extrajeron hace unos 25 años más de 500 cuentas de collar y 3 cerámicas ubicadas en los lados sur y suroeste de la cueva.

\section{El Becerril, barranco de Santos, barrio de la Candelaria}

Cueva sepulcral descubierta en 1944, a 255 msnm, localizada en el tracto medio de la ladera derecha del barranco de Santos, a $50 \mathrm{~m}$ bajando desde la margen derecha y a unos $40 \mathrm{~m}$ sobre el cauce del barranco, en la cota de 295 msnm, frente a Montaña de Guerra. El andén medio es el más adecuado porque al tracto inferior, debido a la curva del barranco, llega el agua con más fuerza y no está ocupado. El tracto superior actualmente está muy afectado por el vertido de aguas negras y la vegetación que ha crecido. Actualmente está al pie del barrio de Candelaria, en el límite de La Laguna frente a Salud Alto, accediéndose desde la calle María Auxiliadora, tras pasar primero por el colegio de los Salesianos Juan Bosco y después por el campo municipal de futbol Pedro Vargas. Hay un camino descendente hacia una barriada de autoconstrucción del que parte un estrecho sendero a pie que va a en dirección NE-SW. También se puede descender por el SE, más complicado, pero que aprovecha actualmente una tubería de agua. El problema principal es la completa reutilización de todas las cuevas de tracto medio, que se abren con orientación $\mathrm{N}, \mathrm{NW}$ y W, para perreras, aperos, etc., y su vallado exterior.

La cueva excavada tiene una orientación $\mathrm{N}$ y mide $0.75 \mathrm{~m}$ de ancho en la entrada y $1.50 \mathrm{~m}$ de altura, que aumenta hasta $2.50 \mathrm{~m}$ de ancho máximo al interior y $2 \mathrm{~m}$ de altura, con $5.50 \mathrm{~m}$ de largo hasta el fondo y una superficie interior de $13.5 \mathrm{~m}^{2}$, presentando un muro de cierre en su entrada $^{72}$. Se localizaron 50 enterramientos, de los cuales se conservaban 30 cráneos y 15 maxilares inferiores que ocupaban toda la superficie de la cueva ${ }^{73}$. Presentaba fragmentos de cerámica aborigen, obsidiana y 85 cuentas de collar $^{74}$. CALL nº 83.

\section{Lomo Tamé}

Estación de cazoletas, a una altitud de $492 \mathrm{msnm}$, realizada sobre una plataforma de pumita o toba rojiza de $30 \mathrm{~m}$ de longitud, que presenta aislada una cazoleta circular, desde donde se visualiza el mar. Por otra parte, hay una plancha inclinada con una canal que acaba en una cazoleta rectangular, y otras cazoletas rectangulares, a veces aisladas y otras veces conectadas por un canal.

\section{El menceyato de Tegueste y sus límites con Tacoronte, Anaga y Güímar}

Los límites del menceyato de Tegueste no están del todo resueltos y existen varias propuestas. La primera interpretación sobre los límites del menceyato fue desarrollada por Bethencourt Alfonso ${ }^{75}$ quien señalaba como las fronteras con el menceyato de Tacoronte la montaña Birmaje (943 msnm), montaña de Carboneros, montaña Coronados, las Mesetas, montaña de Fagundo, montaña de Madruga, el lomo Colorado o de Perdomo y la montaña del Picón en Guamasa. Por otra parte, considera que Tegueste no tenía categoría de reino, sino sólo de achimenceyato ${ }^{76}$, siguiendo presumiblemente a Viana, y cree que tanto Tegueste como punta del Hidalgo eran señoríos o feudatarios de Taoro ${ }^{77}$.

72 ÁLVAREZ DELGADO [y DIEGO CUSCOY] (1947b), pp. 62-64, 62 fig. 9, 64 fig. 10, 65 fig. 11/1-3.

73 ÁLVAREZ DELGADO [y DIEGO CUSCOY] (1947b), pp. 66-67.

74 ÁLVAREZ DELGADO [y DIEGO CUSCOY] (1947b), p. 67; DIEGO CUSCOY (1968), p. 236.

75 BÉTHENCOURT ALFONSO (1991 [1911]), pp. 98, 106.

76 BÉTHENCOURT ALFONSO (1997 [1912]), pp. 83-84.

77 BÉTHENCOURT ALFONSO (1994 [1911]), pp. 67-68; BÉTHENCOURT ALFONSO (1997 [1912]), pp. 53-54, 83-84, 120. 
Estos límites fueron modificados por Álvarez Delgado ${ }^{78}$, quien considera que difícilmente Tegueste superó la cadena montañosa de Las Mercedes, Mesa Mota, El Púlpito y Guamasa, por lo que propone que La Laguna perteneció a Anaga y Los Rodeos a Tacoronte, como prolongación de Los Naranjeros, quizás siguiendo en parte a Viera y Clavijo ${ }^{79}$ quien también incluye a Los Rodeos en el menceyato de Tacoronte. En un trabajo posterior, Álvarez Delgado ${ }^{80}$ considera que Tegueste sería una escisión de los menceyatos de Tacoronte y Anaga, y previamente no había sido nunca un achimenceyato o reino.

Una nueva propuesta sobre el límite fronterizo entre el menceyato de Tacoronte y el de Tegueste fue la ofrecida por Diego Cuscoy ${ }^{81}$, quien propone a la punta del Viento, Juan Fernández, la cruz del Tagoro y la loma del Cardón, encima de valle Guerra, como la frontera con el menceyato de Tacoronte. Otros límites serían montaña de La Atalaya, La Caldera y Naranjeros, el monte bajo de Agua García y Ravelo, formando una línea en dirección sur por las cotas de 700-800 msnm hasta el barranco de San Antonio al suroeste. Y hacia el sureste, El Ortigal, La Esperanza, Ravelo y Las Baboseras ${ }^{82}$.

Una distribución diferente ha sido planteada por Cebrián Latasa, para quien la frontera de Tacoronte con Tegueste seguía la línea de los altos de La Atalaya, Guamasa, El Portezuelo o/y Barranco de Guayonje ${ }^{83}$.

Desde nuestro punto de vista creemos que Tegueste fue un achimenceyato dependiente de Tacoronte hasta que consiguió su independencia como menceyato, unas dos o tres generaciones antes de la conquista, como en parte apunta Álvarez Delgado.

Debieron de haber existido una serie de zonas comunales de pastos, que ya sugiere Cebrián, pero restringidas a Los Rodeos, Los Naranjeros y La Laguna, un espacio con una elevada humedad, áreas lagunares en invierno y mayor abundancia de pastos en verano. No obstante, es posible que este espacio fuera en la práctica dependiente de Tacoronte, siguiendo el antiguo camino que procedente de Tacoronte pasaba por Los Naranjeros y Los Rodeos hasta alcanzar La Laguna, por lo que ceñimos la frontera del achimenceyato de Tegueste a los límites naturales de la cadena montañosa de Las Mercedes, Mesa Mota, El Púlpito y Guamasa, en la línea apuntada por Viera y Clavijo o Álvarez Delgado ${ }^{84}$. Por otra parte, debió de existir un achimenceyato de Aguere, que se extendía hacia la costa del actual Santa Cruz, el cual estaba integrado dentro del menceyato de Tegueste, pero no cabe descartar que en momentos pasados pudo también depender de Anaga.

El territorio alrededor de La Laguna puede haber tenido un uso comunal más amplio, como la zona de Las Cañadas, puesto que en la mitología de los guanches se consideraba el lugar donde residían las almas valientes que habían realizado buenas acciones ${ }^{85}$, por lo que parece haberse producido en ambos casos la sacralización de un área comunal. Además, estaba en un punto de contacto de cuatro menceyatos, Anaga, Tacoronte, Güímar, y más tarde Tegueste, como también sucede con un número mayor de menceyatos en la zona de Las Cañadas, en este caso residencia de las almas y dioses infernales.

El menceyato de Tegueste no era dependiente de Anaga, como lo fue punta del Hidalgo, sino de Tacoronte, y debía de ser un reino de reciente creación. Uno de los problemas es el nombre de los menceyes pues solo se menciona el nombre de «Tegueste (...) rey de Tegueste» en 1464, cuando se firmó el acto de vasallaje con Diego de Herrera ${ }^{86}$, que es citado como Guahuco por Viana $^{87}$. Cuando se mencionan los nombres de los 9 menceyes de Tenerife en el momento de la conquista, Viana ${ }^{88}$ no lo considera mencey, y sí, en cambio, a Guantacara de Teno, y lo cita con

78 ÁLVAREZ DELGADO (1960), p. 274.

79 VIERA Y CLAVIJO (1967-71 [1776-83]), p. 629, IX, 6.

80 ÁLVAREZ DELGADO (1960), pp. 82, 96.

81 DIEGO CUSCOY (1968), pp. 135-136.

82 DIEGO CUSCOY (1968), p. 138.

83 CEBRIÁN LATASA (2001a), p. xvi.

84 MEDEROS y ESCRIBANO (2007), pp. 120-121.

85 SCORY (1992-93 [1626]), p. 105.

86 NÚÑEZ DE LA PEÑA (1994 [1676]), p. 36; I.5.

87 VIANA (1986 [1604]), p. 266; X.

88 VIANA (1986 [1604]), pp. 62-63; I; 266; X 
el nombre de Tegueste. Era el quinto mencey de más edad de Tenerife, superando a los de Adexe, Tacoronte y Taoro ${ }^{89}$.

Este mencey estaba emparentado por matrimonio con la hija del mencey de Tacoronte, portadora de la legitimidad en la herencia.

Tegueste (...) casó con Tejina, bella infanta, hija de Acaymo, rey de Tacoronte, y por dote le dio el hermoso valle que hoy llaman de Tegueste, a causa suya, y aunque algunos afirman, que era reino se engañan, y es error, que solamente fue señorío, y nunca jamás tuvo cetro de hueso antiguo, ni tagoro, ni fue por rey y con calavera electo ${ }^{90}$.

Resulta difícil pensar que Viana, quien realizaba su obra por encargo del señor de valle Guerra, se equivocase en un aspecto tan inmediato y significativo, pero al tratarse de un menceyato de reciente creación sí pudo existir cierto grado de imprecisión en la tradición oral que recibió. Al menos se menciona un hijo de ambos, Teguaco ${ }^{91}$, también transcrito como Teguazo $^{92}$.

Como posible hija del mencey de Tacoronte se menciona a Francisca de Tacoronte o del Castillo, cuyo padre pudo ser el mencey de Tacoronte, o quizás el de Tegueste, y su madre, la hermana del mencey de Tacoronte o de Tegueste, como sugiere Cebrián ${ }^{93}$. En cualquier caso, debería también implicar que pudo haber algún tipo de alianza familiar entre ambos menceyatos, que pudieron actuar de forma simultánea durante la conquista, implicándose más contra la segunda entrada castellana de $1495^{94}$.

La residencia del mencey de Tegueste estaba «junto a un barranco grande que se llama Tejina» ${ }^{95}$, que suponemos el barranco de las Cuevas que atraviesa el pueblo, pues el barranco de Agua de Dios era límite con Anaga y resultaría menos seguro, aunque también podría situarse en la zona de La Fuente y la presa del Manisero, inicio del barranco de Milán, en contacto con el actual pueblo de Tejina y más próximo a su iglesia. También se menciona la presencia del mencey «cerca de un barranco de Tejina» ${ }^{96}$.

No obstante, a pesar de la proximidad de La Laguna, no deja de llamar la atención la ausencia tanto en las datas como en la tradición oral de la presencia de una cueva o auchón del mencey de Tegueste, lo que también sugiere este carácter reciente del menceyato. Una posible referencia a un auchón era inmediata a una cueva horadada en Tegueste, es decir, una cueva excavada en la tosca ya en 1497, un año después de la conquista de la isla ${ }^{97}$. Esta «cueva foradada en Tegeste» fue concedida en julio de $1497^{98}$ y está referenciada en otra data de diciembre de 1500,

[Juan de] Almansa. Una cueva q.[ue] está en Tegeste, alinda con el aviar [auchón] de [H]Ervás, que era la cueva hora[da]da y la tiene cerrada y adobada, y el andén q.[ue] está del cabo de arriba della y un c.[ahíz] encima (...) Que digo que me plaze de daros la cueva con tal que no esté dada ${ }^{99}$.

La palabra aviar no es habitual en las datas, ni siquiera aparece en los índices de Serra o Moreno, y más aún en fecha tan temprana, la cual es leída como auchón por Bethencourt Alfonso $^{100}$, probablemente trascrita como avchon, lo que implicaría una posible mala lectura tanto de E. Serra Ràfols como de F. Moreno.

89 NÚÑEZ DE LA PEÑA (1994 [1676]), p. 121; I.14.

90 VIANA (1986 [1604]), p. 267; X.

91 VIANA (1986 [1604]), p. 341; XIV; NÚÑEZ DE LA PEÑA (1994 [1676]), p. 155; I.15.

92 BÉTHENCOURT ALFONSO (1991 [1911]), p. 353.

93 CEBRIÁN LATASA (1996), p. 385 n. 25.

94 MEDEROS y ESCRIBANO (2007), p. 124

95 VIANA (1986 [1604]), p. 337; XIII.

96 NÚÑEZ DE LA PEÑA (1994 [1676]), p. 154; I.15.

97 MEDEROS y ESCRIBANO (2004), pp. 748-756.

98 SERRA RÀFOLS (1978), p. $19 \mathrm{n}^{\circ} 3$.

99 SERRA RÀFOLS (1978), p. 175 n 859-38; MORENO (1992), p. 22

100 BÉTHENCOURT ALFONSO (1994 [1911]), p. 111. 
La segunda mención a un auchón que hace Bethencourt Alfonso ${ }^{101}$ es un error suyo pues confunde Tejina de Guía de Isora con Tejina de La Laguna. La data de 1504 menciona el auchon de Tegerefete [Tagarafate] de aquella parte de las t[ierr]as. de Fernán García el abad, facia Tejyne ${ }^{102}$.

Un tercer auchón fue concedido en mayo de 1499 al canario «Rodrigo el Coxo. Una f.[anega] de t[ierr]a. de r.[iego] en el valle de Gueste, q.[ue] es en Naga, e unas figueras q.[ue] en el valle están e una cueva con el avchón de arriba e t[ierr]a. q.[ue] sembréis» ${ }^{103}$, lo que podría indicar la margen oriental del barranco de Agua de Dios.

Como señala Viana ${ }^{104}$ sobre el mencey de Tegueste, «eran tantas las crías que tenía en el distrito de la vega hermosa do tiene eterno asiento la laguna, que tenía ocupados cien pastores en guarda suya (...) de ovejuelas». El mencey parece ser el principal propietario del ganado, pues buena parte de la población, incluidos quienes vigilaban el ganado «no es permitido a la plebe comer ganado cuando tiene hambre, sino en los días de fiesta, y con permiso de los amos» y la «leche, también para los pudientes, porque los demás no pueden satisfacer esta necesidad, aunque estén al cuidado de los rebaños» ${ }^{105}$.

En cualquier caso, las datas también apoyan la presencia de un menceyato de Tegueste en el momento de la conquista, y en una de agosto de 1506 se menciona «20 c.[ahices] de t.[ierra] de s.[equero] para pan coger en el Reino de Tegeste, los cuales podréis tomar a donde bien visto fuere» ${ }^{106}$

En cambio, otros autores consideran que Tegueste y punta del Hidalgo eran parte de Taoro, pues Tegueste y Zebensui, dos de los tíos de Betzenuhya, habían permanecido fieles al mencey de Taoro cuando otros achimenceyatos se independizaron, y aceptaron a su sobrino como heredero de menceyato de Taoro. El nuevo mencey los confirmó en sus puestos y les concedió a partir de entonces el carácter de achimenceyatos hereditarios ${ }^{107}$, aunque no conocemos esposa ni hijos de Zebensui.

Respecto a los límites del menceyato de Tegueste con Anaga hacia el este, Bethencourt Alfonso ${ }^{108}$ lo sitúa bordeando el sur de la vega de La Laguna, en el naciente del monte de Las Mercedes, la sierra de Sejéita o del Bronco, San Roque (645 msnm), el barranco de Aragúy, del Rey o de Drago, que situamos en el barranco de la Carnicería, hasta la Cuesta y al sur con el tagoro de Añazo en Santa Cruz de Tenerife, también dentro del menceyato de Anaga.

Hacia el este de Tegueste, o el oeste si lo miramos desde el punto de vista del achimenceyato de punta del Hidalgo, el límite lo sitúa en el barranco de Palmas, lo que incluiría buena parte del norte de Anaga hasta el caserío de Las Palmas frente al roque de Anaga de Tierra. Este achimenceyato que llama de Aguahuco tendría su límite este en el barranco de Casas-Bajas ${ }^{109}$, cuya prolongación en la margen sur de Anaga sería el barranco de Valleseco, que desemboca en Santa Cruz por el castillo de Paso Alto.

En el caso de Diego Cuscoy ${ }^{110}$ el límite con Anaga estaría desde el mar por la mesa de Tejina (662 msnm), picachos de los Lázaros (462 msnm), montaña de la Atalaya (588 msnm) y las montañas que bordean la vega de la Laguna. Sin embargo, cree que aprovecharían los pastos de Los Rodeos y la vega de La Laguna tras atravesar el Portezuelo hacia Los Rodeos y Las Peñuelas hacia La Laguna. El límite se prolongaría por el barranco de Santos hasta su desembocadura.

Por último, Cebrián ${ }^{111}$ sitúa la frontera de Tegueste con Anaga en los altos del Batán (809 msnm) y el barranco del Tomadero, límite actual entre La Laguna y Santa Cruz en Batán de

101 BÉTHENCOURT ALFONSO (1994 [1911]), p. 111.

102 SERRA RÀFOLS (1978), p. 114 n 509-24; MORENO (1992), p. 124.

103 SERRA RÀFOLS (1978), p. 149 n 716-57.

104 VIANA (1986 [1604]), p. 276.

105 PALENCIA (1978 [1490-91]), p. 474.

106 SERRA RÀFOLS (1978), p. 169, nº 832-11.

107 BÉTHENCOURT ALFONSO (1991 [1911]), pp. 343, 346-347, 353; BÉTHENCOURT ALFONSO (1997

[1912]), pp. 53-54, 83-84, 120.

108 BÉTHENCOURT ALFONSO (1994 [1911]), pp. 104, 106.

109 BÉTHENCOURT ALFONSO (1994 [1911]), p. 111.

110 DIEGO CUSCOY (1968), pp. 127, 135-137.

111 CEBRIÁN LATASA (2001b), p. xvi. 
Arriba y el Río, desembocando en la playa de los Troches, lo que implica que los Dos Hermanos ya serían parte de Anaga y el límite estaría junto a punta del Hidalgo.

Es interesante que el camino por el barranco del Batán que se descendía desde el Batán de Abajo hacia la punta del Hidalgo por sus alturas y los imponentes acantilados que formaba en la costa eran denominados Adaar ${ }^{112}$, actualmente Adar. Este mismo término se utilizaba para denominar a las montañas del Atlas, «Adiris - pues, según la opinión general, el Atlas tiene ese nombre en su lengua-» ${ }^{113}$. La raíz 'dr significa "imponente" ${ }^{114}$, como sucede en Rusaddir Rš 'dr, el cabo imponente.

Finalmente, como límite del menceyato de Tegueste con Güímar, Bethencourt Alfonso ${ }^{115}$ apunta que partiría desde montaña Birmaje (943 msnm), pico de las Flores, Laguneta Alta, todos en El Rosario, municipio de incluye en Güímar, y descendía por el barranco de Gánimo o del Hierro, hasta el mar. La inclusión de El Rosario dentro de Güímar viene justificada por la supuesta existencia de un achimenceyato que dirigía Guadameña, hermano del mencey de Güímar, el cual iría desde el barranco Hondo de Candelaria o de Bedijo hasta el límite con Anaga ${ }^{116}$. Por esta razón a Güímar pertenecían tagoros como los de Jagua en El Chorrillo, el Tagoro del cercado de Bello en La Esperanza, el Tagoro del Castillo junto a la Montañeta y La Esperanza, el tagoro de Birmaje, el Tagoro de Zamorano por fuente Guillén, el tagoro de Rodeos Altos y el Tagoro de Taco ${ }^{117}$.

Un límite parecido en el barranco del Hierro y Santa María del Mar, separando Güímar y Anaga, pero que incluiría a valle Tabares, Geneto y Taco en Anaga, es la propuesta de Cioranescu ${ }^{118}$.

Este límite entre Anaga y Güímar se sitúa en el barranco de Guadamojete por Álvarez Delgado ${ }^{119}$, prolongándolo hasta Radazul. En cambio, otros investigadores que han trabajado regularmente con protocolos notariales lo prolongan más allá de Guadamojete, probablemente en el barranco de Santos con Anaga ${ }^{120}$, como también apunta Cebrián Latasa ${ }^{121}$, tras atravesar las zonas de pastoreo comunal, en el barranco de Santos y La Cuesta, hasta donde llegaría Güímar.

Tenemos constancia de enfrentamientos directos entre Tegueste y Güímar,

el cuerpo de éste está mirlado, en una cueva grande, sepultura antigua de los reyes de Güímar, cuyo sobrino era, que está en Guadamoxete. Este murió en una batalla que con los hijos del rey de Tegueste tuvo, y dicen que, yendo a la batalla, dijo cómo habría de ser muerto en ella a manos de los sobredichos ${ }^{122}$.

Este enfrentamiento parece que fue poco antes de la conquista, siendo Tegueste aliado de Taoro, en la

batalla de Güenifante, cerca de Pasacola, en la que fueron completamente derrotados los guimareros muriendo el infante Cayamo, hermano del rey, y el célebre gigante Emotio que pereció a manos de los teguesteros y fue sepultado en Guadamoxete, hecho de armas que obligó a Añaterve a pedir la paz ${ }^{123}$,

información que parece recogerla de una historia del pueblo guanche redactada por Cristóbal Bencomo, cuyo rastro desaparece hacia 1820, comunicándole datos oralmente algunas personas

112 BERTHELOT (1980 [1839]), p. 60.

113 Plin. (N.H., V, 1, 13).

114 FANTAR (1985), p. 127; LIPINSKI (1992), p. 466.

115 BÉTHENCOURT ALFONSO (1994 [1911]), pp. 83, 106.

116 BÉTHENCOURT ALFONSO (1994 [1911]), p. 84.

117 BÉTHENCOURT ALFONSO (1994 [1911]), p. 112 n. 1.

118 CIORANESCU (1977), p. 19.

119 ÁLVAREZ DELGADO (1960), p. 274.

120 GÓMEZ GÓMEZ (2000), p. 11.

121 CEBRIÁN LATASA (2001b), p. xvi.

122 ESPINOSA (1980 [1594]), p. 36.

123 BETHENCOURT ALFONSO (1997 [1912]), p. 54. 
que leyeron el libro, lo que impide contrastar adecuadamente su propuesta y la información debe ser valorada con cautela.

Es complicado con la información de las datas delimitar la frontera de Tegueste en su vertiente sur, si no se acepta una prolongación de Güímar hasta el barranco de Santos, pues no debe olvidarse que El Rosario es un municipio creado en 1812 que fue desgajado en 1812 de La Laguna. Aunque La Laguna fuese un espacio comunal en algunas celebraciones, sólo se cita ganado de Tegueste. Si Anaga llegaba hasta el barranco de la Carnicería y bordeaba la sierra de San Roque, no cabe descartar que en algún tiempo pasado llegó a controlar La Laguna, al menos excepcionalmente. Si continuaba el límite por el barranco de Santos, la cuestión es a quien pertenecía La Cuesta, Taco, Santa Cruz o El Rosario. Si Santa Cruz fue el puerto de La Laguna, no hay por que descartar que el límite de Tegueste y final de La Cuesta llegase hasta el mar.

Güímar con seguridad controlaba hasta el barranco Hondo, actual límite entre Candelaria y El Rosario, pero la bahía natural se prolonga hasta Radazul y la punta de Guadamojete, con lo que límites posibles no creemos que fuese el barranco del Humilladero, actual separación de El Rosario con Santa Cruz, sino debió de incluir también Santa María del Mar y Añaza hasta barranco Hondo y barranco Grande, o algo más en el barranco de los Andenes que desemboca como barranco del Muerto, con lo que Hoya Fría y Montaña de Taco pertenecerían a Tegueste.

\section{El ACHIMENCEYATO DE PUNTA DEL HidAlgo y SU DEPENDENCIA DE ANAGA}

En Tenerife habían hasta 11 posibles unidades políticas independientes o menceyatos en 1464, cuando realizaron un acto de vasallaje con Diego de Herrera,

el año de 1464 el Obispo [Yllescas] y Diego de Herrera tomaron possession de la Ysla de Thenerife por el Rey de Castilla, ante el mismo Escribano Parraga, donde firmaron los dichos con otros que se hallaron presentes a las paces nueve Capitanes gentiles o Reies de ellos, los dos no admitieron pases ni vinieron a ellas, de los terminos Taoro y Teno

según Marín de Cubas ${ }^{124}$. Se mencionan 11 menceyatos por incluir a Punta del Hidalgo y Teno, además de Taoro, Güímar, Anaga, Abona, Tacoronte, Benicod, Adexe, Tegueste y Dabte. Sin embargo, una fuente casi coetánea al acontecimiento deja constancia del hecho, pero reduciendo la cifra de los menceyes de 11 a

nueue reyes canarios de Tenerife obedesçieron e besaron la mano por señor al dicho Diego de Ferrera e estouieron asy pacíficos, e entrauan e salían los christianos en la dicha ysla tiempo de seys años [1464-70], poco más o menos, e que sabe que estauan ende el Obispo de Canaria e otros frayles. E que después se quebró esta pas ${ }^{125}$

o 10 menceyatos si se suma punta del Hidalgo como señorío por Núñez de la Peña ${ }^{126}$.

La mayor parte de la información sobre el achimenceyato de punta del Hidalgo procede de Viana:

la punta que llaman del Hidalgo, que son unos remotos y altos riscos confines con el reino de los Nagas, que los primeros hijos de Tenerfe a Guahuco, bastardo hermano suyo, dieron en partición, y por su muerte los gozaban dos nobles sucesores (...) Tegueste (...) Zebensuí esotro hermano, que en los riscos y punta, tierra y valle de su abuelo vivió continuamente, aquéste fue llamado Hidalgo pobre, que archimenseu, decían en su lengua, a cuya imitación quedó a este término la Punta del Hidalgo ${ }^{127}$.

Su grafía a veces aparece diferente como Sebensui ${ }^{128}$, Zegenseyas ${ }^{129}$ o Zembesuy ${ }^{130}$.

124 MARÍN DE CUBAS (1986 [1694]), p. 131; I, 16.

125 PÉREZ DE CABITOS (1990 [1476-77]), p. 274.

126 NÚÑEZ DE LA PEÑA (1994 [1676]), p. 36; I.5.

127 VIANA (1986 [1604]), p. 266-267; X; NÚÑEZ DE LA PEÑA (1994 [1676]), p. 151; I.15.

128 BÉTHENCOURT ALFONSO (1991 [1912]), p. 352. 
En cambio, en otras ocasiones Zebensui es mencionado como Aguahuco, hijo bastardo de Gran Tinerfe, señor de punta del Hidalgo ${ }^{131}$ y primo, no hermano, del mencey de Tegueste ${ }^{132}$. La otra opción ha sido considerar a Aguahuco el padre de Zebensui ${ }^{133}$, a veces con la grafía de Guahuco $^{134}$ o Aguajuco ${ }^{135}$.

La clara dependencia de Punta del Hidalgo respecto a Anaga la señala Viana en varias ocasiones, «Zebensúi (...) vivía pobremente (aunque le daba para su sustento el rey de Naga cantidad de gofio de renta en cada un año)», «sin rentas, sin ganados, ni crías» ${ }^{136}$, «en mi pobre cueva, solo sin acompañamiento» ${ }^{137}$ situada en la Hoya de punta del Hidalgo.

Esta cueva de Zebensui debe de ser la que la tradición oral de fines del siglo XIX denominaba la hoya del Uchón en el caserío de La Hoya de punta del Hidalgo, donde también se menciona un tagoro ${ }^{138}$. Este auchón sería una «finca o medianería» que incluía también «casitas, chozas y cuevas» ${ }^{139}$, mientras que según Martínez de la Peña ${ }^{140}$ corresponde a «un lugar con cuevas» que servían para guardar ganado o almacenar "grano, queso, pieles o manteca». En cambio, Leopoldo de la Rosa (com. pers. González Antón) optaba por un lugar de almacenaje de grano. Nosotros creemos que debe tratarse de un espacio agrícola cultivado, con alguna cueva grande aneja que podía servir de lugar de almacenaje. Esto implica que al menos era tan importante la idea de un terreno agrícola óptimo como las buenas condiciones de almacenaje que pudiera tener alguna cueva inmediata ${ }^{141}$, condiciones que reúne el actual emplazamiento de la cueva. Respecto al almacenaje de grano dentro de una cueva u hórreo inmediato, aunque no se ha constado con seguridad en ninguna excavación arqueológica, lo indica claramente la crónica de Palencia ${ }^{142}$ que además apunta la intervención del mencey, quien tenía el control del lugar de almacenaje, siendo función de «uno de los jefes encerrar en los graneros la mies recogida, de donde luego sacarán su alimento». Junto a este auchón se localizaba a fines del siglo XIX el tagoro de La Hoya de punta del Hidalgo según Bethencourt Alfonso $^{143}$ y Eugenio de Sainte Marie ${ }^{144}$, lo que refuerza la importancia de esta cueva o auchón de Zebensui (figura 23).

El mencey de Anaga aceptaba con resignación que estuviese «hurtando de continuo ajenos frutos, ganados, y otras cosas a los nagas, sin que hubiese remedio, ni castigo» ${ }^{145}$. Sin embargo, significativamente, Zebensuí no lo hacía en el menceyato de Tegueste, territorio de su hermano, pero dependiente en última instancia de Tacoronte. En cambio, Bethencourt Alfonso ${ }^{146}$ considera que punta del Hidalgo o Aguahuco era un achimenceyato de Tegueste, al igual que Aguere.

129 CASTILLO Y RUIZ DE VERGARA (2001 [1737]), p. 184.

130 CASTILLO Y RUIZ DE VERGARA (2001 [1737]), p. 189.

131 NÚÑEZ DE LA PEÑA (1994 [1676]), p. 36; I.5.

132 NÚÑEZ DE LA PEÑA (1994 [1676]), p. 152; I.15.

133 VIANA (1986 [1604]), p. 266; X; VIERA Y CLAVIJO (1967-71 [1776-83]), p. 209; II.23; BÉTHENCOURT ALFONSO (1991 [1912]), p. 346, 352.

134 VIANA (1986 [1604]), p. 266; X; BÉTHENCOURT ALFONSO (1991 [1912]), p. 346; BÉTHENCOURT

ALFONSO (1994 [1911]), p. 111.

135 MARÍN DE CUBAS (1986 [1694]), p. 278; II.20.

136 VIANA (1986 [1604]), p. 267, 275; X; NÚÑEZ DE LA PEÑA (1994 [1676]), p. 151; I.15.

137 NÚÑEZ DE LA PEÑA (1994 [1676]), p. 152; I.15.

138 BETHENCOURT ALFONSO (1994 [1911]), p. 111.

139 BETHENCOURT ALFONSO (1991 [1912]), p. 302 n. 48; BETHENCOURT ALFONSO (1994 [1911]), p. 399.

140 MARTINEZ DE LA PEÑA (1991), p. 24.

141 MEDEROS y ESCRIBANO (2017), p. 25.

142 PALENCIA, A. de (1978 [1490-91]), p. 474.

143 BÉTHENCOURT ALFONSO (1994 [1911]), p. 111.

144 ALONSO RODRÍGUEZ (2000 [1944]), p. 47, 56.

145 VIANA (1986 [1604]), p. 267; X.

146 BÉTHENCOURT ALFONSO (1994 [1911]), p. 302 n. 47. 


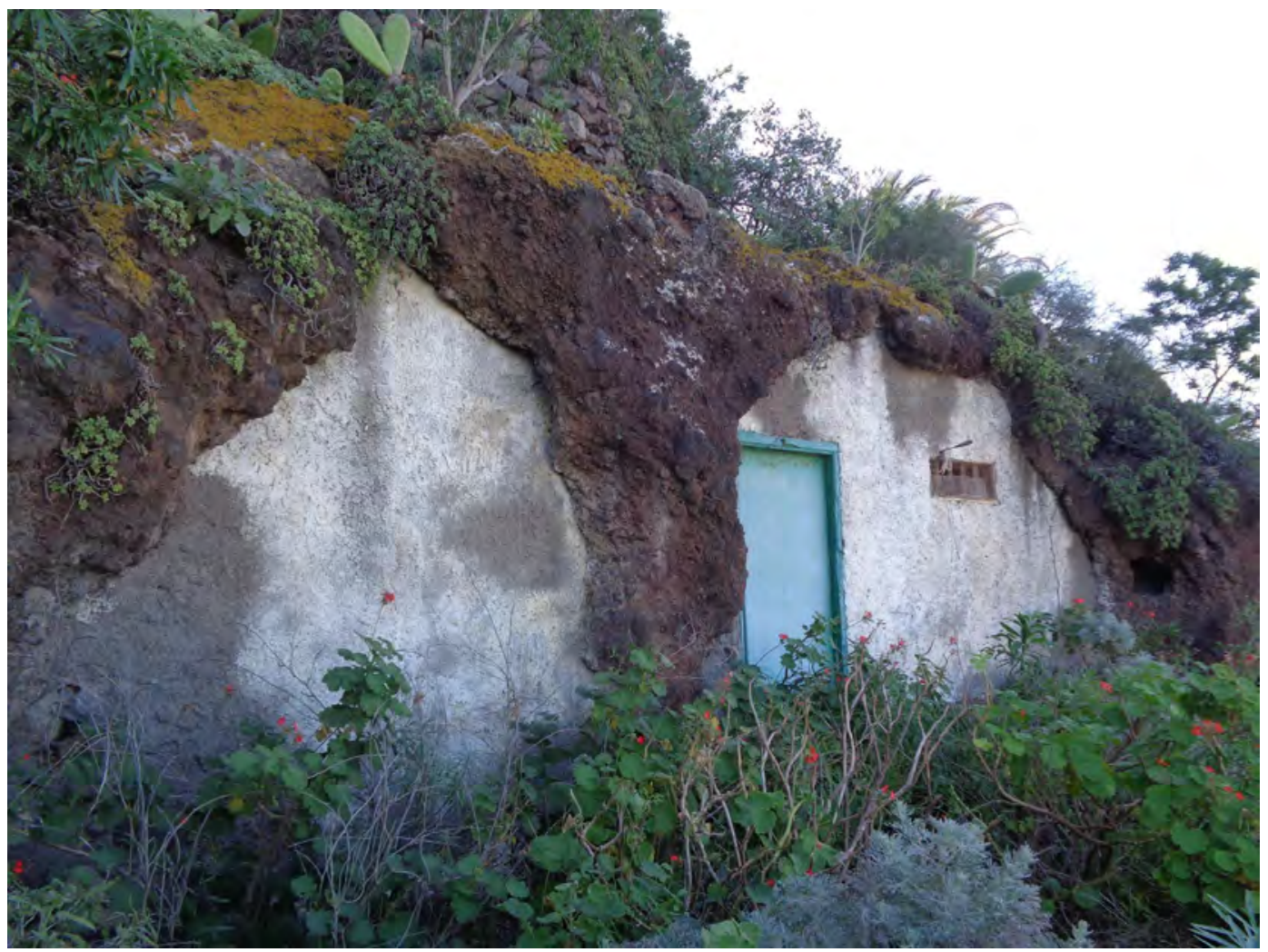

Figura 23. Cueva Zebensui, Punta del Hidalgo

Si observamos la política matrimonial del menceyato de Anaga se aprecia que ni el nuevo menceyato de Tegueste, ni el achimenceyato de punta de Hidalgo, a pesar de su proximidad geográfica, eran barajados para crear una alianza con ellos, lo que apoya una relación de dependencia en el segundo caso y de menor prestigio en el primero. Sobre Anaga se menciona que Guacimara, «hija y sucesora» del mencey ${ }^{147}$, fue ofrecida en matrimonio con unos 20 años, «de los veinte años no he pasado» ${ }^{148}$, a Himenchia, el hermano de Benitomo de Taoro, «te la otorgo en casamiento que quiero que, pues es mi sucesora (...) y sea de mi reino posesora; en ti y en ella» ${ }^{149}$, dentro de una descendencia matrilineal, retomando una antigua alianza, pues todos eran miembros del mismo linaje familiar. «Beneharo, mi rey, señor de Anaga, vuestro pariente (...) y su sobrino, Acaymo Iniaga, que en Tacoronte reina» ${ }^{150}$. En palabras de Himenchia, «Cumplirá su palabra Beneharo, gozaré la princesa [Guacimara] prometida; del gran reino de Anaga seré amparo y en él mi voluntad obedecida; todos me llamarán el rey Tinguaro» ${ }^{151}$. El objetivo final de Benitomo era «si mi hermano sale con la empresa y del reino de Naga se apodera, juntando mi valor con su grandeza, seré absoluto rey» ${ }^{152}$. Sin embargo, inicialmente Benitomo de Taoro había pensado en casarla con su hijo Ruyman con el mismo objetivo, «al príncipe mi hijo sea entregado, como mi sucesor» ${ }^{153}$, que lo hubiese convertido en el futuro mencey de Anaga. Esa debía ser la vía sucesoria más habitual para un hijo de un mencey, ser el marido de la heredera de un menceyato vecino.

Sin embargo, los precedentes en la relación entre Anaga y Taoro eran bastante malos pues habían estado en guerra hasta el mismo año de 1494. Según recoge Viana ${ }^{154}$, «el año de conquista (...) el gran Bencomo (...) poseedor del reino de Taoro, puso treguas a guerras que

147 VIANA (1986 [1604]), p. 109; III.

148 VIANA (1986 [1604]), p. 163; V.

149 VIANA (1986 [1604]), p. 157; V.

150 VIANA (1986 [1604]), p. 100; III.

151 VIANA (1986 [1604]), p. 217; VIII.

152 VIANA (1986 [1604]), p. 159; V.

153 VIANA (1986 [1604]), pp. 103-104; III.

154 VIANA (1986 [1604]), p. 92; III. 
tenía con Acaymo, señor de Tacoronte y Beneharo, viejo rey de Anaga, después de (...) una cruel batalla». Este combate debe de ser el que menciona Bethencourt Alfonso ${ }^{155}$, «una reñida batalla en El Sauzal, en las proximidades del barranco de las Mejías y cerca de la ermita de Los Ángeles por encima de la actual carretera, donde fueron derrotados» los guerreros de Anaga y Tacoronte por los de Taoro, recogida por tradición oral a fines del siglo XIX, o bien a partir de la historia del pueblo guanche redactada por Cristóbal Bencomo, actualmente perdida.

Tegueste y Anaga, según algunos autores, formaron parte con Tacoronte de una alianza que el mencey de Taoro lideraba ${ }^{156}$, «Estaba Beneharo, rey de Naga, con su gente esperando en la laguna aviso del combate de Acentejo», aunque reconoce que Fernández de Lugo avanzó «sin que hallasen gente» pues tanto «el Rey Acaymo y Beneharo (...) con más de tres mil hombres de pelea» habían estado «esperando en la laguna» ${ }^{157}$ para acabar con los que escapasen del ataque en Centejo. En esta espera en La Laguna con 3.000 hombres se incluye también al mencey de Tacoronte en Núñez de la Peña ${ }^{158}$. En este sentido, no hay constancia de que ambos menceyes combatieran en la batalla de la Matanza de Acentejo en mayo de 1494, indicándose que Fernández de Lugo "pasó por el reino de Anaga y de Tacoronte y de Tegueste, sin que le hiciesen resistencia» ${ }^{159}$. Se menciona también un ataque posterior a la batalla de la Matanza, realizado por Haineto, «vasallo del Rey de Anaga», con 400 hombres, contra la torre de Añazo, donde supuestamente murieron 160 guanches y 3 castellanos ${ }^{160}$, incluyendo el propio Haineto ${ }^{161}$. Sin embargo, hay otras dos explicaciones posibles: la primera que Jaineto fuera el mencey de Tacoronte, pues así lo llama Marín de Cubas ${ }^{162}$. Más probable es que se menciona a un capitán Jaineto de Güímar ${ }^{163}$ y cabe la posibilidad de que los de Güímar realizasen el ataque por haber esclavizado a 300 de sus hombres después de la batalla de Acentejo ${ }^{164}$.

En el caso concreto de Anaga, que afectaría a Zebensui, era considerado uno de los bandos de paces en 1494 según indica Fernández de Lugo en 1499 al hablar de esclavos guanches indicando «salvo los de Adexe y Abona y Anaga y Guymar» ${ }^{165}$ y repite Alonso Fernández de Lugo en su Residencia ${ }^{166}$. En la Reformación del Repartimiento de 1506 se indica que

el dicho Adelantado fizo traer ante sí a los guanches del reino de Anaga, en que podían aver entre hombres e mugeres doscientas ánimas, poco más o menos, los quales heran de paces mucho tienpo avían y en la dicha conquista ayudaron a conquistar ${ }^{167}$.

El 1 de mayo de 1494 las tropas castellanas desembarcaron en Santa Cruz de Tenerife por el puerto de los Caballos ${ }^{168}$ o por la caleta de los Negros ${ }^{169}$, aprovechando los acuerdos existentes con el mencey de Anaga para reconstruir la torre, instalando el Real el 3 de mayo, fiesta de la Cruz, «asentó su real e hizo una torre» ${ }^{170}$. Allí vinieron a entrevistarse con Alonso Fernández de Lugo cuatro de los nueve menceyes de la isla, «Acaymo, rey de Güímar y asentó paz con él, y más con el rey de Anaga y con el de Adeje y con el de Abona» ${ }^{171}$.

En la información testifical de Margarita Fernández Guadnarteme se indica con precisión,

155 BÉTHENCOURT ALFONSO (1997 [1912]), p. 55.

156 VIANA (1986 [1604]), p. 241; IX; NÚÑEZ DE LA PEÑA (1994 [1676]), p. 122; I.14; QUESADA Y

CHAVES (2007 [1784]), p. 181.

157 VIANA (1986 [1604]), p. 197; VII

158 NÚÑEZ DE LA PEÑA (1994 [1676]), pp. 125, 131; I.14.

159 ABREU Y GALINDO (1977 [1590-1632]), p. 317; XVIII; ESPINOSA (1980 [1594]), p. 97; III.5.

160 NÚÑEZ DE LA PEÑA (1994 [1676]), pp. 135-136; I.14.

161 VIANA (1986 [1604]), p. 237; VIII.

162 MARÍN DE CUBAS (1986 [1694]), p. 278; II.20.

163 MARÍN DE CUBAS (1986 [1694]), p. 242; II.16.

164 MEDEROS y ESCRIBANO (2007), p. 225.

165 SERRA RÀFOLS (1949), p. $21 \mathrm{n}^{\circ} 116$.

166 ROSA OLIVERA y SERRA RÀFOLS (1949), p. 42.

167 SERRA y ROSA OLIVERA (1953).

168 ROSA OLIVERA y SERRA RÀFOLS (1949), p. 114; TORRIANI (1978 [1592]), p. 291.

169 TORRIANI (1978 [1592]), p. 190.

170 ROSA OLIVERA y SERRA RÀFOLS (1949), p. 113.

171 ABREU Y GALINDO (1977 [1590-1632]), p. 316. 
D. Fernando Guadnarteme por mandato del dicho Adelantado é Capitán fue á donde estaba el Rey de Anaga, Rey Guanche, el cual estaba de paces à le decir y requerir que se viniese á ayuntar con el dicho Adelantado é los cristianos porque se temia de él é que el dicho Guadnarteme fué dos veces al dicho Rey de Naga é entre los Guanches hasta que hizo venir á el dicho Rey de Naga á el Real de los cristianos ${ }^{172}$.

En este sentido, la supuesta locura y senilidad del mencey de Anaga que le atribuye Viana después de la Matanza de Acentejo, pues parece que era el mencey de más edad de los entonces existentes en Tenerife ${ }^{173}$, más parece excusa del reino de Taoro para forzar el matrimonio de la hija del mencey de Anaga, Guacimara, con Himenchia -denominado Tinguaro-, el hermano de Benitomo, desplazarlo del poder e intentar asumir el cargo de mencey de Anaga. Por ello, Benitomo «mandó que en cuanto el viejo Beneharo viviese, no gozasen [Guacimara e Himenchia] el renombre de reyes, y así solo le tuvieron como administradores de justicia» ${ }^{174} \mathrm{y}$ así «Gobierna Tinguaro el reino» ${ }^{175} \mathrm{o}$ «el capitán Tinguaro estaba en el gobierno del quejoso reino» de Anaga ${ }^{176}$, y se mencione que «a la parte de Naga que es territorio de Taoro» ${ }^{177}$. No obstante, Himenchia ya tenía una pareja previa en Taoro, «Guajara; servía como amante a (...) el gran Tinguaro» ${ }^{178}$, que pasaría a ser un cucaha, esposa no principal, al poder ser las élites poligámicas ${ }^{179}$. Estas fricciones explican que después de la batalla de Acentejo «los fuertes soldados de Tinguaro andaban en combate a golpes crudos con los que eran de guardia del rey Naga (...) por ser cosa propia de taorinos hacer mala amistad con los de Naga ${ }^{180}$.

En la batalla de La Laguna, en noviembre de 1495, aparecen claramente los representantes del menceyato de Tegueste y del achimenceyato de punta del Hidalgo, ambos hermanos, apoyando a Tacoronte y Taoro. Se dividieron «en tres escuadras, dándoles la una a Tinguaro y al rey de Tacoronte [Acaymo], la otra a Zebensui y el gran Tegueste, y la tercera» se la quedó Bencomo ${ }^{181}$. Todos lucharon, «rompe Bencomo, hiere el gran Tinguaro, Tegueste embiste, Zebensui maltrata, Acaymo ofende» ${ }^{182}$. La mención de las tropas que aporta cada uno es interesante para valorar la importancia de cada menceyato: Anaga aportaba 2.600 hombres; Tacoronte, 2.000; Tegueste, 1.200 y Zebensui de punta del Hidalgo, 250 hombres ${ }^{183}$.

Tanto Zebensui como el mencey de Tegueste salieron vivos con buena parte de sus tropas de la batalla de La Laguna, pues Viana ${ }^{184}$ comenta que movilizaron a 1.200 hombres controlando el paso de las Peñuelas para evitar una incursión de los castellanos para saquear ganado poco después. Eran básicamente las tropas que ambos habían llevado a la batalla de La Laguna, «Tegueste y Zebensúi con mil» ${ }^{185}$, por lo que o bien el peso de los combates en La Laguna correspondió a tropas de Taoro, o bien el episodio se desarrolló antes de la batalla. En el combate de las Peñuelas se dice que murieron 90 guanches y 12 castellanos ${ }^{186}$.

El caso de Anaga es más complejo pues, aunque se supone que es aliado de Taoro ${ }^{187}$, realmente no intervino en la batalla, sino que su función fue controlar la retirada de los castellanos si eran derrotados, por lo que se situó en San Roque para vigilar el barranco de la Carnicería, «el rey de Naga con la gente que les seguía, que eran mil soldados» ${ }^{188}$, reducidas a

172 TREJO Y CARVAJAL (1891 [1526]), p. 215.

173 NÚÑEZ DE LA PEÑA (1994 [1676]), p. 121; I.14.

174 VIANA (1986 [1604]), pp. 258-259; IX.

175 VIANA (1986 [1604]), p. 241; IX.

176 VIANA (1986 [1604]), p. 267; X.

177 MARÍN DE CUBAS (1986 [1694]), p. 246; II.16.

178 VIANA (1986 [1604]), p. 124; IV.

179 BÉTHENCOURT ALFONSO (1991 [1912]), p. 243.

180 VIANA (1986 [1604]), p. 249; IX.

181 VIANA (1986 [1604]), p. 304; XII.

182 VIANA (1986 [1604]), p. 307; XII.

183 NÚÑEZ DE LA PEÑA (1994 [1676]), p. 142; I.15.

184 VIANA (1986 [1604]), p. 338; XIII; NÚÑEZ DE LA PEÑA (1994 [1676]), p. 154; I.15.

185 VIANA (1986 [1604]), p. 281; XI.

186 NÚÑEZ DE LA PEÑA (1994 [1676]), p. 155; I.15.

187 VIANA (1986 [1604]), p. 281; XI; NÚÑEZ DE LA PEÑA (1994 [1676]), p. 142; I.15; ÁLVAREZ

DELGADO (1961), p. 25.

188 VIANA (1986 [1604]), p. 304; XII. 
300 o 400 hombres por Espinosa ${ }^{189}$, sin precisar menceyato. Este autor reconoce que en la batalla de La Laguna sólo «los de Tegueste, Tacoronte y Taoro habían llevado lo peor e iban de huida ${ }^{190}$. La supuesta intervención de los de Anaga se ciñe a una escaramuza con una partida de 12 castellanos que llevaban 7 heridos al real de Añazo, donde la principal motivación fue enterarse el mencey del resultado de la batalla ${ }^{191}$ y un posterior ataque al Real de Añazo con tropas no cuantificadas y sin participación del mencey ${ }^{192}$.

En cambio, el único enfrentamiento que Núñez de la Peña ${ }^{193}$ recoge resulta más lógico porque fue debido a una incursión de rapiña de ganado dentro del menceyato de Anaga, enfrentándose el mencey «por el atrevimiento que han tenido de entrar en mi Reyno». Es interesante que pese a su edad y supuesta enfermedad combatió contra ellos perdiendo presuntamente 70 hombres e incluso para escapar «tuvo por mejor dar un asalto la tierra abaxo, a riesgo de matarse, que entregarse».

El dato de Anaga es aún más contradictorio porque poco antes de la batalla de La Laguna, Viana menciona que los de Anaga estaban a las órdenes de «Tinguaro con tres mil» guerreros ${ }^{194}$, que luego se convierten en $1000^{195}$. Para justificar la llegada de estas tropas con el mencey de Anaga, Viana considera que «el rey de Naga (...) sanó de su locura». En cambio, según otros autores, «el de Anaga (...) no vino con ellos, por hallarse con una grave enfermedad» ${ }^{196}$. Si tenemos en cuenta el intento del hermano del mencey de Taoro de desplazar del poder al mencey de Anaga que relata Viana, difícilmente a Beneharo, futuro D. Fernando de Anaga, le interesaría una victoria de Benitomo en la batalla de La Laguna, aunque es posible que algunos guerreros de Anaga bajo el mando del hermano o hermanastro del mencey de Taoro, Himenchia, colaborasen en la resistencia.

No suele mencionarse que pudo haber un enfrentamiento posterior a la Victoria de Acentejo, pues volviendo Lugo «a Santa Cruz, hallò a el Rey de tacoronte, y Tegueste, que lo esperaban en la cuesta de la Matanza; en donde se dio otra batalla, llevando tambien la misma victoria (...) y hubo una numerosa mortandad de Barbaros» ${ }^{197}$. En este sentido, aunque lo contradicen otras fuentes, Viana sugiere que en la batalla de la Victoria de Acentejo murieron Acaymo, mencey de Tacoronte, y su hermano Badeñol ${ }^{198}$ y también Tegueste y su hermano Zebensui ${ }^{199}$. En cualquier caso, es posible que en una de estas dos batallas cayese la mayor parte de las tropas de Tegueste y punta del Hidalgo que no habían sido muy dañadas en la batalla de La Laguna.

Por esta razón, después de la derrota de los guanches en La Victoria de Acentejo, Viana considera que los supervivientes se refugiaron en la Sierra de Tigaiga sólo encabezados por Bencomo de Taoro y Beneharo de Anaga ${ }^{200}$. Otros autores, en cambio, incluyen a los menceyes de Taoro, Tacoronte, Tegueste, Anaga, más Zebensui de punta del Hidalgo ${ }^{201}$, cuatro menceyes que también menciona Quesada ${ }^{202}$. Mientras que otros lo reducen a los menceyes de Taoro y Tacoronte, junto con Zembesuy o Zegenseyas «señor de Punta del Hidalgo» ${ }^{203}$, pero no menciona al mencey de Tegueste, que había participado en la batalla de La Laguna, ni al mencey de Anaga.

Los cronistas defienden que un ejército con los menceyes de Taoro, Tacoronte, Tegueste y Anaga, todos del norte y noreste de la isla, pactaron un acuerdo a cambio de mantener su libertad, como gozaba el antiguo guanarteme de Gáldar, condiciones que aceptó Fernández de

189 ESPINOSA (1980 [1594]), p. 108; III.8.

190 ESPINOSA (1980 [1594]), p. 109; III.8.

191 VIANA (1986 [1604]), pp. 316-317; XII.

192 VIANA (1986 [1604]), pp. 317-318; XII.

193 NÚÑEZ DE LA PEÑA (1994 [1676]), pp. 156-157; I.15.

194 VIANA (1986 [1604]), p. 281; XI.

195 VIANA (1986 [1604]), p. 304; XII.

196 NÚÑEZ DE LA PEÑA (1994 [1676]), pp. 142 y 150; I.15.

197 QUESADA Y CHAVES (2007 [1784]), p. 188.

198 VIANA (1986 [1604]), p. 355; XIV.

199 VIANA (1986 [1604]), p. 357; XIV.

200 VIANA (1986 [1604]), p. 377; XV.

201 NÚÑEZ DE LA PEÑA (1994 [1676]), p. 163; I, 16; VIERA Y CLAVIJO (1967-71 [1776-83]), p. 660; IX.19.

202 QUESADA Y CHAVES (2007 [1784]), p. 191.

203 CASTILLO Y RUIZ DE VERGARA (2001 [1737]), pp. 184, 189. 
Lugo el 25 de julio de 1496, Santiago Apóstol y San Cristóbal ${ }^{204}$, una fecha que primero propone Viana ${ }^{205}$, pero al solo presuponer que sobrevivían Bencomo y Beneharo ${ }^{206}$, no menciona ni a Acaymo ni a Tegueste.

Según algunas propuestas, una vez producida la rendición, entre agosto y septiembre de 1496, los menceyes de Taoro y Anaga se dedicaron junto con tropas castellanas a reducir a los alzados que no aceptaron el acuerdo en cada uno de sus menceyatos, «Bencomo y Beneharo pacifican la isla» ${ }^{207}$, que Bethencourt Alfonso amplía al mencey de Tacoronte ${ }^{208}$. En cambio, según otros autores, fueron los menceyes de Anaga y Tegueste los que estuvieron reduciendo a los alzados, y así «en las tierras de Zebensui auia otros Guanches rebeldes, que apaciguò el Rey de Tegueste» ${ }^{209}$ pues 30 guanches y 30 castellanos consiguieron rendir a un grupo después de 3 muertos y 7 heridos ${ }^{210}$.

Dos meses después, el 29 de septiembre, Arcángel San Miguel, se presentó en Tigaiga un nuevo ejército con los menceyes de Icode, Dabte, Adexe y Abona, del noroeste, este y suroeste de la isla, quienes aceptaron también la sumisión a los Reyes Católicos ${ }^{211}$.

En el caso de Zebensui parece que no se rindió con los otros menceyes pues previamente abandonó la sierra de Tigaiga y se mantuvo resistiendo al menos «hasta Enero de 1497» pues entre «los Rebeldes y sublevados (...) siendo uno el Hidalgo que estava en las altas sierras de su estado en la Punta de su nombre, entre los Reynos de Tegueste, y Anaga» ${ }^{212}$. Uno de sus puntos de refugio se ha sugerido que fue en la fortaleza de Tegmoseque o montaña de Tejina ${ }^{213}$. Es posible que en su rendición participase el mencey de Anaga, pues

muchos rebeldes naturales se resistían en un alto risco del término de Naga, adonde llaman, por esta causa antigua, Fortaleza. Mas Beneharo, el rey, con cien soldados fue a remediar tal daño y conducirlos; y así, como llegó y lo conocieron, se dieron sin batalla y bajaron del risco, demandando perdón ${ }^{214}$.

El mencey de Tegueste, una vez que fue a Almazán (Soria) en el verano de 1496, fue bautizado delante de los Reyes Católicos y debió de recibir el trato de don. Bien el propio mencey, bien su hijo, aparece en los protocolos notariales de Tenerife a partir de 1509. Ante el escribano Sebastián Páez toma en renta, junto con don Pedro de Tacoronte, de 60 puercas de Gonzálo del Castillo durante 4 años, recibiendo el trato de don Juan de Tegueste ${ }^{215}$. En la contratación interviene un traductor, Francisco de Tacoronte, lo que indica que aún no sabía el castellano, y hace más probable que se trate del propio mencey.

\section{CONCLUSIONES}

La información arqueológica sobre el municipio de La Laguna es mucho más pobre que otros municipios inmediatos, caso de Tegueste. Aunque se ha realizado la excavación de 4 cuevas sepulcrales con numerosos enterramientos, 10 en Las Goteras (1933), 50 en El Becerril (1944), 24 en Milán (1946) y 15 en La Palmita (1952), corresponden en los tres últimos casos a la etapa inicial de Diego Cuscoy y carecemos que cualquier tipo de plano o distribución en planta o nivel y un análisis individualizado por enterramiento o espacio sepulcral que nos aporte información significativa. Por otra parte, de estas amplísimas series antropológicas depositadas

204 NÚÑEZ DE LA PEÑA (1994 [1676]), pp. 163-165; QUESADA Y CHAVES (2007 [1784]), pp. 191-192;

VIERA Y CLAVIJO (1967-71 [1776-83]), p. 661; IX.20.

205 VIANA (1986 [1604]), p. 360; X; MARÍN DE CUBAS (1986 [1694]), p. 247; II.16.

206 VIANA (1986 [1604]), p. 377; XV.

207 VIANA (1986 [1604]), p. 381; XVI.

208 BETHENCOURT ALFONSO (1997 [1912]), pp. 159-160.

209 NUÑEZ DE LA PEÑA (1994 [1676]), p. 166; I, 16.

210 VIANA (1986 [1604]), pp. 382, 384; XVI.

211 NÚÑEZ DE LA PEÑA (1994 [1676]), pp. 166-168; QUESADA Y CHAVES (2007 [1784]), pp. 192-193.

212 QUESADA Y CHAVES (2007 [1784]), p. 194.

213 BETHENCOURT ALFONSO (1997 [1912]), p. 160.

214 VIANA (1986 [1604]), p. 382; XVI.

215 CEBRIÁN LATASA (2001b), p. xviii. 
en el Museo Arqueológico de Tenerife, solo hay una datación de la cueva de La Palmita en comparación con las 11 procedentes de Tegueste ${ }^{216}$ y salvo estudios de la serie de Las Goteras no ha habido una atención detallada desde un punto de vista bioantropológico. Respecto a las cuevas de habitación, sólo se ha excavado una campaña en El Calabazo (1985) y, aunque existe un estudio preliminar ${ }^{217}$, el único nivel intacto aborigen era el inferior y fue localizado en una superficie pequeña.

Nuestro objetivo principal ha sido presentar un estudio en conjunto del poblamiento y distribución de manifestaciones rupestres en el municipio. Para ello se ha tratado de correlacionarlo en lo posible con el primer inventario elaborado, el Inventario del Patrimonio Arqueológico de las Canarias Occidentales en 1989, encargado por el Gobierno de Canarias, cuyas numeraciones se han incorporado cuando existe coincidencia para facilitar cualquier futura consulta, aunque en dicho inventario se hacían fichas colectivas que agrupaban a veces bajo un mismo número varias cuevas de habitación y sepulcrales, y en ocasiones no se accedía a alguna de las cuevas de más difícil emplazamiento. Este trabajo ha tenido continuación a veces en zonas concretas, como el Inventario Arqueológico de la margen izquierda del Barranco de Agua de Dios (Tejina, San Cristóbal de La Laguna) en 2003, por parte de la Universidad de La Laguna y el Ayuntamiento de La Laguna. Posteriormente, con el Inventario del Patrimonio Cultural del Área Metropolitana, en 2008 del Cabildo de Tenerife, que incorporó también yacimientos de interés etnográfico o arquitectónico y finalmente con las últimas prospecciones en el barranco de Milán en 2018, de nuevo patrocinadas por el Ayuntamiento de La Laguna, entre otros. Se trata, en su práctica totalidad, de documentos internos de las administraciones que nunca se han publicado, con solapamiento de estudios por la insuficiente circulación de la información entre estas administraciones, por lo que cada una acaba encargando un estudio propio, Gobierno de Canarias, Cabildo Insular de Tenerife y, más recientemente, el Ayuntamiento de La Laguna, siempre dentro de una orientación de la investigación básicamente patrimonial para su ubicación en un SIG y en los PGOU.

Aunque ciertamente la antigua laguna y su entorno fue un área de pastoreo en época aborigen, como señala Viana ${ }^{218}$, los actuales límites del municipio de La Laguna se integran en el territorio del antiguo menceyato de Tegueste, que inicialmente debió de ser un achimenceyato que alcanzaba los límites naturales de la cadena montañosa de Las Mercedes-Mesa Mota-El Púlpito-Guamasa, dependiente de Tacoronte si aceptamos a Viana ${ }^{219}$, que se había independizado hacía 2 o 3 generaciones, y se mantenía independiente desde que se firmó el acta del Bufadero en $1464^{220}$ en la costa de Anaga de María Jiménez, como recogen las datas de Tenerife ${ }^{221}$.

En el nuevo menceyato se integró también otro achimenceyato de Aguere que alcanzaba hasta la costa de Santa Cruz y cuyo control político pudo oscilar entre Tacoronte y Anaga, pero que eran aliados en el momento de la conquista al estar enfrentados a Taoro ${ }^{222}$. Tampoco cabe descartar a Güímar por disputarse zonas actualmente en el municipio de El Rosario, contra el cual tuvo también enfrentamientos antes de la conquista. Su creación reciente ayuda a explicar que no haya una tradición clara a una cueva o aunchón del mencey de Tegueste, aunque sabemos que residía en Tejina ${ }^{223}$ en el momento de la conquista.

En cambio, punta del Hidalgo y su achimencey Zebesui dependían del menceyato de Anaga $^{224}$ y su cueva y tagoro se ubicaba en la Hoya del Uchón en el caserío de La Hoya de punta del Hidalgo ${ }^{225}$.

Si analizamos la distribución del poblamiento en el municipio de La Laguna claramente está vinculada a los espacios que han sido menos antropizados y refleja un patrón muy parecido al de

216 MEDEROS, ESCRIBANO y VALENCIA (2015), pp. 13-14 tabla 3.

217 VALENCIA y ÁLAMO (2011).

218 VIANA (1986 [1604]), p. 276; X

219 VIANA (1986 [1604]), p. 267; X.

220 PÉREZ DE CABITOS, E. (1990 [1476-77]), p. 274.

221 SERRA RÀFOLS (1978), nº 832-11.

222 VIANA (1986 [1604]), p. 92; III.

223 VIANA (1986 [1604]), p. 337; XIII.

224 VIANA (1986 [1604]), pp. 267, 275; X.

225 BÉTHENCOURT ALFONSO (1994 [1911]), p. 111. 
la comarca de Acentejo ${ }^{226}$. Las zonas con mayor representación de yacimientos es el litoral de valle Guerra, Bajamar y punta del Hidalgo, a veces aprovechando zonas acantiladas junto a la costa donde se utilizan cuevas de habitación y funerarias, zonas de clima más templado, en pisos con vegetación de tabaibal (Euphorbia balsamifera) y cardonal (Euphorbia canariensis). Escasean, en cambio, los concheros, que presentan principalmente lapas -Patella sp.- y burgados -Osilinus atratus-, por los usos actuales del litoral.

\begin{tabular}{|c|c|c|c|c|c|}
\hline Sector & $\begin{array}{c}\text { cueva } \\
\text { habitación }\end{array}$ & $\begin{array}{c}\text { cueva } \\
\text { sepulcral }\end{array}$ & $\begin{array}{c}\text { cabaña o } \\
\text { material } \\
\text { superficie }\end{array}$ & $\begin{array}{c}\text { grabados o } \\
\text { cazoletas y } \\
\text { canales } \\
\end{array}$ & concheros \\
\hline Punta de la Romba, valle Guerra & - & 3 & - & - & 1 \\
\hline Finca del Apio, valle Guerra & 1 & - & - & - & - \\
\hline $\begin{array}{l}\text { Punta de la Baja Izquierda, valle } \\
\text { Guerra }\end{array}$ & 2 & 1 & - & - & - \\
\hline Barranco Chamorro, valle Guerra & 2 & - & - & - & - \\
\hline El Calabazo, valle Guerra & 1 & 2 & - & - & - \\
\hline $\begin{array}{l}\text { Barranco de las Cuevas, valle } \\
\text { Guerra }\end{array}$ & 1 & - & - & - & - \\
\hline $\begin{array}{l}\text { Punta de la Barranquera, valle } \\
\text { Guerra }\end{array}$ & 3 & 1 & - & - & - \\
\hline La Caleta, valle Guerra & 1 & 1 & - & - & - \\
\hline Barranco del Horno, valle Guerra & 2 & 1 & - & - & - \\
\hline Playa del Roquillo, valle Guerra & 3 & 1 & 1 & - & - \\
\hline Punta del Jurado, valle Guerra & 3 & - & - & - & - \\
\hline Punta del Guincho, valle Guerra & 1 & 1 & - & - & - \\
\hline Punta del Fraile, Tejina & - & 1 & - & - & - \\
\hline Lomo del Cardón, valle Guerra & - & 1 & - & 1 & - \\
\hline El Bucio, pico de los Lázaros & - & - & - & 1 & - \\
\hline Pico Bermejo, Tejina & 1 & - & - & 3 & - \\
\hline Cueva de la Palmita, Tejina & - & 1 & - & - & - \\
\hline \multicolumn{6}{|l|}{ Barranco de las Cuevas, Jover } \\
\hline Barranco de las Cuevas, Tejina & 1 & - & - & - & - \\
\hline \multicolumn{6}{|l|}{ Barranco Bajo de Milán } \\
\hline \multicolumn{6}{|l|}{ Barranco de Milán, Jurada } \\
\hline Barranco de Milán, Tejina & 2 & - & - & - & - \\
\hline Barranco de Milán, Manisero & & 5 & & & \\
\hline Barranco de Milán, & 5 & & & & \\
\hline Barranco de Milán, & 2 & & & & \\
\hline Barranco de Milán, Pilones & 4 & 1 & & & \\
\hline Las Goteras, Bajamar & - & 2 & - & - & - \\
\hline Barranco de la Goleta, Bajamar & 3 & - & - & - & - \\
\hline Barranco de la Goleta, Bajamar & 5 & 1 & - & - & - \\
\hline La Hoya, punta del Hidalgo & 1 & - & - & - & - \\
\hline $\begin{array}{l}\text { Dos Hermanos, punta del } \\
\text { Hidalgo }\end{array}$ & - & - & - & 2 & - \\
\hline $\begin{array}{l}\text { Barranco del Río, punta del } \\
\text { Hidalgo }\end{array}$ & - & 2 & - & - & - \\
\hline Monte de San Diego & - & - & - & 1 & - \\
\hline La Verdellada & - & - & - & 1 & - \\
\hline Gracia, Barranco Guajara & - & - & - & 1 & - \\
\hline Valle Colino & - & - & 1 & - & - \\
\hline Risco Negro, Finca España & - & - & - & 1 & - \\
\hline $\begin{array}{l}\text { Pico de Cho Canino, La } \\
\text { Higuerita }\end{array}$ & - & - & 1 & - & - \\
\hline $\begin{array}{l}\text { Pico de la fuente del Lomo, } \\
\text { Finca España }\end{array}$ & - & - & 1 & 1 & - \\
\hline
\end{tabular}




\begin{tabular}{|l|c|c|c|c|c|}
\hline Gonzalianez, valle de las Chozas & - & - & - & 1 & - \\
\hline Pico el Canario & - & - & - & 1 & - \\
\hline Chinamada & - & - & - & 2 & - \\
\hline $\begin{array}{l}\text { Montaña de Guerra, valle } \\
\text { Jiménez }\end{array}$ & 1 & 2 & - & - & - \\
\hline El Becerril, barranco de Santos & $\dot{\complement} ?$ & 1 & - & - & - \\
\hline Lomo Tamé & - & - & - & 1 & - \\
\hline Total & 45 & 28 & 4 & 17 & 1 \\
\hline
\end{tabular}

Tabla 2. Tipos de yacimientos en el municipio de La Laguna.

A ellos se suma el cauce de algunos barrancos, como el de las Cuevas de Tejina, el de Milán que es la prolongación del barranco de Agua de Dios y como sucede en Tegueste es el principal núcleo de hábitat y funerario, el barranco de la Goleta en Bajamar o el barranco del Río o del Tomadero en punta del Hidalgo. Aunque los cauces de los barrancos aportaban el agua necesaria, tanto con corriente permanente, como cuando se obtenía de eres en el fondo de sus cauces, bien naturales sobre roca donde se retenía el agua, bien excavando en su cauce, su conservación también depende de lo escarpado de sus paredes que ha ayudado a conservar los yacimientos funerarios o de habitación, a lo que se suma el actual abandono de su uso agrícola lo que ha propiciado su ocultamiento por la vegetación en la vertiente de solana donde hay más cuevas de habitación y en la vertiente de umbría o pequeñas grietas con usos principalmente funerarios (figura 24).

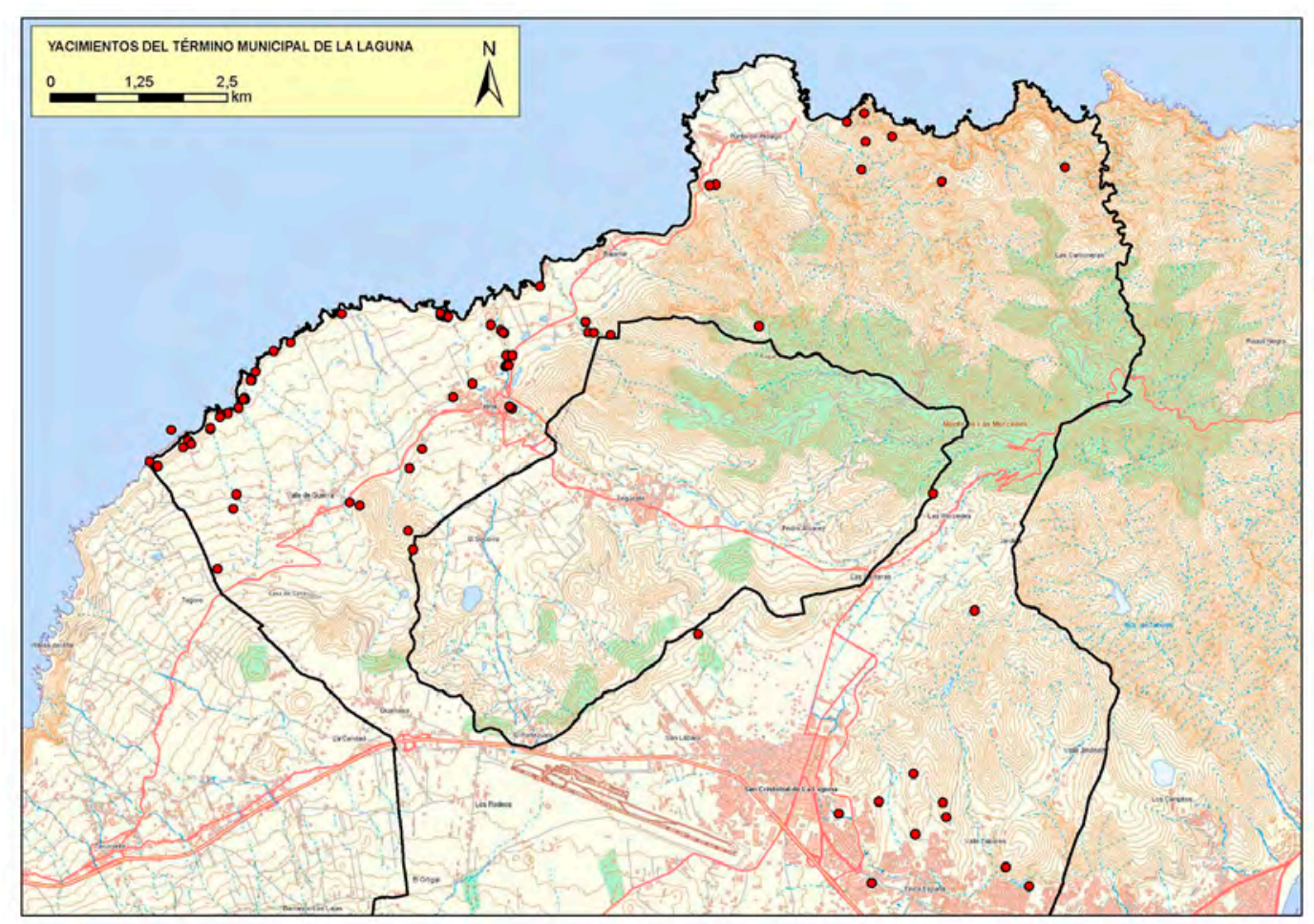

Figura 24. Mapa con la distribución de los yacimientos en el municipio de La Laguna.

Finalmente, queremos señalar que en este trabajo no incluimos las numerosas estaciones de grabados rupestres de Geneto y Los Baldíos por falta de espacio, muchos de ellos actualmente reutilizados en paredes de caminos, que serán tratados en un futuro trabajo monográfico. 


\section{REFERENCIAS}

ABREU y GALINDO, A. de (1977 [1590-1632]). Historia de la conquista de las siete islas de Canaria. En CIORANESCU, A. (ed.). Tenerife: Goya Ediciones.

ALMAGRO GORBEA, M. (1970). «Las fechas del C-14 para la Prehistoria y la Arqueología peninsular». Trabajos de Prehistoria, núm. 27, pp. 9-43.

ALONSO RODRÍGUEZ, Ma . R. (2000 [1944]). «La cueva de Zebensui». Un rincón tinerfeño. Punta del Hidalgo. La Laguna: Ayuntamiento de La Laguna, pp. 47-56.

ÁLVAREZ DELGADO, J. (1947a). Excavaciones arqueológicas en Tenerife (Canarias). Plan Nacional 1944-1945. Madrid: Informes y Memorias, 14. Comisaría General de Excavaciones Arqueológicas. Ministerio de Educación Nacional.

ÁLVAREZ DELGADO, J. (1947b). «La necrópolis guanche del Becerril [La Laguna]». Excavaciones arqueológicas en Tenerife (Canarias). Plan Nacional 1944-1945. Madrid: Informes y Memorias, 14. Comisaría General de Excavaciones Arqueológicas. Ministerio de Educación Nacional, pp. 60-69.

ÁLVAREZ DELGADO, J. (1947c). «Habitaciones y necrópolis guanches del litoral. De la Punta del Viento a la Punta de la Barranquera [Tacoronte]». Excavaciones arqueológicas en Tenerife (Canarias). Plan Nacional 1944-1945. Madrid: Informes y Memorias, 14. Comisaría General de Excavaciones Arqueológicas. Ministerio de Educación Nacional, pp. 71-85.

ÁLVAREZ DELGADO, J. (1947d). «El poblado del Barranco Milán (Tejina, La Laguna, isla de Tenerife)». Excavaciones arqueológicas en Tenerife (Canarias). Plan Nacional 19441945. Madrid: Informes y Memorias, 14. Comisaría General de Excavaciones Arqueológicas. Ministerio de Educación Nacional, pp. 140-156.

ÁLVAREZ DELGADO, J. (1959). «La Conquista de Tenerife. Un reajuste de datos hasta 1496». Revista de Historia Canaria, núm. 25 (127-128), pp. 169-196.

ÁLVAREZ DELGADO, J. (1960). «La Conquista de Tenerife. Un reajuste de datos hasta 1496». Revista de Historia Canaria, núm. 26 (129-130), pp. 71-93 y núm. 26 (131-132), pp. 245-297.

ÁLVAREZ DELGADO, J. (1961). «La Conquista de Tenerife. Un reajuste de datos hasta 1496». Revista de Historia Canaria, núm. 27 (133-134), pp. 6-65.

ÁLVAREZ DELGADO, J. (1985). «La división de la isla de Tenerife en nueve reinos». Anuario de Estudios Atlánticos, núm. 31, pp. 265-341.

ARCO AGUILAR, $\mathrm{M}^{\mathrm{a}}$. del C. del (1976). «El enterramiento canario prehispánico». Anuario de Estudios Atlánticos, núm. 22, pp. 13-124.

ARCO, Mª . del C. del; GONZÁLEZ ANTÓN, R.; ARCO, M. del; ROSARIO ADRIÁN, C.; RODRÍGUEZ MARTÍN, C. y MARTÍN OVAL, M. (1999). Los guanches desde la arqueología. Tenerife: Museo de la Naturaleza y el Hombre-Instituto Canario de Bioantropología. Cabildo de Tenerife.

ARCO, Ma . del C. del; GONZÁLEZ ANTÓN, R.; BALBÍN, R. de; BUENO, P.; ROSARIO ADRIÁN, C.; ARCO, Mª M. del y GONZÁLEZ GINOVÉS, L. (2000a). «Tanit en Canarias. Iconografía». En JORGE, V. O. (ed.). $3^{\text {er }}$ Congresso de Arqueología Penínsular (Vila Real, 1999). 4. Pré-história Recente da Peninsula Iberica. Porto: Adecap, pp. 599-612.

ARCO, Ma . del C. del; GONZÁLEZ ANTÓN, R.; BALBÍN, R. de; BUENO, P.; ROSARIO ADRIÁN, C.; ARCO, M. del y GONZÁLEZ GINOVÉS, L. (2000b). «Tanit en Canarias». Eres (Arqueología), núm. 9 (1), pp. 43-65.

ARNAY, M.; GARCÍA PÉREZ, A. Mª; GONZÁLEZ REIMERS, E. y AFONSO VARGAS, J. A. (2011). «Los materiales antropológicos procedentes del Barranco de Agua de Dios (Tegueste) depositados en el Instituto Cabrera Pinto: un recurso para la investigación y la enseñanza». En SOLER, J., PÉREZ CAAMAÑO, F. y RODRÍGUEZ, T. (eds.). Excavaciones en la Memoria. Estudio historiográfico del Barranco de Agua de Dios y de la Comarca de Tegueste (Tenerife). Tenerife: Gobierno de Canarias-Ayuntamiento de Tegueste, pp. 169-201.

BELLO LEÓN, J. M. (2015). Los protocolos notariales de los escribanos de Tenerife Sebastián Páez y Antón de Vallejo (Años 1505-1506). La Laguna: Fontes Rerum Canariarum, 49. Instituto de Estudios Canarios. 
BERTHELOT, S. (1839). Histoire Naturelle des Îles Canaries. Tome I. Partie 2. Miscellanées canariennes. Paris: Béthune et Plon.

BERTHELOT, S. (1980 [1839]). Primera estancia en Tenerife (1820-1830). Tenerife: Cabildo Insular de Tenerife-Instituto de Estudios Canarios.

BÉTHENCOURT ALFONSO, J. (1991 [1912]). Historia del Pueblo Guanche. I. Su origen, caracteres etnológicos, históricos y lingüísticos. En FARIÑA, M. A. (ed.). La Laguna: Francisco Lemus editor.

BÉTHENCOURT ALFONSO, J. (1994 [1912]). Historia del Pueblo Guanche. II. Etnografía y Organización socio-política. En FARIÑA, M. A. (ed.). La Laguna: Francisco Lemus editor.

BETHENCOURT ALFONSO, J. (1997 [1912]). Historia del Pueblo Guanche. III. La conquista de las Islas Canarias. En FARIÑA, M. A. (ed.). La Laguna: Francisco Lemus editor.

CASTILLO y RUIZ DE VERGARA, P. A. del (2001 [1737]). Descripción histórica y geográfica de las Islas Canarias. En BÉTHENCOURT MASSIEU, A. DE (ed.). TenerifeLas Palmas: Conde de la Vega Grande de Guadalupe.

CEBRIÁN LATASA, J.A. (1996). «Revisando la Historia de Canarias». Estudios Canarios, núm. 41, pp. 355-395.

CEBRIÁN LATASA, J.A. (2001a). «Supervivencia guanche en el término jurisdiccional de Tacoronte (I)». El Mundo, 10-11-2001. Aislados, artes y letras del archipiélago, núm. 121, pp. xv-xviii.

CEBRIÁN LATASA, J.A. (2001b). «Supervivencia guanche en el término jurisdiccional de Tegueste (I)». El Mundo, 14-9-2001. Aislados, artes y letras del archipiélago, núm. 113, pp. xv-xviii.

CIORANESCU, A. (1977). Historia de Santa Cruz de Tenerife. I. 1494-1803. Caja General de Ahorros de Santa Cruz de Tenerife. Tenerife.

CRANE, H.R. y GRIFFIN, J. B. (1968). «University of Michigan Radiocarbon Dates XII», Radiocarbon, núm. 10 (1), pp. 61-114.

DIEGO CUSCOY, L. (1941). «El collar de las cuentas de barro». En DIEGO CUSCOY,

L. Entre Pastores y Ángeles. Tenerife: Ediciones Escuela Azul, pp. 40-47.

DIEGO CUSCOY, L. (1944). «Adornos de los guanches. Las cuentas de collar». Revista de Historia Canaria, núm. 10 (66), pp. 117-124.

DIEGO CUSCOY, L. (1953). Nuevas excavaciones arqueológicas en las Canarias Occidentales. Yacimientos de Tenerife y La Gomera (1947-1951). Madrid: Informes y Memorias, 28. Comisaría General de Excavaciones Arqueológicas. Ministerio de Educación Nacional.

DIEGO CUSCOY, L. (1964). Una Cueva Sepulcral del Barranco del Agua de Dios en Tegueste (Tenerife). Madrid: Excavaciones Arqueológicas en España, 23. Ministerio de Educación y Ciencia.

DIEGO CUSCOY, L. (1968). Los Guanches. Vida y cultura del primitivo habitante de Tenerife. Tenerife: Publicaciones del Museo Arqueológico de Tenerife, 7.

DIEGO CUSCOY, L. (1971). Gánigo. Estudio de la cerámica de Tenerife. Tenerife: Publicaciones del Museo Arqueológico de Tenerife, 8.

DIEGO CUSCOY, L. (2011). "Resultados de las últimas campañas arqueológicas desarrolladas en la isla de Tenerife. Escondrijos, paraderos pastoriles y cuevas sepulcrales [1952-1954]. 5. La cueva sepulcral de La Palmita (Tejina, La Laguna)», en MEDEROS, A. y ESCRIBANO, G. Julio Martínez Santa-Olalla, Luis Diego Cuscoy y la Comisaría Provincial de Excavaciones Arqueológicas de Canarias Occidentales (1939-1955). Sevilla-Tenerife: Canarias Arqueológica Monografías, 5. Museo Arqueológico de Tenerife, pp. 555-568.

ESPINOSA MONTEMAYOR, A. de (1980 [1594]). Historia de Nuestra Señora de Candelaria. [Del origen y milagros de la Santa Imagen de nuestra Señora de Candelaria, que apareció en la Isla de Tenerife, con la descripción de esta Isla]. En CIORANESCU, A. (ed.). Tenerife: Goya Ediciones.

FAJARDO SPÍNOLA, F. (1995). Historia del Instituto de Canarias. Tenerife: Centro de la Cultura Popular Canaria. 
FANTAR, M. (1985). «Adir, Addir». En CAMPS, G. (ed.). Encyclopédie Berbère. I. AdAguh-n-Tahlé. Aix-en-Provence: Edisud, pp. 127-129.

GARCÍA BARBUZANO, D. (1983). El asentamiento guanche de El Calabazo. Valle Guerra, La Laguna: Centro Social y Cultural Némesis.

GARCÍA-TALAVERA CASAÑNAS, F. (1995). «La estatura de los guanches». I Congreso Internacional de Estudios sobre Momias (Puerto de la Cruz, Tenerife, 1992). I. La Laguna: Museo Arqueológico y Etnográfico de Tenerife. Cabildo de Tenerife, pp. 177-186.

GÓMEZ GÓMEZ, M. A. (2000). El Valle de Güímar en el Siglo XVI. Protocolos de Sancho de Urtarte. Tenerife: Ayuntamiento de Güímar.

GONZÁLEZ REIMERS, E.; ARNAY, M. y VELASCO, J. (2006-07). «Líneas de Harris y estatura en la población prehispánica de Tenerife preservada en el Instituto Cabrera Pinto (La Laguna)». Estudios Canarios, núm. 50-51, 2006-07 (2008), pp. 689-696.

GUIMERÁ RAVINA, A. (1973). «La cueva sepulcral del Roque de Tierra. Roques de Anaga (Tenerife)». Anuario de Estudios Atlánticos, núm. 19, pp. 207-212.

JIMÉNEZ DÍEZ, J. A. y MEDEROS, A. (2001). Comisión de Antigüedades de la Real Academia de la Historia. Baleares. Canarias. Melilla. Gibraltar. Extranjero. Catálogo e Índices. Madrid: Real Academia de la Historia.

JIMÉNEZ GÓMEZ, Ma . de la C. (1971): Contribución a la Carta Arqueológica del N.E. de Tenerife. Memoria de Licenciatura inédita. La Laguna: Universidad de La Laguna.

JIMÉNEZ GÓMEZ, Ma. de la C.; TEJERA, A. y LORENZO PERERA, M. (1980). Carta Arqueológica de Tenerife. Enciclopedia Canaria, 15. Tenerife: Cabildo Insular de Tenerife.

JIMÉNEZ SÁNCHEZ, S. (1941). «Embalsamamientos y enterramientos de los 'canarios' y 'guanches', pueblos aborígenes de las Islas Canarias». Revista de Historia Canaria, núm. 7 (55), pp. 257-268.

KELLEY, M.A. y BOOM, K. (1995). «Harris lines and environment: the early inhabitants of Tenerife». I Congreso Internacional de Estudios sobre Momias (Puerto de la Cruz, Tenerife, 1992). I. La Laguna: Museo Arqueológico y Etnográfico de Tenerife. Cabildo de Tenerife, pp. 93-98.

LIPINSKI, E. (1992). Dictionnaire de la Civilisation Phénicienne et Punique. Turnhout: Brepols.

MARÍN de CUBAS, T. (1986 [1694]). Historia de las siete islas de Canaria. En JUAN CASAÑAS, A. DE, REGULO, Mª y CUENCA, J. (eds.). Las Palmas: Real Sociedad Económica de Amigos del País.

MARTÍNEZ de la PEÑA y GONZÁLEZ, D. (1991). Historia de Arico. Tenerife: Ayuntamiento de Arico.

MEDEROS, A. y ESCRIBANO, G. (2004). «Hábitat aborigen en cuevas artificiales del Sur de Tenerife (Arico-Granadilla)». Anuario de Estudios Atlánticos, núm. 50 (2), pp. 731-779.

MEDEROS, A. y ESCRIBANO, G. (2007). Prehistoria de la Comarca de Acentejo. El menceyato de Tacoronte. Madrid: Menceyatos de Tenerife, 1. Ceder.

MEDEROS, A. y ESCRIBANO, G. (2017). «Los límites del menceyato de Taoro (Tenerife, Islas Canarias) y el emplazamiento de la cueva del mencey». Anuario de Estudios Atlánticos, núm. 63 (18), pp. 1-43.

MEDEROS, A.; ESCRIBANO, G. y VALENCIA, V. (2015). «Prospección arqueológica del municipio de Tegueste (Tenerife)». Anuario de Estudios Atlánticos, núm. 61 (9), pp. 1-40.

MELO DAIT, R.E. (2007). «Los Tagoros de Tenerife. Pervivencia de la tradición oral, recogida por Bethencourt Alfonso en el siglo XIX». El Día-La Prensa, Santa Cruz de Tenerife, 13 de enero de 2007, pp. 1-3 y 10 de febrero de 2007, pp. 6-7.

MORA POSTIGO, C. (1995). «Momias guanches en el Museo Nacional de Etnología». I Congreso Internacional de Estudios sobre Momias (Puerto de la Cruz, Tenerife, 1992). I. La Laguna: Museo Arqueológico y Etnográfico de Tenerife. Cabildo de Tenerife, pp. 267-271.

MORENO FUENTES, F. (1992). Las Datas de Tenerife (Libro primero de datas por testimonio). La Laguna: Fontes Rerum Canariarum, 35. Instituto de Estudios Canarios. 
MUÑOZ JIMÉNEZ, R. (1994). La piedra zanata y el mundo mágico de los guanches. Tenerife: Museo Arqueológico. Cabildo Insular de Tenerife.

NÚÑEZ DE LA PEÑA, J. (1994 [1676]). Conquista y Antigüedades de las Islas de la Gran Canaria, y su descripción. Con muchas advertencias de sus Privilegios, Conquistadores, Pobladores, y otras particularidades en la muy poderosa Isla de Thenerife. En BÉTHENCOURT MASSIEU, A. DE (ed.). Madrid-Las Palmas: Universidad de Las Palmas de Gran Canaria.

PALENCIA, A. de (1978 [1490-91]). Cuarta Década. La conquista de Gran Canaria. En MORALES PADRÓN, F. (ed.): Canarias: crónicas de su conquista. Sevilla-Las Palmas: Ayuntamiento de Las Palmas-Museo Canario, pp. 471-496.

PERERA LÓPEZ, J. D. (1992). «Los grabados de 'La Pedrera', Tenerife». Eres (Arqueología), núm. 3 (1), pp. 33-73.

PÉREZ DE CABITOS, E. (1990 [1476-77]). Pesquisa de Cabitos. Información sobre cuyo es el derecho de la isla de Lançarote, y conquista de las Canarias, hecha por comisión de los reyes Cathólicos Don Fernando y Doña Ysabel. En AZNAR, E. (ed.). Madrid-Las Palmas: Ínsulas de la Fortuna, 1. Cabildo Insular de Gran Canaria.

PÉREZ GONZÁLEZ, E.; CHÁVEZ, Ma . E. y GOÑI, A. (2005). «La evaluación del Patrimonio Arqueológico. Una propuesta aplicada a parte del conjunto de yacimientos del Barranco del Agua de Dios (Tejina, San Cristóbal de La Laguna, Tenerife)». V Jornadas de Patrimonio Histórico: La arqueología canaria. Análisis de partida (Arrecife, Marzo, 2005). Arrecife.

PÉREZ GONZÁLEZ, E.; CHÁVEZ, Mª . E. y GOÑI, A. (2009-10). «La evaluación del patrimonio arqueológico. Una propuesta aplicada a parte del conjunto de yacimientos del Barranco del Agua de Dios (Tejina y San Cristóbal de La Laguna, Tenerife)». Tabona, núm. 18, 2009-10 (2014), pp. 135-144.

PLINIO EL VIEJO (1998). Historia Natural. Libros III-VI. Trad. E. del Barrio Sanz (Libro V). Madrid: Biblioteca Clásica Gredos, 250.

QUESADA y CHAVES, D. de (2007 [1784]). Canaria Ilustrada y puente americano. En FERNÁNDEZ PALOMEQUE, P., GÓMEZ PABLOS, C y PADRÓN, R. (eds.). La Laguna: Instituto de Estudios Canarios.

RODRÍGUEZ MARTÍN, C. (1995). «Osteopatología del habitante prehispánico de Tenerife, Islas Canarias». I Congreso Internacional de Estudios sobre Momias (Puerto de la Cruz, Tenerife, 1992). I. La Laguna: Museo Arqueológico y Etnográfico de Tenerife. Cabildo de Tenerife, pp. 65-78.

ROSA OLIVERA, L. de la (1990-92 [1933]). «Restos arqueológicos de las Cuevas de 'Las Goteras' (Bajamar) y 'El Prix’ (Tacoronte)». TEJERA, A. (ed.). Estudios Canarios, núm. 3637, pp. 203-210.

ROSA, L. de la y SERRA, E. (1949). El adelantado D. Alonso de Lugo y su Residencia por Lope de Sosa. La Laguna: Fontes Rerum Canariarum, 3. Instituto de Estudios Canarios.

SCORY, E. (1992-93 [1626]). «Extractos de las Observaciones de Sir Edmund Scory acerca del Pico de Tenerife y otras particularidades que observó allí». En CASTILLO, F. J. (ed.). «El texto de Sir Edmund Scory sobre Tenerife». Tabona, núm. 8 (1), pp. 93-115.

SERRA RÀFOLS, E. (1949). Acuerdos del Cabildo de Tenerife. Vol. I, 1497-1507. La Laguna: Fontes Rerum Canariarum, 4. Instituto de Estudios Canarios.

SERRA RÀFOLS, E. (1978). Las Datas de Tenerife (Libros I a IV de datas originales).

Laguna: Fontes Rerum Canariarum, 12. Instituto de Estudios Canarios.

SERRA, E. y ROSA, L. de la (1953). La Reformación del Repartimiento de Tenerife en 1506. Tenerife: Instituto de Estudios Canarios-Cabildo Insular de Tenerife.

SOLER, J.; PÉREZ CAAMAÑO, F. y RODRÍGUEZ, T. (2011). Excavaciones en la Memoria. Estudio historiográfico del Barranco de Agua de Dios y de la Comarca de Tegueste (Tenerife). Tenerife: Gobierno de Canarias-Ayuntamiento de Tegueste.

TORRIANI, L. (1978 [1592]). Descripción e historia del reino de las Islas Canarias antes Afortunadas, con el parecer de sus fortificaciones. En CIORANESCU, A. (ed.). Tenerife: Goya Ediciones. 
TREJO y CARVAJAL, M. de (1891 [1526]). «Información del Rey D. Fernando Guanarteme que lo fue de esta Isla de Gran Canaria, en tiempo de los Canarios, según consta desta probanza fecha con los conquistadores desta Isla y de Tenerife y la Palma en aquel tiempo». En CHIL Y NARANJO, G. Estudios históricos, climatológicos y patológicos de las Islas Canarias. III. Las Palmas-Paris: Imprenta de La Atlántida-Ernest Leroux LibrairesEditeurs, pp. 203-234.

VALENCIA, V. y ALAMO, F. (2011). «El conjunto arqueológico La Barranquera y la excavación de la Cueva El Calabazo (Barranco de las Cuevas, Valle de Guerra, La Laguna)». Canarias Arqueológica, núm. 19, pp. 75-108.

VALENCIA, V., ESCRIBANO, G. y MEDEROS, A. (2014). «Los grabados rupestres de la comarca de Acentejo (Tenerife, Islas Canarias)». Canarias Arqueológica (Eres), núm. 20, pp. 253-273.

VIANA HERNÁNDEZ de MEDINA, A. de (1986 [1604]). Conquista de Tenerife. En CIORANESCU, A. (ed.). Tenerife: Editorial Interinsular Canaria.

VIERA y CLAVIJO, J. de (1967-71 [1776-83]). Noticias de la Historia General de las Islas de Canaria. I-II. En CIORANESCU, A. (ed.). Tenerife: Goya Ediciones.

VIVANCOS, E.; BENÍTEZ, C.; FAJARDO, O. y PÉREZ ESPÓSITO, S. (2016). Chinech, la isla de los letreros. Inscripciones en las piedras de Tenerife. Tenerife: Ediciones Idea. 